

\section{$79^{\circ}$

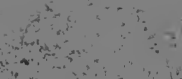

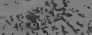

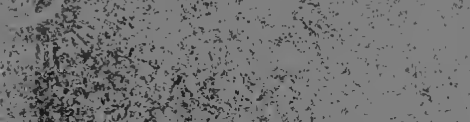

s.

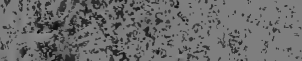

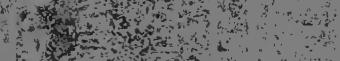

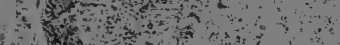

s.

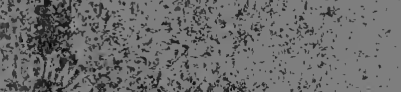








\title{
THE WASSERMANN SER0-DIAGNOSIS OF SYPHILIS IN ITS APPLICATION TO PSYCHIATRY
}

\author{
BY \\ DR. FELIX PLAUT
}

SCIENTIFIC ASSISTANT IN THE PSYCHIATRIC CLINIC OF THE UNIVERSITY OF MUNICH

AUTHORIZED TRANSLATION

BY

SMITH ELY JELLIFFE, M.D., Ph.D.

PROFESSOR OF PSYCHIATRY, FORDHAM UNIVRRSTTY, NEW YORK

AND

LOUIS CASAMAJOR, A.M., M.D.

ASSISTANT NEW YORK NEUROLOGICAL INSTITUTE

NEW YORK

THE JOURNAL OF NERVOUS AND MENTAL DISEASE PUBLISHING COMPANY 


\section{NERVOUS AND MENTAL DISEASE MONOGRAPH SERIES}

\section{Edited by}

Dre. SMITH ELY JELLIFFE and WM. A. WHITE

\section{Numbers Iseued}

1. Outlines of Psychiatry. By Wm. A. White, M.D.

2. Studies in Paranoia.

By Drs. N. Gierlich and M. Friedman

3. The Psychology of Dementia Praecox.

By Dr. C. G. Jung.

4. Selected Papers on Hysteria and other Psychoneuroses. By Prof. Sigmund Freud.

5. The Wassermann Serum Diagnosis in Psychiatry.

By Dr. Felix Plaut.

6. Epidemic Poliomyelitis. New York Epidemic, r907.

7. Three Contributions to Sexual Theory.

By Prof. Sigmund Freud.

Copyright, I9II, by

The Journal of Nervous and Mental Disease

Publishing Company, New York 
DEDICATED

To His Teacher,

PROFESSOR DR. A. WASSERMANN,

IN HONOR AND THANKFULNESS BY

THE AUTHOR. 



\section{CONTENTS}

PAGE

INTRODUCTION

vii

I. On the Development and the Conditions of the Serum Diagnosis of Syphilis ............ I

II. The Utilization of the Different Methods in Practice ......................... 20

iII. Observations Concerning the Technigue of the Wassermann Reaction ............... 27

IV. The Clinical Specificity of the Wassermann Reaction ....................... 34

V. Clinical Investigations.

A. Cases of Syphilis Without Complications in the Nervous System .............. 42

B. General Paresis ................... 45

C. Cerebral Syphilis $\ldots \ldots \ldots \ldots \ldots \ldots \ldots \ldots . \ldots . \ldots$

D. Tabes and Tabes Plus Psychosis .......... 125

E. Feeblemindedness upon Hereditary Syphilitic Foundation $\ldots \ldots \ldots \ldots \ldots \ldots \ldots \ldots \ldots \ldots \ldots \ldots \ldots$

VI. Influence of Disease and Mercurial Treatment upon the Wassermann Reaction ......... I 72

VII. Comparative Serological and Cytological InvesTIGATIONS-LITERATURE 



\section{PREFACE}

The Wassermann serodiagnosis of syphilis is based upon a method the technique of which is highly complicated. Further, the nature of the method is such that different biological factors can enter into the reaction and so obscure the clearness and specificity of the result. Finally the nature of this phenomenon of complement fixation, which Wassermann has applied to syphilis, is still very indefinite.

In the short time elapsing since the knowledge of the reaction has been spread abroad by Wassermann, Neisser, and Bruck, there has been an overflow of workers in this field. The pros and cons have been animatedly discussed, and the question has become even more confused, in the course of the debate, by the appearance of a whole series of modifications and simplifications of the method which, in themselves, have given rise to new contentions.

If we wish to be clear ourselves upon this question, in so far as a decision of the matter is possible at this time, we are forced to examine from two different points of view a method which, up till now, has not been used in the field of immunity research. We must, on the one hand, examine the theoretical foundation of the reaction and discuss, quite independently, the practical results of the application of the method at the bedside. We must ever bear in mind the signal fact that, although we are working with a biological reaction about the character of which we know but little, and concerning whose nature we are confused by the different ideas advanced, nevertheless the application of this undetermined phenomenon in practice gives clear uncontradictory results, which at the present time are contested by hardly any earnest worker.

I shall try to give a short survey of the historical development of the method and of the diagnostic opportunities that have been afforded for the serodiagnosis of syphilis in my application of the method in the clinic, especially in the field of psychiatry. 



\section{THE WASSERMANN SERO-DIAGNOSIS OF SYPHILIS IN ITS APPLICATION TO PSYCHIATRY}

\section{THE DEVELOPMENT AND THE NATURE OF THE SERODIAGNOSIS OF SYPHILIS}

In I90I Bordet and Gengou published some experiments to show that Ehrlich's idea of the multiplicity of the complement is not correct. Bordet and Gengou wished to prove that the hæmolytic and bacteriolytic complements were identical, and to demonstrate the method of complement binding or fixation. Their method of procedure was as follows: Cholera vibrios in their natural state were mixed with the corresponding immune serum, which had been rendered inactive, and to this were added fresh normal guinea pig serum (complement). After remaining in the incubator till the combination had taken place, hæmolytic serum and the blood corpuscles of the corresponding animal were added. Here hæmolysis did not take place, while the dissolving of the vibrios occurred promptly. If the order were inverted and the cholera vibrios, together with the prepared immune amboceptor, were added to the previously made mixture of blood corpuscles + hæmolytic serum + complement, the vibrios did not dissolve and hæmolysis occurred early. Thus it was demonstrated that the common complement is applicable for bacteriolysis as well as hæmolysis. Ehrlich and Morgenroth, in a series of classical articles, have defended their multiplicity idea of the complement, while the French authors have endeavored to uphold their contrary standpoint by further brilliant experiments. But I cannot allow myself to go further into this matter, nor to discuss here the divergence of opinion between Bordet and Ehrlich concerning the structure and method of working of the specific reaction products which bring about complement fixation, for these differences of opinion do not obstruct a fair judgment of the end results.

Of greater importance is the fact that Bordet and Gengou 
have proved that complement fixation occurs only when the proper bacteria are brought into contact with their specific reaction product, that, for instance, typhoid bacilli can fix the complement, and thus prevent hæmolysis only in the presence of typhoidimmune serum; in other words, that the reaction is distinctly specific. Thus the method gained importance for differential diagnosis of bacteria on one side and of immune sera on the other. Therefore, by assuming a knowledge of one component, one was able to ascertain whether or not the other belonged to it.

From this it is evident that the fact of complement fixation in the bacteria-immune serum complex is capable of two different proofs, a direct and an indirect. The direct proof manifests itself in the dissolving of the bacteria, and the indirect in the prevention of hæmolysis. With these experimental methods, $i$. $e$., the use of complete bacteria as antigen and bacteriolytic amboceptor as antibody, there can be no doubt, in the event of a positive result, of the specificity of the reaction and the specific complement fixation in this particular case.

Things become more complicated when one turns away from the direct proof to the indirect, where we must confine ourselves to the observation of the conduct of hæmolysis. The necessity for this restriction lay in the nature of conditions under which Gengou worked when, in the following year, he went over to the use of albumen solution, blood serum, white of egg, casein, fibrinogen and similar albumens in place of whole bacteria as antigen, with correspondent antisera in similar experiments. The results of these experiments were positive. In this way it was proved that albumen solutions can bring about the production of specific amboceptors, and in this case the end products and reaction products prevent hæmolysis by the ordinary test methods. But here is lacking the direct proof of complement fixation, which with the use of whole bacteria is unquestionably demonstrated by the dissolving of them. One can no longer doubt that the prevention of hæmolysis shows a true anti-complement action; one that is specific, and depends absolutely on fixation of the complement to the specific amboceptor.

This new situation brought forward great difficulties in the judgment of experimental results, because the anti-complement action can be occasioned by different factors which cannot easily 
be foreseen, but which can be overcome so long as one has such a positive criterion of fixation of the complement as bacteriolysis. The method found no practical application for the time being, and for the next three years was not enlarged upon in any direction. In I905 Moreschi continued the researches of Gengou, but without previously knowing of them, and reached the conclusion that precipitation is the deciding point of complement fixation in the case of the combination of egg albumen-anti-egg albumen because this brings about a mechanical precipitate of the complement. It should be remarked here that Wassermann and Bruck had succeeded in proving that immune sera can lose their precipitation capacity without suffering a loss of power to fix the complement to their corresponding antigen. Likewise complement fixation has not the same significance as precipitation, and is not dependent upon it. Moreschi, however, has come over to this idea.

In the same year the method found its first practical use in that it was put forward for medico-legal blood determination by M. Neisser and Sachs in place of the Wassermann-SchutzeUhlenhut precipitation method for the differentiation of albumens.

Wassermann and Bruck now proceeded to further modify the method in order to make it applicable for the diagnosis of infectious diseases. The fundamental change that they made in the original Bordet method consisted in using as antigen not whole bacteria but dissolved bacterial products and bacterial extract on one side, and the corresponding amboceptors on the other. In the beginning the stumbling block in the experiments lay in the proof of the specific amboceptors, but Wassermann and Bruck were able to demonstrate them by means of the complement fixation method, in connection with extracts of typhoid bacilli, meningococcus and the bacillus of swine plague. In the extended investigations of Leuchs, more especially, the practicability of the method for typhoid bacillus was shown; while Cohen's similar investigations on epidemic cerebrospinal meningitis gave likewise good results. Further in general gonococcic infection the serum amboceptor for dissolved gonococcus products was found by Müller and Oppenheim and also by Bruck. Then Wassermann and Bruck proceeded to the study of tuberculosis with this method. They found in some cases of miliary tuberculosis, espe- 
cially in patients who had been injected with tuberculin, that the serum in connection with tuberculin checked hæmolysis; and hence they concluded the presence of anti-tuberculin. Then they extended their experiments to tuberculous tissue and, by the complement fixation method, proved tuberculin on one hand, and antituberculin on the other. On the ground of their discovery they put forward an ingenious theory of the working of tuberculin, and the nature of the local and general reaction of the tuberculous organism towards it. Lüdke and likewise Citron corroborated the findings of Wassermann and Bruck; while objections were raised to it by Weil and Nakajama, and von Morgenroth and Rabinovitsch. Further in lyssa (Hella and Tomarkin, Friedberger) and in vaccine (Jobling, Heller and Tomarkin) proof of a specific amboceptor in the serum was sought for but without uniform results. However, the results that Weil obtained in cholera and Eitner in leprosy were more favorable.

Taken as a whole, the method has not been so successful in proving the presence of bacterial products, $i$. $e$., antigen, in serum as in proving that of the presence of the amboceptor. Bruck was of the opinion that he had found a tubercle bacillus antigen in a case of miliary tuberculosis, and frequently in suspicious pleuritic exudates and that further he had succeeded in demonstrating streptococcus antigen in the serum of a number of cases of severe abscesses. Nothing more seems to have been made of these few findings and, as far as I can find in the literature, confirmatory reports of antigen demonstration in body fluids in different infectious diseases have not been published.

Although up to the present time the complement fixation method had found application only in infectious diseases whose exciting causes are known and obtainable in pure culture, Wassermann now proceeded to extend his researches to syphilis, a disease whose exciting cause is as good as proven in the Spirochata Pallida, although it is not obtainable in pure culture. The great difficulty lay in the fact that here it was not possible to obtain a satisfactory antigen, which would correspond to the bacterial products derived by extraction of pure cultures in other infectious diseases. Wassermann resolved to make extracts of luetic organs in the expectation that some soluble material having relation to the luetic infection would be able to pass over into the extract. 
It is well known what brilliant results came from this investigation and how, on this ground work, the serum diagnosis of syphilis was founded by Wassermann in association with Neisser and Bruck.

Wassermann, Neisser, and Bruck proceeded with their investigations by experiments on monkeys. Monkeys were injected with syphilis, then treated with aqueous extract of a luetic organ, and it was shown that the serum of these monkeys in contact with luetic organ extract was enabled to fix the complement, while with the use of normal organ extract there was no prevention of hæmolysis; and also the serum of monkeys treated with normal organ extract in the presence of luetic extract showed no complement fixation. The specificity of the reaction appeared now to be assured, and it was therefore accepted as authoritative that the two unknown, interreacting substances could be spoken of as antigen and antibody in analogy to the already observed conditions in infectious diseases of known etiology. On the foregoing grounds it was considered that the antigen lay in the extract of highly infectious material, and it was believed that one could not go astray in concluding that the reacting substance was the corresponding amboceptor, in that the monkey was first rendered capable of reacting by treatment with the extract.

After the propitious results, which were obtained in the monkey experiments, the investigation of human syphilis was immediately taken up. In Neisser's laboratory, especially, the action of serum of syphilitics was investigated (Neisser, Bruck, and Schucht); while at the same time in Wassermann's laboratory were being carried on investigations of metaluetic diseases, especially upon the spinal fluid of paretics (Wassermann and Plaut).

In the first place it could not be accurately decided which of the two bodies that had been met with in the monkey experiments could be expected in the human serum, or spinal fluid; whether one would find the antigen or amboceptor. Experiments in both directions were arranged, and the body fluid to be tested was mixed with the serum of luetic-immune monkeys on one hand and with luetic organ extract on the other. A positive result with the first named combination would show the presence of the antigen and with the second the antibody. It was shown that, with the organ extract, human body fluids in luetic cases reacted, 
while when mixed with the immune serum complement fixation was practically never observed. It had now to be accepted that in the serum in syphilis and paresis, and here too in the spinal fluid, we were dealing with the luetic antibody, and as a result all further investigations were directed toward proving the antibody. Neisser, Bruck and Schucht investigated in their first series of experiments 250 sera from different stages of lues, and succeeded in proving the antibody in 19.5 per cent. of the cases, while the non-syphilitic control material without exception reacted negatively. But the percentage of positive cases was not high enough. The negative results in positive lues were so preponderant that it did not appear as though the method in this form could have a great practical importance in the diagnosis of syphilis. In contrast to this, the investigation of paretics was from the first more favorable; for in the spinal fluid in 76 per cent. of cases and in the serum, by continual investigation of a smaller group, a positive reaction could be obtained almost without exception. So it appeared from the beginning as though there existed a real difference of reaction power between the serum of syphilitics and that of meta-syphilitics and as though the serum diagnosis in its published form had a far-reaching diagnostic importance only in the latter.

On account of the relatively poor results in proving the antibody in serum of luetics Neisser and Bruck worked in another way to prove the antigen in the human organism. They believed that this substance existed in the erythrocytes; extracted it by shaking with normal saline solution and allowed this blood cell extract to react with luetic immune serum. Complement fixation was actually observed here with a positive percentage of $5^{8}$ per cent., considerably higher than that of the antibody in the serum. Yet the control experiments were not entirely satisfactory, for out of 85 normal blood extracts 5 reacted positively. Immediately the successful results appeared promising. Later the antigen tests became of no account when the antibody tests, even in the earlier stages of lues, were in almost all cases successful. It so happened that the corroborative tests, which were taken up by Citron and by me in Wassermann's laboratory at the request of the authorities, were not favorable, for the extract of normal erythrocytes sent us showed no real difference from the 
luetic. Here, of course, some disturbance might have taken place, due to the transportation of the blood extract. No further unobjectionable proof has, however, so far as it known to me, ever been brought forward anywhere. Confirmation of these results remains unestablished and Neisser and Bruck have dropped their investigations and have gone over again completely to antibody diagnosis. Lately Neisser has expressed himself as being satisfied as to the accuracy of the antigen experiments and he has gone so far as to say that the presence of the antigen in erythrocyte extract proves the presence of living luetic virus in the body; but one must wait to see whether the resumption of the experiments that Neisser announces will be able to support his theory. For the present one will do well to leave the question open, whether it is possible to demonstrate the antigen, in Neisser's sense, in syphilis.

From now on the whole discussion centered itself simply around the question of whether actual proof of the luetic antibody, in the serum in lues and in the spinal fluid as well as the serum in paresis, could be obtained with the Wassermann reaction: i. e., whether the reaction allowed an interpretation of the reacting substance in this way.

It has already been pointed out that it is not easy to obtain concise proof that the organ extract contains the antigen and the body fluids the antibody, for, under the conditions, the two substances are proven only as a complex which works upon the complement. However that the component found in the organ extract could be spoken of as the antigen was proved when, in the monkey experiments, on injection of the extract the reacting substance was caused to appear. Later the question arose whether the monkey immune serum really was formed by the extra injections, $i$. e., the "titer" was raised or more simply whether it was not formed as a result of the regular inoculations that had been given. The latter theory has without doubt the greater probability on its side. The idea that the extract contains the material sought for appears to be supported by the fact that parallel investigations of luetic organs for Spirochatce and serological reacting substances have given strikingly similar results. The Spirochata investigations were undertaken in Berlin by $\mathrm{Bab}$ and Mühlens, while at the same time we made the biological investigations of 
the organs in Wassermann's laboratory. It was then demonstrated that the extract was capable of reacting biologically only when obtained from organs in which Spirocheta pallida were found in large numbers. It appears to be proved that extract containing the active substance is found only in infectious luetic matter and it may be taken for granted that the extra-component in the extract can be considered the antigen and the one in the serum, which reacts with it, the counter body. From these comparative investigations the subject followed different sides. Wassermann and his scholars considered the "antigen" as a direct derivative of the Spirochata pallida, a stand that has never been satisfactorily proven. There has never been any discussion on this point, but there was some with a view of determining whether the reacting substance was found only in infectious luetic lesions, that is, in those containing Spirochata. It was universally agreed that the antigen was bound up in the luetic lesion, but not that it can be looked upon as a living portion or metabolic product of the Spirocheta. Still less is the view held that the antibody represents a protection substance but only a specific reaction product. Later investigations by Levaditi and Bruck have proved that the antibody is not an immune substance in the strict sense.

A real support of the theory of Wassermann and his coworkers, that this is a specific reaction for lues, would be that when luetic serum is mixed with extract of non-luetic organs complement fixation never takes place. Later it was maintained that the reaction of the serum of luetics was not connected exclusively with the luetic "antigen," as had been accepted, but that the reaction capacity could be proven to a certain degree towards non-luetic "antigen," $i$. e., aqueous extract of normal liver. Marie and Levaditi were the first to publish the statement that they had succeeded in obtaining the phenomenon of hæmolysis prevention with the spinal fluid of paretics and extract of normal liver, although in a concentration of Io. This was also observed, but in only one case (spinal fluid of a tabetic), by Weygandt and the author. Confirmatory results were obtained by Weil and Braun, Landsteiner, Michaelis, Fleischman and others in corresponding investigations.

The reaction was thus, to all appearances, divested of its specificity; the luetic antigen-antibody theory was shattered and 
it could not be seen what it had to do with luetic infection when one observed it working with constituents of normal organs. And it was still more astounding, as it appeared, that such normal extracts reacted only with the body fluids of luetics; so that one obtained a phenomenon which clinically limited itself specifically sharply to syphilis, but which could be demonstrated with substances that really had nothing in the least to do with syphilis.

The matter, however, was not so simple. Marie and Levaditi had already called attention to the fact that it required a strong concentration of the normal liver extract to bring about the reactions with luetic serum; and it was plain that through such a change in concentration a biological reaction that, like all others, has a specific character only within narrow limits, can take on an entirely different meaning. However, one finds in rare cases livers of non-syphilitic fœtuses which react in the same concentration used for luetic extract (o.2-0.I). This is certainly not frequent, and with the majority of normal livers the reaction is not obtainable. Nevertheless, I found out of twenty non-luetic livers two, which in the above mentioned small doses of 0.2 and o.I, caused a definite complement fixation with syphilitic serum. It must, therefore, be accepted as the most probable explanation that the antigen of the luetic and normal is the same, but that the luetic liver in general contains it in much larger amount or that it is more easily extracted with water from the luetic liver than from the non-luetic. In accepting this it must be demanded that, in the investigation of a large group of cases, similar results are obtainable with both extracts; that also the intensity of the hæmolysis prevention should show the relationship of the difference of content of the reacting substance in the extract so as to make the parallelism clear; and likewise that a serum which prevents hæmolysis more strongly with luetic extract than another also gives a better result with the normal extract than the other.

I have already shown that the curves of reaction do not run parallel, but that their course is strikingly abrupt and irregular. In the accompanying curve representations of the type of reaction of a series of sera and spinal fluids towards aqueous luetic liver extract on one hand and non-luetic on the other, this incongruity becomes very apparent. 
TABLE I

Quantities: Extract 0.2: Spinal Fluid or Serum 02.

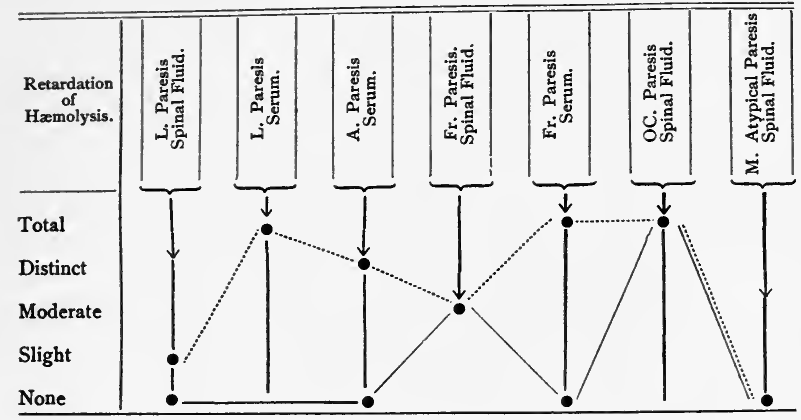

with aqueous luetic liver extract.

- with aqueous normal liver extract.

The relation of the spinal fluid to the serum of Paresis Fr. appears especially striking. The spinal fluid that with luetic extract showed only a slight prevention of hæmolysis, with normal extract showed a reaction of like intensity, while the serum of the same case, which with luetic extract totally prevented hæmolysis, occasioned no trace of such action with normal extract.

These results brought me to the conclusion that we had to do here with fixation phenomenon of a different sort of substance which can be differentiated from that in specific luetic hæmolysis prevention. Michaelis on the contrary found only gradual variations. His idea was that normal extract acted in the same manner as luetic extract, but in high concentration only. As proof he offered a diagram in which, however, were recorded, not the final results of hæmolysis prevention, but only differences in hæmolysis retardation. However, the parallelism is not fully carried out and it appears to me as especially unproven that one can identify difference of hæmolysis retardation with different grades of hæmolysis prevention.

In any case it has been proven that a substance is found in luetic serum which reacts also towards products of normal tissues, and that the original conception of the biological specificity of 
the reaction is therefore no longer to be held as correct in its full sense.

Weil and Braun carried this turn of affairs further to the formulation of a theory in keeping with it, after they had proven that tumor extracts react with luetic serum. They offered the hypothesis that antibodies for certain cell components exist in the blood in lues, tabes, and paresis. They wished to advance the idea that auto-antibodies are set free as a result of the decay of nascent altered albumens similar to the continual and lasting decay of tissues in lues. There remains now the question of whether a continual tissue decay takes place in syphilis, and this cannot be admitted; at least for numerous old latent cases whose serum still gives a strongly positive reaction. On the other hand, in diseases where the reabsorption of body albumen is more extensive than in syphilis, such as in apoplexies with destruction of large brain areas, in progressive phthisis, disintegrating neoplasms, etc., one must expect a similar behavior of the serum. This stand, with but few upholders, among whom are Weil and Braun, is contested on all sides, and, according to my own idea and experience, rightly.

The investigation of the nature of the reaction now entered an entirely new phase when it was observed from three sides, at about the same time that the reacting substance of the organs was extractable with alcohol ; that is, soluble in alcohol (Wassermann-Porges-Meier, Landsteiner-Müller-Pötzl, Levaditi and Jamanouchi). After this one had to accept that, in the active organ components, we are dealing not with albumenoid matter but with lipoids. Not alone the alcoholic extract from luetic liver but that from normal and different other human animal organs proved itself more or less active. The alcoholic extract of guinea pig heart, recommended by Landsteiner, appeared especially useful. Levaditi and Jamanouchi also, by means of alcoholic extraction from the brains of man and the guinea pig, the erythrocytes of guinea pigs, the leucocytes of rabbits, and from rabbit and guinea pig serum, were able to get extracts which, in part, according to the statements of the authors, fixed the complement in conjunction with luetic serum.

A further noteworthy discovery was made by Levaditi and Jamanouchi that not only the "antigen" but also the "antibody" 
in the spinal fluid of paretics is soluble in alcohol and is to be considered among the lipoids.

After it had become so probable that the reacting organic substance, on account of its solubility in alcohol, is, at least, closely related to the lipoids, the next and most natural step was to substitute pure lipoid in place of the alcoholic organ extract in complement fixation experiments.

Among the experiments in this direction those with lecithin first attracted attention (Porges and Meier). The results reported from different quarters were practically uniform, as it was maintained on all sides that luetic serum in the presence of lecithin was enabled actually to fix the complement. Most of these, however, were purely experimental investigations which were available to give a demonstration of the working value of this modified method in comparison with the original method, using aqueous extract of luetic organs.

A far-reaching parallel, although not observed in all cases, was noticed in the tables published by Porges and Meier. For a short time it was believed that it was lecithin that represented the active substance in luetic liver and was either present here in greater amount or was more easily extractible with water than in normal liver. Lecithin is, however, not capable of bringing about the production of a specific antibody in the organism, which fact had been proven long before by the experiments of Wassermann and Citron. The logical conclusion was evident that in the active substance of the serum and the spinal fluid we are dealing not with reaction products at all but rather with a toxine which, on account of its chemical affinity for lecithin, attacks the organism. While Wassermann discussed the possibility that this toxine attacks the lecithin and uses up this substance, so important to life, and especially valuable to the brain cells, Peritz inclined to the theory that the toxine did not work "in loco," but used up the lecithin going from the intestines to the tissue juices and prevented it from entering the cell to supply it with the necessary compensation for used material. Peritz offered the hypothesis that tabes has its cause in an impoverishment of the cells in lecithin, as a result of which comes a cell degeneration.

Immediately it was shown that lecithin alone is by no means capable of reaction, but that one can employ just as well sodium 
oleate (Sachs and Altmann), cholesterin and vaseline (Fleischmann), salts of the bile acids, especially sodium glycocholate (Levaditi and Jamanouchi). Therefore, it appeared no longer permissible to speak of a specific chemical affinity of the "antibody" for lecithin, but the boundary must be placed further, and an affinity for a whole group of lipoid substances accepted. Wassermann at that time expressed himself as believing that there exists in the serum of luetics a lipophile substance and he spoke of a lipophilia of luetic sera in the wider sense.

Through the establishment of this fact it was, at all events, proven that there are luetic sera which in the presence of lipoids can fix the complement. But at the same time it has not yet been proven that we are dealing here with a process similar to that which lies at the basis of the original reaction with aqueous extract of luetic liver. In order to establish absolutely the identity of these fixation phenomena, it is to be demanded that always in those cases where luetic serum reacts with aqueous luetic organ extract, it shall also react with lipoids; and that only sera positive to the Wassermann test shall fix the complement together with lipoids. In case of negation of the first named condition, it must be accepted that lipophilia is a peculiarity which is possessed only by a certain group of luetic sera, more or less independently of the antibody reaction. The negation of the second question leads to the conclusion that lipophilia is a property of certain sera, of which perhaps luetic sera form a large part but by no means all. Unless one of these two conditions, especially the second, is not satisfied, one cannot with complete identity associate lipophilia with the antibody reaction. The practical conclusions that one can draw from this concerning the usefulness of lipoid-complement fixation are obvious. In one case the reaction will frequently fail when it should be present, in another, even non-luetic, it will be positive, and thereby render differential diagnosis impossible. I will not now go further into this practical clinical side of the question, but will do so later and more connectedly.

Porges and Meier, who first proposed the substitution of lecithin in the place of organ extract in complement fixation tests, now went on to the problem of determining whether luetic sera did not possess the property of reacting, in the sense of precipitation, with lecithin emulsion. It was not the first attempt to use pre- 
cipitation for the serodiagnosis of syphilis. In consideration of the close relationship of the two phenomena one must, of course, reckon with the possibility that the union of antigen with antibody in syphilis besides complement fixation can also occasion precipitation, but, as has been already stated, the view that complement fixation is only a consequence of precipitation had been expressed by Moreschi. From the beginning Wassermann and his pupils carefully observed whether precipitates were noted when organ extract and luetic serum came together, but it was shown that this was not the case, and it was proved anew that complement fixation can take place independently of precipitation.

Michaelis observed in one case that in a mixture of an especially active luetic liver extract, with an especially active luetic serum, a true precipitation serum formation was occasioned, which was proved as specific by necessary controls. That this represents an exception that is possible only under very special fortunate circumstances stands beyond question. The fact possesses therefore simply a theoretical interest and has been considered as of no further value by Michaelis himself.

Starting from an entirely different point of view, Fornet and Schereschewsky endeavored to put precipitation in the service of syphilitic serodiagnosis. They started with the theoretical idea that in the later stages of syphilis and in post-luetic affections, reaction products, in the sense of precipitins, can be found in the serum, and that the corresponding precipitogen exists possibly in the serum of florid lues. Fornet had already applied a similar idea in typhoid and had obtained similar results. Fornet and Schereschewsky proceeded thus. They poured, for example, a layer of serum obtained from a patient in the florid stage of syphilis over that obtained from a paretic in varying dilution and they observed at the boundary line of the two fluids a ring formation which they spoke of as a specific precipitate. Different combined control tests served to prove the specificity of the reaction. Further tests, which were done on many sides (Plaut, Heuck and Rossi, Bruch, Bauer), were not so favorable, but showed rather that likewise in the use of non-syphilitic sera and even in forming layers of different dilutions of one and the same serum on each other a ring formation at the boundary occurred just as frequently and as clearly. 
A still greater interest was now taken in precipitation experiments made with lecithin. In Wassermann's laboratory Porges and Meier found that syphilitic sera possess the power of producing a flocculum in a homogeneous lecithin emulsion. The accuracy of this observation was soon verified on many sides, and the great simplicity of this lecithin precipitation method was the occasion of extended investigation being taken by many workers. One was inclined to accept the idea that the substance which caused precipitation of lecithin also brought about complement fixation with lecithin, alcoholic extract of normal organs and likewise with aqueous and alcohol extract of luetic organs. But here again extended comparative investigations were needed and these being made it was proved that lecithin precipitation and the original Wassermann reaction did not depend on the same factors. The same holds for the observations of Sachs and Altmann, who observed that syphilitic sera produce precipitates with soap solution.

Klaussner's reaction forms the end of the series of substitution reactions. In this a globulin separation forms in a mixture of syphilitic sera and distilled water. Here, in the first place, one could not consider this an immune reaction, even if it occurred only with luetic sera. The question is simply this: Is the globulin in the sera of luetics increased or does it exist here in a condition more easy of separation? Spiegler investigated the sera of luetics for their globulin ratio, according to Hamarsten's method, and he found that the relation of the serum albumen to the globulin was disturbed in a marked degree. There was a decrease of globulin content in an exceedingly large proportion of cases, but at the same time a considerable increase of the globulin ratio. That in general a decrease of ratio occurs may lie at the bottom of the Klaussner phenomenon of easier separability of the globulin.

There only remains to be investigated the possibility of proving that the substance in luetic serum which brings about complement fixation with aqueous luetic organ extract is also the principle of the numerous later developed reactions.

Elias, Neubauer, Porges and Salomon endeavored to make a uniform explanation of all the phenomena in that they considered precipitation as well as complement fixation in lues as non-specific colloid reactions based on fixation of lecithin to serum albumen. 
That precipitation and likewise complement fixation can be based on a colloid reaction which is not necessarily a specific immunity phenomenon is absolutely proved. Seligmann has demonstrated in very excellent experiments that, in the interaction of colloids, complement fixation can occur without simultaneous precipitate formation. First he showed that a chemically indifferent precipitate caused the complement to disintegrate. A colloid iron hydroxide solution separated out on addition to aqueous solutions and formed a voluminous precipitate. Complement added to the solution was caused to disappear and when blood corpuscles joined to hæmolytic amboceptors were added no hæmolysis occurred. According to Seligmann colloid reactions, not accompanied by precipitate formation, act in the same way. For example, serum prevents precipitation of mastic and shellac emulsions by salts, but nevertheless complement fixation takes place. When Seligmann let two colloids react one with another as, for instance, mastic + gelatine, and shellac + gelatine, the complement was likewise fixed without simultaneous precipitation. Therefore, as Seligmann demonstrated, it is not the molecular condition in itself which causes the disappearance of the complement but the change in the molecular condition of the colloid in the case. By these investigations it was absolutely proved that complement fixation does not primarily rest upon the interaction of substances which stand to each other in the relation of antigen and antibody.

According to the formula of Wassermann and Citron, the change in the physico-chemical condition of a molecule through the addition of another substance to it is the cause of complement fixation. Elias, Neubauer, Porges and Salomon put before themselves the task of finding out whether separation out of lecithin emulsion through action of luetic serum follows the laws of colloidal reactions, and whether complement fixation in a mixture of alcoholic extract of guinea pig heart and luetic serum is subject to the same rules. They found that precipitation of lecithin emulsion by luetic serum depends upon an optional proportion of the reacting components, and in this a typical characteristic of colloid reactions must be considered as fundamental The authors found further that not only with luetic sera but also with any other serum the close precipitation takes place and that here a reaction curve with a maximum is obtained in the same manner. 
Luetic and normal sera behave the same way with lecithin and also with sodium glycocholate.

According to the author's view, precipitation is due to a colloidal reaction of lecithin or other lipoids with serum albumens. The difference between the action of luetic and normal sera lies only in that the limits of reaction of luetic sera are further apart and that precipitation occurs here quicker than with normal sera. The authors see the cause of this in that the albumen bodies of luetic sera which react with lipoids exist in a more easily precipitable condition than in other sera. A decrease of alkalescence, the presence of an especially active albuminous compound, or an increase of a certain fraction of the normal serum albumens are, on the contrary, not to be looked upon as the cause of the different behavior of luetic sera. As a special peculiarity of the reaction there is to be noted its enhancement by acids and the influence upon it of alkalies as well as the fact that active sera precipitate lecithin and sodium glycocholate quicker and more completely than inactive ones. Now, the authors continue, the complement fixation reaction in syphilis is a colloidal absorption phenomenon and occurs through the coming together of the serum with the lipoids of the extract. According to the proof of Sachs and Altmann the complement fixation reaction, as likewise precipitation, is favored by acids and retarded by alkalies, and inactive sera work less readily than active ones; therefore, the Wassermann reaction is a colloidal reaction of the same sort. The objection that the Wassermann reaction is specific and that precipitation is not, and that they therefore depend on different processes, is frail, for with certain proportions of reagents one can at will get a positive or a negative result in the precipitation test as well as in the complement fixation reaction. Here a definite reaction curve with an optimum is evident. The authors have put forward the statement that the degrees of retardation with alcoholic heart extract are striking. Here the retardation phenomena are so exceedingly slight, and the differences so hazy, that one may surely doubt whether the authors are really correct in such decided conclusions. There are three sera of which the two most positive reactions are reported as "slight retardation," and the third "sediment," and with these are two other sera which only dissolve "almost completely." 
If one wishes to look upon the statement as really far-reaching, it has been shown that the characteristic reaction curves of the two, the complement fixation and the lecithin precipitation reactions, apparently possess the same type of peculiarities; and the complement fixation with alcoholic extract of normal organs is identical with the lecithin precipitation. The authors accept implicitly that the reacting substance of the aqueous extract of the luetic organs is identical with the lipoids of the alcoholic extract of normal organs, and they speak of Wassermann reaction without any explanation when they use alcoholic heart extract as "antigen." This agreement cannot be even provisionally accepted; at least the Wassermann school have worked from first to last with luetic organ extract. Wassermann himself has lately declared before the Vienna Congress for Internal Medicine that "to-day he still holds that extract of syphilitic organs is necessary for an absolutely reliable serodiagnosis of syphilis." This claim was actuated by his belief that the antigen consists of a combination of lipoids with a very small amount of some substance closely resembling albumen.

The salient point is this: the lecithin precipitation is not as Porges and Meier and others would have it, specific for syphilis. Elias and his co-workers explain it as identical with the complement fixation reaction with alcoholic heart extract and, according to their nomenclature, with the Wassermann reaction; and they conclude that the Wasserman reaction is likewise a non-specific colloid reaction. One can also reach the following conclusions: lecithin precipitation is not specific. The complement fixation reaction with alcoholic heart extract comes under the same rule and is therefore even so little specific-consequently the complement fixation with alcoholic heart extract is not identical with that with luetic organ extract. In other words, Elias and his coworkers must first prove that normal sera behave the same with luetic organ extract as with lecithin in precipitation tests.

From all this it appears to follow that a completely satisfactory explanation of the nature of the Wassermann reaction, so far, has not been found. It is still left to the opinion of the individual to choose one of the following explanations which have been suggested by others.

I. The Wassermann reaction is a biologically specific antigen- 
antibody reaction for lues; in which the antibodies, on one side, have the peculiarity of reacting not alone with luetic antigen but also with normal tissue constituents, and the antigen, on the other hand, is very closely related to the lipoids, probably it is a specific albumen-lipoid compound.

2. The reacting substances of the luetic serum are not antibodies but substances which owe their origin to luetic infection and possess a chemical affinity for lecithin.

3. In the Wassermann reaction specific and non-specific fixation processes go hand in hand. 


\section{THE PRACTICAL UTILITY OF THE DIFFERENT METHODS}

Inasmuch as the biological processes which form the basis of the different, widely varying methods which have been recommended for the serodiagnosis of syphilis are, as already outlined, unexplained, we must decide for the time being simply from the results obtained to which of them to give preference. From the whole number one must exclude those methods which have been proved to possess only a limited specificity for syphilis. This includes, and to-day we can look upon it as proven, the precipitation methods, that of Fornet and Schereschewsky as well as that of Klaussner, and likewise the precipitation methods with different lipoids. Hence the discussion narrows itself down to the experiments in the field of complement fixation. We consider here the use of:

I. Aqueous extract of syphilitic liver.

2. Alcoholic extract of syphilitic liver.

3. Aqueous extract of normal organs.

4. Alcoholic extract of normal organs.

5. Lipoids.

For the present it is not determined whether the methods which work with "antigen" from non-leutic organs, give positive results only where lues really exists, $i . e$., whether the clinical specificity is as far reaching as with the use of luetic material. The reaction with alcoholic heart extract seems to offer rather a good guarantee in regard to clinical specificity. Müller found 500 nonsyphilitic control cases reacting almost without exception negatively; only a few cases showed a trace of hæmolysis prevention. Among the "normal" were cases of carcinoma, nephritis, typhoid, pneumonia, and, especially numerous, tuberculosis. Boas, likewise, obtained completely negative results with alcoholic heart extract in 77 normal individuals. However, up to the present, a truly wide experience has been had only with the original Wassermann method, while the substitute methods have been used in many instances simply as laboratory orientation experiments. 
Therefore the Wassermann technique, with which the first large series of experiments with non-luetic material was completed, is the preferable (Congress for Internal Medicine in Vienna). Nevertheless, it has not been proven as yet that the substitute methods are clinically less specific.

Another question is whether the methods for the determination of syphilis, where it positively exists, are of equal value or whether in syphilis one method or another gives a higher percentage of positive results. In order to answer these questions one cannot rely too fully on statistics. The values claimed by different authors differ markedly, even when working with the same method. For instance, Bruck and Stern claim only 54 per cent. of positive results in their tests, while Fischer and Meier bring the figures up to 83 per cent., although in both cases aqueous. extracts of luetic liver were used. These differences can be caused by differences in the clinical material, varying activity of the liver extract, and also by minute variations in the technique of so difficult a method. Therefore, one cannot conclude offhand that because one author with one method has obtained higher or lower percentages than a second with another method, one method is superior or inferior to the other. One can form an opinion only if one author has tried out both methods, side by side, with the same clinical material. In order to make a truly accurate comparison this alone does not suffice, but it must be so arranged that a group of patients should always be tested in the same series of tests, on the same day with the different antigens whose activity is to be tested. It is no small consideration that has brought me to this conclusion, but the experience that the results on different days can vary markedly, even when the antigen and the serum to be tested are the same. One cannot offhand compare the varying results of different days, a fact into which I shall go later. Comparative investigations between syphilitic extract and Landsteiner's guinea pig heart extract have been published, also between syphilitic extract and Meier's lecithin emulsion, but it is not stated in the publications whether and in how far the results were obtained from experiments carried on at the same time.

I have compiled the comparative investigations only under the precautions above mentioned, first between alcoholic and aqueous 
syphilitic extract, and secondly, between alcoholic extract of guinea pig heart (Landsteiner) and aqueous syphilitic extract. The following tables (II and III) contain the results in parallel columns.

\section{TABLE II}

Comparative Investigations of Degrees of Hamolysis Prevention in Use of ( $a$ ) An Alcoholic, ANd ( $b$ ) AN Aqueous Extract of the Same Syphilitic Liver

Amount of extract in each o, I. Amount of spinal fluid and serum in each $0,2$.

\begin{tabular}{|c|c|c|}
\hline \multirow{2}{*}{ Diagnosis. } & \multicolumn{2}{|c|}{ Results. } \\
\hline & (a) & $(b)$ \\
\hline 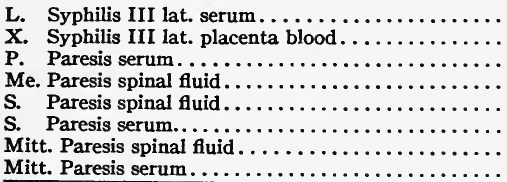 & $\begin{array}{l}\text { Incomplete. } \\
\text { Complete. } \\
\text { Almost O. } \\
\text { Complete. } \\
\text { Almost O. } \\
\quad \text { O } \\
\text { Incomplete. } \\
\quad \text { O }\end{array}$ & $\begin{array}{l}\text { Almost } O \text {. } \\
\text { Almost } O \text {. } \\
\text { O } \\
\text { O } \\
\text { O } \\
\text { O } \\
\text { O } \\
\text { O }\end{array}$ \\
\hline
\end{tabular}

Explanation of signs: $0=$ complete hæmolysis prevention. Complete $=$ Complete solution. Incomplete, Sediment, etc. are intermediary values.

As the table shows, the aqueous extract worked with me better than the alcoholic. In four cases the degree of hæmolysis retardation are almost equal, while with the other four more intense prevention was obtained with the aqueous extract. The alcoholic extract was completely wrong only in Case X, for here the result was completely negative against a clearly positive result with the use of aqueous extract. The diagnosis could not be established with the alcoholic extract. In view of these results I saw no reason to renounce the proved aqueous extract in favor of the alcoholic. This modification does not offer any simplification although, in view of the fact that syphilitic fœetuses are difficult to obtain, it can well be that the alcoholic extract keeps better than the aqueous, but no experience has been had with it, hence this advantage cannot compensate for the diminished activity of the alcoholic extract as proved by my investigations.

These tables show an undeniable advantage for the syphilitic extract over the heart extract. Without doubt, one can obtain complete hæmolysis prevention with the heart extract, but it fails 


\section{TABLE III}

Comparative Investigations of Degrees of Homolysis Retardation in the Use of (a) An Alcoholic Extract of Guinea Pig Heart;

(b) An Aqueous Extract of Syphilitic Liver Amounts and Signs Used as in Table II.

\begin{tabular}{|c|c|c|}
\hline \multirow{2}{*}{ Diagnoses. } & \multicolumn{2}{|c|}{ Results. } \\
\hline & (a) & (b) \\
\hline 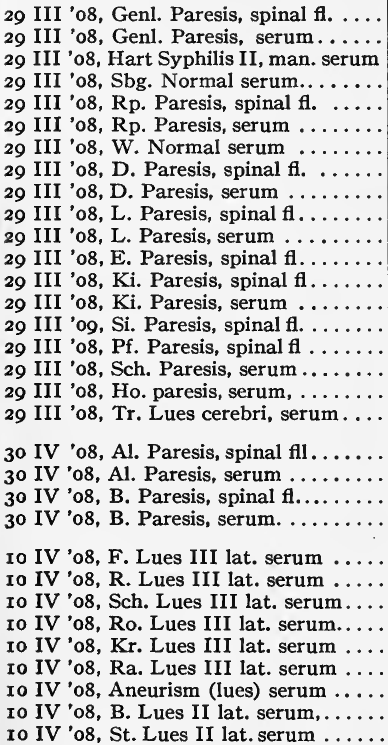 & $\begin{array}{l}\text { Complete. } \\
\text { Complete. } \\
\text { O } \\
\text { Complete. } \\
\text { Complete. } \\
\text { Complete. } \\
\text { Complete. } \\
\text { Sediment. } \\
\text { Large sediment. } \\
\quad \text { O } \\
\quad \text { O } \\
\text { O } \\
\text { Complete. } \\
\text { Complete. } \\
\text { Complete. } \\
\text { Trace of prevention } \\
\text { Incomplete. } \\
\text { Almost complete. } \\
\text { Complete. } \\
\text { Large sediment. } \\
\text { Almost O. } \\
\text { O } \\
\text { Very large sediment. } \\
\text { Complete. } \\
\text { Complete. } \\
\text { Complete. } \\
\text { Complete. } \\
\text { Complete. } \\
\text { Almost complete. } \\
\text { Complete. }\end{array}$ & 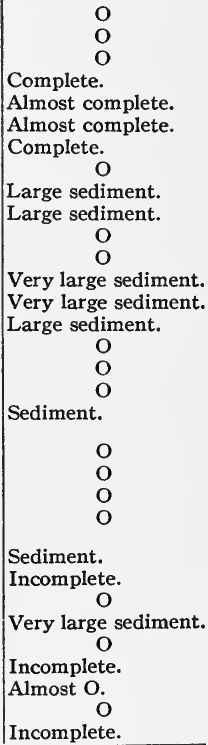 \\
\hline
\end{tabular}

in certain cases where the syphilitic extract causes complete hæmolysis prevention. But, moreover, where the syphilitic extract brings about only partial prevention the heart extract fails us almost completely and this is annoyingly noticeable in psychiatric material, if not so strikingly so in paresis. Old cases of cerebral syphilis frequently retard hæmolysis only partially with syphilitic extract and here the serological proof of syphilis would simply not be brought out with heart extract. Perhaps the heart 
extract is sufficient for dermatological practice and this explains the variance of my results from those of Müller. If one could succeed in making alcoholic heart extract so that it would be a substitute of equal worth, naturally it would be an exceptional advance in technique. For that would bring out a constant series of results from all possible places. In any case, at least according to my experience, Landsteiner's heart extract is still the best substitute, and it is greatly to be desired that, through some modification, someone could make it applicable to all cases.

My experience with aqueous normal liver extract, as I have just mentioned, has not been successful. From among twenty non-syphilitic livers I found only two which could be considered and these did not give satisfactory results. The alcoholic extract of normal liver was of just as little service to me.

Among the lipoids lecithin was used in a large series of complement fixation tests by Porges and Meier. The results were not bad so far as the number of positive results in syphilis goes, but control tests on the normal are so sparse that one can form no judgment of its specificity. In that it has been shown that lecithin precipitation is so unspecific it is necessary in this case to investigate very extensive control material. But if for the time being one would leave the question of specificity completely out of consideration, the use of lecithin, as brought out in the paper of Porges and Meier, offers exceedingly great technical difficulties. In order to get the reaction at all, one must use 0.05 c.c. of lecithin. Smaller amounts do not give sufficient results. In the amount mentioned lecithin tends to work as anti-complement of itself. It has to be used, then, in an amount which will not prevent hæmolysis, and therewith we lose sight of the strictly demanded postulate of Wassermann, that double the amount of "antigen" must not, of itself, prevent hæmolysis. Herewith the door is opened again to the objection, with which the Wassermann method had to fight so long, that hæmolysis retardation, looked upon as specific complement fixation by Wassermann, depends simply on the addition of small amounts which retard slightly. Porges and Meier attempted to overcome the tendency of hæmolysis retardation of lecithin by enormous increases of hæmolytic serum, using four to six times the ordinary amounts. Such freedom with the hæmolytic serum requires such a mastery 
of the technique, and for this reason is so toilsome, that one cannot possibly adopt it in practice. I have tried out this test and have convinced myself of the difficulties in the technique. In practice, at least thus far, it has had no success.

So little material has so far been collected in the complement fixation test with sodium oleate, as recommended by Sachs and Altmann, that we are not able to judge at present of its usefulness. Sachs and Altmann investigated thirteen syphilitic sera and found nine among them which prevented hæmolysis, while eleven non-syphilitic control cases resulted in complete solution. Corroborations have not so far been made.

Finally other tests are to be mentioned which aim at a simplification of the method in an entirely different direction. Bauer made the suggestion that the normal hæmolytic amboceptor of the human serum will alone bring about hæmolysis and entirely replace the artificial hæmolytic amboceptor of the rabbit serum. By this a new source of error is added to the numerous sources already existing for, even as Bauer himself specifically notes, the enormous difference of human sera in their content of hæmolytic amboceptor for sheep's blood must cause the greatest difficulty in judging the result. In psychiatry especially, Bauer's idea cannot be considered, for the investigation of the spinal fluid which contains no hæmolytic amboceptor is not possible without the addition of hæmolysin.

Maslakowetz and Liebermann go still further in that they eliminate the guinea pig complement and use complement and hæmolysin conjoined in the form of fresh serum from a pig which has not been subjected to any previous treatment. The authors describe their results as favorable without however making any further statements. Here also it appears that the greatest circumspection is necessary. ${ }^{1}$

This consideration forces me to the decision that-for the present at least-the original Wassermann method, that works

${ }^{1}$ Tschernogubow (Ber. klin. Woch. 1908, No. 47) used as hemolytic system the blood corpuscles and the complement from the human blood being tested, and a serum which dissolves human blood corpuscles. Hecht (Wien. klin. Woch., I908, No. 50) has simplified Bauer's method still further in that he uses besides the normal sheep's blood amboceptor of human serum, also its complement content for the hæmolytic system with sheep's blood corpuscles. 
with aqueous syphilitic liver extract as antigen, with guinea pig serum as complement, and with artificial hæmolytic rabbit serum, is the only really reliable one. Therefore, I have always returned to the old method after I had tried in vain to get satisfactory results with the substitutes. The clinical investigations which will be reported later are based on this method in all cases. 


\section{REMARKS ON THE TECHNIQUE OF THE WAS- SERMANN REACTION}

With this method one can suffer shipwreck in two ways: In the first place, a false positive result may be obtained through prevention of hæmolysis from different influences, and secondly with the use of syphilitic serum complete solution may occur where by observation of certain check methods the prevention of hæmolysis brought about by complement fixation can be obtained.

The greatest stress has been laid from the beginning on the first named source of error. When the method was published, all the controls by means of which it was possible to differentiate between the atypical and the characteristic hæmolysis prevention were already specified. It is not so very difficult to master this control technique, and by its careful use it offers every guarantee of avoiding false diagnosis, in so far as one will not diagnose syphilis where hæmolysis retardation occurs through some factor not connected with the specific reaction. I need not here go into the necessary controls in toto, for everything that bears on that subject is described in detail in the literature from different sources. None of the controls have been shown to be superfluous, however, and one must now, as then, hold to them as formulas in a pedantic manner. One can perhaps dispute only whether it can be maintained that sera which retard hæmolysis with syphilitic organ extract can cause no retardation with normal extract. We know surely that there are normal extracts which fix the complement with syphilitic sera, and in this regard many of the controls with normal extract which were originally put forward as essential appear irrelevant. I believe also that, in general, one can waive them. Of course it can occur that one finds sera which will retard hæmolysis with every organ extract in the same manner as with syphilitic extract, also with normal extracts with which the majority of sera, luetic included, do not retard, and which has then in reality nothing to do with syphilis, but these are extremely rare occurrences which I, personally, have never encountered, and of which I have heard only in brief 
through private correspondence with Professor Wassermann. If one, however, wants to be especially careful, one should make further controls with normal extract.

The behavior of syphilitic organ extract in its frequent tendency of and by itself to retard hæmolysis has always caused the greatest difficulty. In order to prevent disturbances of this kind it is necessary one should make: (I) controls with double amount of extract, and (II) controls with single amount of extract.

Many authors, as I note in periodical literature, appear to consider it sufficient to make but one of the two controls. Since great danger lies in leaving out either of the controls just mentioned, I do not like to neglect to call attention to these dangers.

In excluding Control II, the authors under consideration apparently reason as follows: "The extract controls are made to determine whether the extract alone retards hæmolysis. If I am convinced by Control I that double the amount of extract used does not retard, I can trustfully waive the control with the single amount of extract, for here I would surely not have to reckon with a retardation." This conclusion, however, is erroneous. In general, the retardation tendency of the extract increases with its increasing concentration. As I have often convinced myself, it is frequently paralyzed in a dose of 0.4 through the assertion of hæmolytic peculiarities which the extract acquires in large doses. It can so happen that 0.4 extract as a result of its hæmolytic capabilities overcomes the tendency to retardation, and causes complete solution, while the test with the usual dose of 0.2 strongly retards hæmolysis. One can, and must, insure one's self against this occurrence by simultaneously making the control with 0.2 extract which, in this case, would show a clear retardation and prevent a wrong interpretation.

The danger is still greater when one relies upon the fact that double the amount of extract will not retard hæmolysis and contents one's self unquestionably with the result of Control II. In the presence of tests in which the control glass "double amount of extract" shows incomplete solution, one must under all conditions speak of a "non liquet." One should not come to a compromise in that one argues this way: "The serum under investigation together with the single dose of extract (0.2) prevents hæmolysis completely, while the double amount of extract alone 
retards hæmolysis only partially. This proves mathematicallypresupposing the anti-complementary inactivity of the serumthat no simple addition of anti-complementary properties of the single components helped, but that the retardation has a specific character."

Experience teaches that considerations of this sort can lead to great fallacies. I can say, for I have already observed it, that at times, in spite of this, one reaches his goal, but there is always great danger that the inexperienced especially will be led into fatal errors. I lay particular stress upon this point because I see that, although we have always laid the greatest weight on this point and have referred to it very exhaustively, articles are still being published which pay no attention to this necessity. One notes, for instance, the protocols which Much and Eichelberg added to the paper wherein they published their investigations on children with scarlet fever. The result was that about 40 per cent. of scarlet fever sera prevented hæmolysis with luetic organ extract. In the protocol one finds simply the control "single amount of extract" (O.I). Now it may be that the controls were fortunate and worked with extract of slight retardation tendency, and therefore their results are correct throughout, but one of the most important guarantees in the correct judgment of results is lacking, and no one can be blamed for reserving judgment on results which have been obtained in this manner. It is this tendency of the extracts to prevent hæmolysis independently which is a true cross for the practical worker, and the question is how can one overcome these difficulties. One way has been chosen which does not appear to me to be exactly favorable in that from double the amount of hæmolytic sera which would dissolve the blood corpuscles to three or even four times this amount has been adopted. One can doubtless in this way occasionally overcome the retardation action of the extract and really attain one's end. On the other hand one runs the danger that syphilitic sera, which otherwise give a definite, or less intensive positive result, are no longer able to retard hæmolysis, and are falsely looked upon as negative. It appears to me to be more efficacious to increase the affinity of the hæmolytic amboceptor for the complement by letting the sheep's blood corpuscles bind themselves to the amboceptor before addition to the mixture. By "sensitizing" the 
blood corpuscles in this way the rapidity of solution is considerably increased, and, at the same time, the retardation action of the extract is in a large measure opposed. I have been completely won over to giving up the separate addition of blood and hæmolysin and as a result I almost never suffer from extract retardation. The fixation of the hæmolysins to the erythrocytes often takes place very rapidly. An increase of affinity for the complement can be observed after a few minutes, and one can allow the binding to go on for half an hour. It appears to me to be unnecessary to go over this time.

The danger that specific retardation of hæmolysis can be obscured by the anti-complementary ability of the sera or spinal fluid is small. Controls with a double and single amount permit it to be easily recognized when a serum or spinal fluid tends to retard. With sera the control "single amount" is important, for in higher doses the normal hæmolytic amboceptor comes into activity and, as a result, the control "double amount" alone does not allow the possibly existing retardation action of smaller doses to be recognized. In general, sera and spinal fluids alone in doses of $0.1,0.2$ to 0.4 do not retard hæmolysis, but one must inactivate the fluids as soon as possible after removal. If the sera or spinal fluids are allowed to stand for a long time in not inactivated condition, one sees that they can retard alone in very small amounts, even when they have been kept entirely sterile in a refrigerator. The experience of Fleischmann that inactivated sera also change in a similar way in the course of time, I have never observed. I have found far oftener that the sera, if one only inactivates them at the right time, adds carbolic acid, and protects from contamination and keeps in a refrigerator, indefinitely preserve their working power undiminished.

Apart from the fact that its strength changes in the course of time, which, however, one is able to judge easily by previous testing before each experiment, hæmolytic serum can suffer disturbance which one cannot offhand ascertain by the ordinary controls. One may have the experience that the hæmolytic (titer) strength suffers no changes, but the affinity for the complement is considerably diminished. This is brought to notice by the fact that in all the tubes, even in those containing proven non-retarding normal sera, more or less marked retardation occurs although the system 
controls show complete solution. At times the use of more concentrated hæmolytic serum helps, but this is not to be recommended on the above mentioned grounds. In general one should prepare a new serum.

These different points should be carefully observed in order to avoid a possibility of error in the false diagnosis of syphilis on the ground of a non-specific hæmolysis retardation. Here we need only a certain amount of care and the necessary instruction on the part of the teacher.

On the contrary it is not so simple to learn to avoid the other possibility of error, namely, to overlook syphilis where it is capable of serological diagnosis. It is a peculiarity of those methods which work with aqueous organ extract that absolutely no one is able to say that he is in a condition in every case in which a positive result is obtainable able to bring it out. The cause of this uncertainty of the work exists in the fact that extracts vary remarkably in their activity and we are not in a position to measure the content of antigen quantitatively. Every careful worker will have exactly similar experiences. $\mathrm{He}$ acquires mastery of the technique in all its details only through a long stay in one of the laboratories, working in this field, and by means of the study of the literature of the subject. Then he begins to work by himself, using a syphilitic liver which he extracts. He gauges the usefulness of his extract by the fact that he obtains strong or complete retardation of hæmolysis with a few syphilitic sera. This reassures him, and he designates all sera which do not give any retardation with this extract as negative. In reality he is in no way able to give judgment in the early days of his work on negatively reacting syphilitic sera, for he has no objective gauge for the value of the extract with which he is then working. Has chance placed a very valuable extract in his hand, he will find a high percentage of his syphilitic sera reacting positively. In the other case only a small part of the cases will appear positive to him. The inequality of the extracts explains the fact that the results of certain authors differ one from another so markedly and that in the beginning only little of positive worth was obtained. Every one is thrown on his own resources on this point, and he cannot make use of the experience of others. It must be clear to him from the beginning that before he has acquired a large per- 
sonal experience he must abstain from any judgment on negatively reacting syphilitic sera. When he has tried out a series of extracts, in the course of time he will finally place particular value on one of them with which the largest majority of syphilitic sera react positively. The results which he obtains with this extract he must try to attain regularly in his later investigations, and the possession of a rich standard material of sera and spinal fluids allow him to accomplish it. The first thing that he has to do will be to re-test with his newly acquired strong extract all the luetic body fluids which previously were negative with his old extract, and he will often be astonished how the percentage of positive results will rise. In order to protect himself in the future from unconsciously sinking below the high standard he has reached through changing of the extract he must possess a very large number of sera and spinal fluids. The general dose of serum and spinal fluid used now and undoubtedly most suitable for the test is 0.2 c.c. As standard fluids only those are suitable which in this dose do not completely prevent hæmolysis but occasion only a partial retardation, and it is recommended to keep a stock of such fluids which in the dose of 0.2 with 0.2 extract cause different grades of partial retardation (incomplete, sediment, large sediment, almost $\mathrm{O}$ ). These standard fluids serve to try out new extracts. The new extract is only then useful when it presents, with the different standard sera, at least the same degrees of retardation. If one finds later an extract of still higher worth he can correspondingly increase his claims in future cases and one finally reaches a point where one can make a diagnosis in all cases that are capable of a reaction. Differences must exist in different laboratories, however, so long as there is no conventional standard establishing certain values for the antigen. Perhaps an agreement will be reached so that one laboratory with specially large experience will distribute samples of extracts and standard fluids on which other laboratories can rely.

It is still further to be borne in mind that even in the use of the same extract tests on different days can differ considerably. The cause may lie in the almost daily necessary charges of guinea pig serum, further in changes which affect the hæmolytic serum, and finally the sheep's blood may play a rôle. Occasionally one cannot bring out the slightest grades of retardation with a proved 
active extract. It eludes the proof. Therefore, it is recommended even with the use of the same extract to run through a known standard material from test to test. I am accustomed in each test to put in tested sera which under proper circumstances in the dose of 0.2 I know can bring about the following grades of retardation: (I) incomplete, (2) sediment, (3) complete retardation. In addition to this, at least two non-retarding normal sera or spinal fluids are always run through. If the control tubes do not show the required degree of retardation I repeat the investigation of the sera which in the test under consideration have completely dissolved until the control tests give objectionless results. Then I am in a position to convince myself of the negative results of the reaction.

From the practical standpoint the first named possibility, $i . e$, that a positive result be falsely accepted, is more weighty than the one just mentioned. The positive result of a biological reaction proves that the infectious disease under consideration exists, while a negative result does not give the same security in excluding the disease. In known syphilitic affections, one finds a positive serum reaction so very frequently-in paresis almost without exception-that a negative result can be relied on even with only certain reserve. Therefore it appears to me expedient to go into the second point a little more fully.

I wish to consider, shortly, still one other question, not entirely without weight, namely, whether it is permissable to establish a diagnosis from a partial retardation of hæmolysis. It may be correct for an inexperienced investigator to consider only complete retardation as a positive result. In the hands of an expert, according to my opinion, the less intensive results also have complete diagnostic force. I would even consider it a mistake, assuming the absolute exactness of the work, to disregard partial retardation, for then straight old cases which are not easily recognizable clinically would be excluded from diagnosis. I have had experiences of this sort, especially with old cases of cerebral syphilis, in which I have made the diagnosis on the ground of a very weak result of the reaction, and the autopsy has shown its accuracy. 


\section{THE CLINICAL SPECIFICITY OF THE WAS- SERMANN REACTION}

After the initial opposition the question of the practical utility of the reaction in general became separated from the critique of the nature of the processes underlying it. This separation was shown to be necessary by the fact that investigators who differed in their ideas of the theory obtained for the most part identical practical results. Therefore, most of them reached a unity in the clinical field, while the theoretical, scientific differences continued and persist to the present time.

One may full well desire of the Wassermann reaction that it should indicate syphilis only where syphilis really exists. The clinical utility of the reaction would, however, not be markedly affected if certain limitations were established as necessary, in so far as in a few other affections the results obtained are similar. Were it possible to fix the limits of these exceptions, it would still be possible to make a diagnosis of syphilis if one could exclude in a given case the affections which come into question. There is no biological method which has not been obliged to have imposed upon it certain restrictions as to its specificity; even the very excellent Gruber-Widal agglutination in typhoid has not been exempt from it.

The first doubts were expressed by Kraus and Volk even at a time when the first experiments were in progress and the methods not completely worked out. These authors remarked that they could notice no clear difference at all between normal and syphilitic sera. Kraus and Volk later abandoned their standpoint of general doubt.

All workers who later occupied themselves with the serodiagnosis of syphilis at last acknowledged the fact, with few exceptions, that syphilitics, taken as a whole, differ clearly from the majority of non-syphilitics in their behavior in the reaction.

While in syphilis, according to the stage and type of the infections, a positive result is obtainable more or less frequently, but always in the majority of cases, the "normal" shows a positive reaction only exceptionally, while in general the entire control 
material is negative. L. Michaelis found positive reactions in two cases of typhoid and one of malaria, and Hoffman and Blumenthal stated that one waitress with Psoriasis vulgaris and a negro with Frambosia tropica among their control material had reacted positively to the Wassermann reaction. Other authors, such as Citron, Fleischmann, Meier, Müller and many others, had negative results without exception in non-syphilitics.

Wassermann reported I, OIO control cases at the Congress for Internal Medicine in Vienna. These were cases in which syphilis was absolutely excluded, which reacted negatively without exception. Among these were the most varied types of diseases, tuberculosis, pneumonia, typhoid fever, septic diseases, etc., and besides these a very large number of malignant new growths.

Only two groups of workers have had strikingly unfortunate results with their control material, and really often obtained a positive result with the reaction. Elias, Neubauer, Porges and Salomon found in 77 control cases 14 reacting positively, and among these positive cases were 5 tuberculoses and 2 neoplasms. These authors further remark that these were mostly aged patients who possibly had had syphilis in early life, but in a few, however, syphilis could be excluded with absolute certainty. The results of Weil and Braun were much more unfavorable. Their investigations were directed systematically toward infectious processes and tumors. In 12 pneumonias, 4 reacted positively, in 20 typhoid cases 2 , in 21 phthises 2 , in I4 tumors 4 , and finally one diabetic.

One can make the objection to both groups of authors that they worked not with syphilitic organ extract, but with alcoholic guinea pig heart extract, and their results speak probably more against the utility of the heart extract than against the reliability of the Wassermann reaction. Before an extensive knowledge of the action of extract of non-syphilitic organs is obtained-and it is not positively determined that a positive reaction has the same meaning as with syphilitic extracts-one cannot, offhand, put the results which are possibly of entirely different value in the same category. It must at least be put down as noteworthy that investigators who worked with syphilitic extract observed absolutely negative results in the same disease forms.

With reference to a few positive findings in different protozoal diseases, as in an already mentioned case of malaria, and in 
a case of Frambesia tropica, and further in one of sleeping sickness, the supposition has been broached that there may be an action of serum with the Wassermann reaction peculiar to protozoon diseases in general. Landsteiner, who first considered this possibility, endeavored to obtain confirmation of his idea by animal experiment. In connection with Müller and Pötzel, he injected rat's blood containing Trypanosoma equiperdum intraperitoneally in rabbits, and these rabbits fifteen to twenty days after infection, acquired the property of retarding hæmolysis with alcoholic heart extract, a property which they did not possess before infection. In order to meet the objection that the retardation was occasioned by the albumen amboceptor of the injected rat's blood, they injected control rabbits with rat blood free from trypanosomes and here retardation did not result. In later experiments with Trypanosoma gambiensis the authors had corresponding results, but they remarked that at times normal rabbit serum also gave the reaction clearly. According to Fleischmann's experience, rabbit serum retards hæmolysis very frequently with syphilitic liver extract, as also with lecithin, and Bruck and Stern likewise observed this. It can very well be that normal animal sera in general frequently give anticomplement action with extracts and in favor of this idea is the communication of Bruck and Stern that sera of the lower apes (Macacus cynomolgus, Nemestrinus, Rhesus) and also guinea pig sera not infrequently normally contain "antibody."

Schilling and Meier, however, found rabbits reacting only after the infection, and Hartoch and Jakimoff likewise confirmed Landsteiner's statement. The difficulty in judging of the results lies in the fact that with the exception of Schilling and Meier, who, however, used only a few animals, the authors did not confine themselves to syphilitic extracts as antigen. Landsteiner used alcoholic guinea pig heart extract and Hartoch and Jakimoff aqueous guinea pig liver extract. The problem is certainly of great interest, and it is much to be wished for that extensive investigations with human protozoon diseases will soon be undertaken. Animal experiments do not permit the question to be answered free from objections. In view of the hitherto sparse, and also in part not objectionless results, it appears a little premature to make the inference and to consider the above mentioned 
experiments as proof of the protozoan nature of the excitant of syphilis.

Much and Eichelberg wished even to conclude from the positive findings which they got in scarlet fever that the excitant of scarlet fever is to be classed with the protozoa. These scarlet fever investigations of Much and Eichelberg appeared for a long time to throw doubt on the utility of the Wassermann reaction. Much and Eichelberg with the use of syphilitic organ extract report that 45 out of Ioo children with scarlet fever reacted clearly positively. ${ }^{1}$ The objection that a complication with hereditary syphilis and not the scarlet fever brought about the positive reaction they refuted in that they found children who did not give the reaction in the beginning of the disease but did in a later stage of it.

In the meantime two studies on the same subject have appeared, in which the statements of Much and Eichelberg have not been confirmed. Jochmann and Töpfer investigated with syphilitic organ extract 33 children with scarlet fever, light and severe cases and in different stages of the disease. In 12 patients they repeated the experiments at different times. Thirty-two cases reacted completely negative in the usual dose 0.2 , but in the dose 0.4 hæmolysis was retarded. Jochmann and Töpfer decidedly refuted the results of Much's and Eichelberg's investigations. Boas and Hauge in Copenhagen came to the same result from a still greater amount of material. Out of 6 I cases one showed at times a weak retardation, which later disappeared, while all the others were completely negative. Boas and Hauge used, however, alcoholic heart extract and therefore one cannot place complete reliance on their investigations.

I have personally been able to investigate five cases in the second and third weeks of the disease, and further 22 children who had passed through scarlet fever one to two years before, and I found a positive reaction only in one of the last named chil-

${ }^{1}$ The same authors found, as I gather from the second edition of Nonnes' book "Syphilis und Nervensystem" which has appeared in the meantime, spinal fluid and serum reacting positively in multiple sclerosis, the spinal fluid alone positive in pseudo-tabes alcoholica and from nine cases of idiopathic epilepsy without syphilis the blood positive in five. The findings in epilepsy are especially noteworthy for it recalls how frequently a syphilitic brain disease masquerades under the picture of a genuine epilepsy. 
dren, but here the presence of hereditary syphilis was absolutely established. ${ }^{2}$

In the following I give a tabulated statement of the nonsyphilitic cases investigated by me.

From this review one sees that I found no spinal fluid which reacted positively. If I add to the 75 spinal fluids mentioned 25 others from non-luetic persons which were examined by Wassermann and myself in Wassermann's laboratory, and likewise found negative without exception, I can dispose of over 100 normal fluids in all of which not a single one gave a positive result.

On the other hand, in the sera of 126 persons, in whom no sure point for the diagnosis of syphilis appeared to exist, there was a positive finding in five cases; that is, in 4 per cent. In four of these cases the spinal fluid tested at the same time reacted completely negatively in contrast to the serum. In the fifth the test had to be limited to the serum. The cases consist of one patient each with arteriosclerosis, with tuberculous meningitis, with psychopathy, with multiple sclerosis and with leucæmia. The two last named patients I did not see personally. They were sent to me with the diagnosis and I found in the histories, which I later looked up, neither anamnestic statements nor clinical findings mentioned which pointed towards syphilis.

In the three remaining patients from our clinic the first was an arteriosclerosis in an old man who was unable to give any information concerning a syphilitic infection, but there was a suspicion

'Lately four authors have confirmed the investigation on scarlet fever with a large amount of material. Meier, likewise Höhne used luetic liver extract, Schleissner, also Seligmann and Klopfstock alcoholic heart extract. Not a single case gave a positive reaction. Seligmann and Klopfstock state, however, that they almost drew false conclusions from their results on account of trouble with the extract.

Halberstädter, Müller and Reiche confirm Much's statements in part. Among a series of extracts they found one of five scarlet fever sera which retarded during a short, circumscribed period in the course of the disease. Because the reaction occurred only transitorily the authors state that the clinical utility of the reaction for syphilis is not influenced by it. Hence I cannot concede that the clinical specificity of the reaction has been compromised by the results of Much and Eichelberg. Perhaps their results are due to faulty technique, and I have already remarked concerning this, that the authors have neglected to ascertain the eventual retardation action of their extract by making the control "double amount of extract." 
TABLE IV

Disease Forms.

(a) Psychiatric Cases.

Alcoholism Chronic. . . . . . . . . . . . . .

Korsakow's psychosis................

Alcoholic psychosis $\ldots \ldots \ldots \ldots \ldots \ldots \ldots \ldots \ldots$

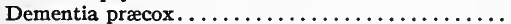

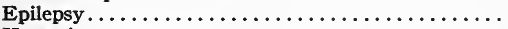

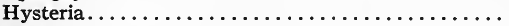

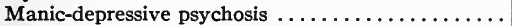

Tumor cerebri (with exception ofgummata) ......

Arteriosclerosis . . . . . . . . . . . . . . .

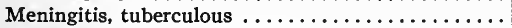

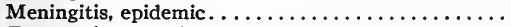

Traumatic neurosis. .................

Post-traumatic psychosis ...............

Psychopathy.....................

Psychic disturbances in infectious diseases........

Organic disease of brain-unknown type. ........

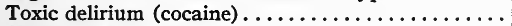

Multiple sclerosis. ...................

Pachymeningitis hæmorrhagica ............

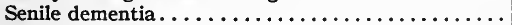

Idiocy and imbecility $\ldots \ldots \ldots \ldots \ldots \ldots \ldots$

Excitement following malaria.............

Total ......................

(b) Neurological Cases.

Compression myelitis $\ldots \ldots \ldots \ldots \ldots \ldots \ldots \ldots \ldots$

Landry's paralysis . . . . . . . . . . . . . . . .

Poliomyelitis. . . . . . . . . . . . . . . . . . .

Progressive neurotic muscular atrophy .........

Progressive spinal muscular atrophy...

Spinal spastic paralysis..................

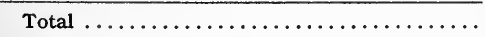

(c) Other Cases.

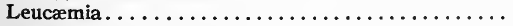

Scarlet Fever $(3-4$ weeks) . . . . . . . . . . . . .

Lymphatic constitution . . . . . . . . . . .

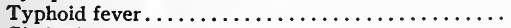

Cirrhosis of liver $\ldots \ldots \ldots \ldots \ldots \ldots \ldots \ldots \ldots \ldots$

Nephritis . . . . . . . . . . . . . . . . . .

Gout . . . . . . . . . . . . . . . . . . . . .

Sepsis. . . . . . . . . . . . . . . . . . .

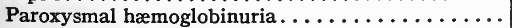

Ulcer of stomach.

Rheumatism . . . . . . . . . . . . . . . .

Total . . . . . . . . . . . . . . . . .

Entire non-syphilitic material tested.........

\begin{tabular}{|c|c|c|c|}
\hline \multicolumn{2}{|c|}{ Negative. } & \multicolumn{2}{|c|}{ Positive. } \\
\hline $\begin{array}{l}\text { Spinal } \\
\text { Fl. }\end{array}$ & Serum. & $\begin{array}{l}\text { Spinal } \\
\text { Fl. }\end{array}$ & Serum. \\
\hline 8 & IO & - & - \\
\hline 3 & 5 & - & - \\
\hline 4 & 4 & - & 一 \\
\hline 3 & 3 & - & - \\
\hline 2 & 8 & - & - \\
\hline 4 & 7 & 一 & - \\
\hline 5 & 9 & 一 & - \\
\hline & 6 & & - \\
\hline I3 & I 7 & - & - \\
\hline 4 & 3 & - & $\mathbf{I}$ \\
\hline I & I & - & I \\
\hline 3 & 3 & 一 & - \\
\hline 2 & - & - & - \\
\hline 2 & 3 & - & I \\
\hline 2 & 2 & - & - \\
\hline 4 & 4 & 一 & 一 \\
\hline I & I & - & - \\
\hline 2 & 2 & - & I \\
\hline I & $\mathbf{I}$ & - & - \\
\hline- & I & - & - \\
\hline I & 4 & - & - \\
\hline- & I & - & - \\
\hline 68 & 95 & - & 4 \\
\hline - & 2 & - & - \\
\hline I & I & - & - \\
\hline - & I & - & - \\
\hline- & I & 一 & - \\
\hline I & $\mathbf{I}$ & - & - \\
\hline I & I & - & - \\
\hline 3 & 7 & - & - \\
\hline $\mathbf{I}$ & 3 & - & I \\
\hline & 5 & - & - \\
\hline - & I & - & - \\
\hline 2 & 2 & - & - \\
\hline - & 2 & - & - \\
\hline 一 & I & - & - \\
\hline- & I & 一 & - \\
\hline - & $\mathbf{I}$ & - & - \\
\hline - & $\mathbf{I}$ & - & - \\
\hline & I & 一 & - \\
\hline $\mathbf{I}$ & I & - & - \\
\hline 4 & I9 & - & I \\
\hline 75 & I2I & - & 5 \\
\hline
\end{tabular}


here that a syphilitic infection had existed which perhaps had been overlooked or forgotten. This suspicion was grounded upon the marked increase of lymphocytes in the spinal fluid ( 35 cells in one c.mm.). The patient with tuberculous meningitis was an officer who was admitted in a stuporous condition, and therefore could give us no useful statements concerning his early life. The autopsy showed nothing suspicious of syphilis, but by questioning the relatives we learned that the patient had gone with women to a great extent, and had been a decided sport. The third patientpsychopathy-was a neurasthenic in whom we suspected beginning paresis, but the symptoms were not sufficient to make a diagnosis, and after many. weeks residence in the clinic the patient was discharged in an unchanged condition. Syphilis was denied here, while gonorrhœa was admitted.

I must confess that these five cases are not able to awaken in me a doubt of the clinical utility of the reaction, and I even find it odd that in the "normal" the reaction is not oftener positive. With all proper scepticism that one may bring to bear upon a new method of investigation, one cannot overlook the fact that the clinical diagnosis of a latent syphilis is in so many cases impossible in that remains of bygone syphilitic disease processes are absent. One is often compelled to rely upon the statements of the patient and one knows that in the lower social strata, especially where they are not used to careful observation, syphilitic symptoms can be completely overlooked, particularly as syphilis does not always occasion definite symptoms even to the medical eye. In women especially the initial sclerosis is without doubt exceedingly frequently overlooked, and secondary or tertiary skin affections are often considered something quite harmless and soon forgotten. Lately a woman, whose husband was suffering from cerebral syphilis, and whose son was an imbecile, as a result of hereditary syphilitic brain disease, assured me that nothing had ever been the matter with her. Examination of the woman showed a tertiary skin syphilide, larger than the palm of the hand, which the patient thought was of no importance; it was a spot which she had had for two years, and had never caused her any pain. When one examines parents of hereditarily syphilitic children one frequently hears from them that they never noticed in themselves any suspicious disease symptoms. I have often seen 
such cases whose investigation was brought about by the presence of a syphilitic disease in one of their children, and they then reacted positively. In another place I shall speak of experiences of this sort. By neglecting a careful examination of the family history, such cases find use most readily as normal control cases when they come to a hospital on account of a disease not connected with syphilis, for example, a typhoid ; and these cases are arranged under the positive reacting "non-syphilitics." The difficulties which stand in the way of the anamnestic determination of syphilis are so thoroughly appreciated on all sides and suspicious cases of this sort are brought occasionally into the debates on serodiagnosis by Wassermann and Citron, so that it is not worth while to enlarge again here on what has so frequently been said on this matter. One notices only the very interesting observations recently published by Fritz Lesser. Lesser examined all the cases of syphilis of the internal organs which came to autopsy in the Moabit Hospital for years. He found 30 gummata of the liver, 3 of the heart and even 2 of the suprarenals and heart, which caused no difficulties and were not diagnosed clinically.

I think that, concerning the sporadically occurring positive reactions in the so-called normal control material as far as it is found in patients with different known clinical affections, one may rightly accept that one has to do here with syphilitics who, as so often happens, know nothing about their infection. Serious considerations point against the frequent occurrence of positive reactions in definite non-syphilitic disease forms, and one must await whether the same thing is observed in other protozoan diseases. This cannot be observed at all in any one of the diseases occurring with us, not even in scarlet fever, the only disease in which a suspicion in this direction has been directed, and by further tests even this suspicion has been proved to be absolutely unfounded. 


\section{CLINICAL INVESTIGATIONS}

A. Cases of Syphilis Without Complication of the Central Nervous System. (With the Exception of Hereditary Syphilis)

TABLE V

\begin{tabular}{|c|c|c|c|c|c|c|}
\hline & \multicolumn{2}{|c|}{ Negative. } & \multicolumn{2}{|c|}{ Positive. } & \multicolumn{2}{|c|}{ Total. } \\
\hline & $\begin{array}{l}\text { Spinal } \\
\text { Fluid. }\end{array}$ & Serum. & $\begin{array}{l}\text { Spinal } \\
\text { Fluid. }\end{array}$ & Serum. & $\begin{array}{l}\text { Spinal } \\
\text { Fluid. }\end{array}$ & Serum. \\
\hline Primary lesion. . . . . . . . . . . & 0 & $\mathbf{I}$ & o & 4 & 0 & 5 \\
\hline Syphilis II manifest. . . . . . . . . . & Io & $\mathbf{I}$ & 0 & 26 & Io & 27 \\
\hline Syphilis II latent . . . . . . . . . & 4 & $\mathbf{I}$ & $\mathbf{0}$ & Io & 4 & II \\
\hline Syphilis III manifest . . . . . . . . & $\mathbf{I}$ & 0 & o & 7 & $\mathbf{I}$ & 7 \\
\hline Syphilis III latent. . . . . . . . . & I2 & I6 & o & 25 & 12 & $4 \mathrm{I}$ \\
\hline Total.................... & 27 & I9 & $\mathbf{0}$ & 72 & 27 & $9 \mathbf{1}$ \\
\hline
\end{tabular}

One sees from the table that the entire 27 spinal fluids examined reacted negatively $=100$ per cent.

Of the $9 \mathrm{I}$ sera $72=79$ per cent. reacted negatively, and $\mathrm{I} 9=\mathbf{2 I}$ per cent. reacted positively.

Of the I9 negative sera $16=84$ per cent. belong to the latent tertiary stage.

One of the five patients in the stage of initial sclerosis reacted negatively. As a few secondary efflorescences appeared in this patient after four weeks the serum was examined anew and its reaction this time was intensely positive.

Of the case which I have designated syphilis II latent, the following is noteworthy. It was a student whose primary sore was excised by Lassar before the appearance of the secondary manifestations. In the meantime a year passed without the appearance of any general symptoms, but, in spite of this, this patient's blood reacted strongly positively.

The disappearance of the reaction in the tertiary latent stage is very striking, as has already been observed by Bruck and Stern, Citron and others in many cases. While in manifest syphilis hardly a patient reacted negatively and furthermore in the latent secondary stage not one patient failed in the secondary reaction, in $4 \mathrm{I}$ sera of tertiary latent syphilitics there were $16=40$ per 
cent. negative findings. One can draw the conclusion from this that the property of a syphilitic to retard hæmolysis in the Wassermann test can disappear with the vanishing of infectious symptoms, and that the reaction cannot simply be the expression of a constitutional peculiarity which the sera of persons who have been infected with syphilis shows continually. There doubtless exists a close connection between syphilis as a disease still existing in the body and the appearance of the characteristic material in the serum. The positive reaction is the expression of the general infection. I have been able to see this very clearly in my case cited above, which reacted negatively in the primary stage and after a few weeks with the appearance of the first symptoms of general infection reacted positively. The reaction has nothing positive to do with the contagiousness.

It can further be accepted that persons in the tertiary stage who react positively are not free from syphilis. But one must be careful about reversing the statement, and saying that in persons in the latent tertiary stage who react negatively syphilis has absolutely left the body. Among these negative cases was one patient who at no time, even in the florid stage, was in a condition to produce reacting substances. Further there were those who showed the reaction once and later lost it but who are possibly still syphilitic, and finally there are those that are really cured. In individual cases, on the other hand, one must be very careful with regard to the question of cure, and especially in the latent tertiary stage with a negative result of the reaction. Here one should not neglect therapeutic measures if one considers it to be indicated on any ground whatsoever.

Specific curative means appear to have an influence on the reaction, according to Citron and Fritz Lesser, whose views Bruck has lately accepted. Other authors are still skeptical, and demand a further careful testing of this question.

In a very large series of patients I obtained very exact statements concerning their previous treatment.

I will quote briefly here only the tertiary latent cases under which I include patients whose infection dated back at least four years.

Twelve patients were treated very thoroughly for years and of these six reacted positive and six negative. Among the positive 
cases of this group in one the infection has occurred twenty-six years previously and the last symptom likewise many years back. In another the infection was seventeen years old and the last symptoms seven years previous. Another was infected nine years before and for eight years had been free from symptoms. He had up to 1902 taken seven inunction cures, and one inunction cure each in 1906 and 1907 , has three healthy children and reacts positively.

Five patients were insufficiently treated, and of these two reacted negative and three positive. Two patients were not treated at all and both reacted negative.

It is striking that the four insufficiently or entirely untreated cases which gave negative reactions should never have had any general symptoms. Perhaps these diagnoses were incorrect, although in each the diagnosis was made at the time by a physician and two of the patients showed preputial scars. Of the two positive cases two claimed never to have had general symptoms and the infection occurred sixteen and fourteen years before. One certainly cannot consider that the lack of general symptoms signifies a lack of general infection, and the absence of the serum reaction cannot be interpreted offhand in this way. In all of my cases of III latent stage which reacted negatively, the majority were very thoroughly treated, so that I have the impression that the reaction, at least in a series of cases, is influenced by therapeutic measures. In the course of time this question will doubtless be cleared up definitely, and then one will be able to come to prognostic conclusions perhaps in the direction that well treated persons who still react positive are in a higher degree in danger of developing metasyphilitic processes than those from whose blood the reaction has disappeared.

As a very weighty result of this investigation it must be noted that the spinal fluids, entirely independent of the action of the serum, reacted positive in none of these cases of syphilis without nervous involvement. Levaditi, Ravaut, and Jamanouchi obtained the same results. They found the spinal fluid reacting negative in eleven cases of syphilis without nervous involvement. Stertz had analogous results in seven cases. We will see later that this gives valuable support for differential diagnosis. 


\section{B. GENERAL PARESIS}

When Wassermann and I first started to extend the serodiagnostic investigations to general paresis, we had to try to work up a group of clinically undoubted cases as a foundation, in order to determine, in clinically certain material, how far the result is positive in paresis, and how far one can find any regularity in the result of the reaction. We began by testing the spinal fluid, with the idea that a positive result was most likely to be expected and the blood examination was originally omitted for the further reason that no very encouraging results were obtained in the first examinations of the blood of syphilitics, which were under way in Neisser's laboratory in Breslau, and concerning which we were well posted. The first published experimental results from the Neisser Clinic, published shortly after ours, showed positive findings in only one fifth of the cases of positive syphilis. But later it was possible to make a diagnosis of syphilis from the blood in a much higher percentage, up to 90 and over. We believed then, as I have said, that we had still to accept that the chances for diagnosis from the blood were not very favorable, and this was the main reason why we directed our interests principally toward the spinal fluid. After we had found that the spinal fluid reacted positive in an overwhelming majority of cases of general paresis, we next tested the serum in twenty patients, and in those patients whose spinal fluid reacted positive the reaction of the blood was never lacking. I was able to say in a later appearing publication, on the ground of my investigations, that the serum of patients whose spinal fluid showed a positive finding presented the same reaction.

As stated above, we used, as original material, cases in which we were informed that no doubt of the diagnosis of paresis could exist, and they were almost all advanced disease stages. The material came from different sources. Part was sent from Munich and part was placed at our service in the Berlin City institutions, and I can give no personal statement of the clinical peculiarities of the different cases, because I never came face to face with a large part of the patients. We were satisfied with knowing that we had undoubted advanced cases for investigation. Our results were so arranged, that in our material of 54 spinal fluids $4 \mathrm{I}$ reacted positive and 5 negative, and further 8 showed 
only a slight retardation of hæmolysis. We withheld judgment in the last named group and designated them as questionable.

One must bear in mind that, at this time, we had not had the technical experience which allows us to-day to bring out the reaction in clear fashion with greater accuracy. In part we used the sera in too slight concentration (o.I c.c.) and we lacked a standard material, which to-day makes it possible for us to find out exactly what claims we can make for the activity of our organ extract. On these grounds I believe that if the cases with weak positive reaction, which we thus called questionable, came to us for testing to-day, they would without doubt unexceptionally give a positive result. The cases which reacted negative, however, require earnest thought. From this it was apparently proved offhand that the appearance of the specific substance in the spinal fluid in paresis is not regular; that even if the majority reacted uniformly, still one group did not show the reaction. These five patients, according to the statements of the physicians in charge, were ordinary straightforward cases of paresis. Further study of these cases showed that in part real false diagnoses had been made. One of these patients, whom I have already reported in another place, and who had been considered one of advanced paresis, was transferred to another institution and the clinical picture changed in a surprising fashion. At first he had appeared as a much deteriorated paretic and for a long time had been unclean in his habits, but in the new institution he was completely orderly and clear. Vivid auditory hallucinations and fantastic delusions appeared, and after a little time the patient was discharged with the diagnosis "paranoid dementia præcox."

A second patient, concerning whom I fostered doubts of paresis at the start, is without doubt a stationary dementia on a nonparetic groundwork. The third case continues after more than two and a half years in entirely unchanged condition, in Eglfing, and is considered one of cerebral syphilis. The fourth case was discharged from the institution a short time after the investigation, and to the end was looked upon as an undoubted paretic, and I have personally never seen him again. The development in this case was extremely unusual. The disease was ushered in with a stuporous condition, lasting a year and a half, and a diagnosis katatonia was made. Later the original doubt completely disap- 
peared. The fifth case was a paretic and the patient has died in the meantime of paretic convulsions. Here, at least, it is not improbable that the negative result of the reaction was due to the technique. The case was one of the first which we investigated and the spinal fluid was tested in a concentration ( $\mathrm{I}: \mathrm{IO}$ ), which we later determined is not sufficient in all cases. Possibly here a positive result could have been obtained with the use of stronger concentration.

It is seen from this that further following of the cases showed that three of the five negative cases of paresis were really false diagnoses, and that the two remaining cases were true paresis, but that one ran an abnormal course, and the last named would possibly have reacted positive with proper technique. If one would thus wish to solve the question of whether the appearance of the reaction in the spinal fluid in paresis is at all regular or characteristic the first series of experiments gives no decisive negative answer.

Our first blood investigations consisted of only twenty cases, of which one was negative. This was the serum of a patient who, as the further course showed, was considered a non-paretic dementia, and whose spinal fluid is included under the five negative ones mentioned previously. The group of investigated sera was too small to draw general conclusions from, but here the regularity of the positive reaction was absolute, for the only negative finding was in a non-paretic patient.

Before I go further into my investigations, I wish to give a short survey of the results others have obtained in the meantime with the serodiagnosis of syphilis in paretics. I limit myself to the investigations of different authors with spinal fluids in particular.

Neisser, Bruck and Schucht: 8 spinal fluids, $4=50$ per cent. positive. The small number of positive reactions here is to be ascribed to the same causes which gave the author only 20 per cent. positive results in the original blood investigations in syphilis. A. Marie and Levaditi : 39 spinal fluids, $29=75$ per cent. positive. Morgenroth and Stertz: 8 spinal fluids, $8=100$ per cent. positive. Michaelis and Lesser (cases from Edel): 20 sera, $I 8=90$ per cent. positive. Citron: 5 cases, 5 positive. Kroner: 6 cases, 5 positive. Braun: 12 cases, $10=83$ per cent. positive. Förster: 
Io spinal fluids, 5 positive, 4 negative, I questionable. FraenkelHeiden: 14 cases, $\mathrm{I} I=7 \mathrm{I}$ per cent. positive. Raviart, Breton and Petit: 72 spinal fluids, $67=93$ per cent. positive. A. Marie, Levaditi and Jamanouchi : 30 spinal fluids, $28=93$ per cent. positive ; 27 sera, $16=59$ per cent. positive. Stertz: 45 spinal fluids, 40 positive, 3 doubtful, 2 negative $=89$ to 95 per cent. positive.

In the negative and doubtful cases the blood reacted positive three times. Stertz recommends therefore that the serum also be investigated in all cases. ${ }^{2}$

While the investigators, up to the present time, have worked only with spinal fluid, excepting Michaelis and Lesser, who investigated only the sera in paresis, Marie, Levaditi and Jamanouchi alone tested the spinal fluid and serum side by side. In my further investigations of paresis I have, with a few exceptions, regularly tested the spinal fluid and serum at the same time. I intend to show later that the testing of both body fluids in the same patient is not without importance.

I will first mention the results which I obtained in cases when the diagnosis of paresis was made without restriction.

The material consisted in all of 153 cases of paresis : 107 men and 46 women.

Concerning the syphilitic infection we were able to obtain confirmation of it in 73 of the 107 men and 23 of the 46 women, partly from enquiry of the relatives, and partly from questioning the patients. The infection was denied in the male patients in only 16 ( 22 per cent.), while it was proven in 45 ( 62 per cent.) and probably existed in 12 more ( 16 per cent.) Thus for the male patients from whom reliable anamnestic statements were obtainable it was possible to accept syphilis as actually or probably existent in 78 per cent.

In the women we could get reasonable reliability in only one half the cases. Here syphilis existed surely in 8 cases ( 35 per cent.) and probably in 5 others ( 22 per cent.), while ro women (43 per cent.) never had noticed anything of an infection. The percentage of women who truly or probably had contracted syphilis was thus 58 .

If the anamnesis concerning the fact of infection in our paretics

2 Nonne (Ed. 2 of "Syphilis und Nervensystem") found the spinal fluid and serum reacting positive in 90 per cent. of his cases of paresis. 
were of little value the statements concerning treatment were still less reliable. Yet it was ascertained that 25 men were thoroughly treated and five others but poorly. Among the women we could determine that a thorough treatment had been undergone only in five.

The treated cases differed in no way from the untreated in regard to the intensity of the reaction; nor the well treated from the poorly treated.

Investigations.

Spinal fluid + serum in I 31 cases.

Spinal fluid alone in 16 cases.

Serum alone in 6 cases.

The results of the serum investigations will be taken up next.

Including the 19 sera of paretics investigated by us in Berlin and found positive, the result was that ${ }^{5} 56$ paretics, all without exception, showed the reaction in the serum. Hence I committed myself to the belief that the serum in paresis always reacts positive. That exceptions can occur, as in all biological reactions, is not out of the question here, but on account of their great infrequency, they cannot be considered of great practical importance in view of these results. In true syphilitic affections, even in the florid stage itself, no such complete regularity has existed, and it is striking, according to my ideas, that paresis seems here to occupy a unique position among all the varied clinical forms of syphilis. What this unique position may depend upon it is difficult to state. According to my ideas, we may have to count on the possibility that perhaps the syphilitics, who lack the reaction in the florid stages, have no tendency to develop paresis later, and that, further, the production of the reacting substance represents a primary condition in the development of metasyphilitic diseases. The practical conclusions which we can draw from the uniform behavior of the sera of paretics is this, that we can exclude the existence of paresis with great probability when the serum of the patient reacts negative. Paresis is thus the only one of all the syphilitic affections in which a negative result is of clinical value.

The material investigated comprised cases of the most varied stages and types. The rule of positive blood reaction applies not only to patients in the height of the development of the disease, but also to cases in the earliest beginning as to those in the agonal 
stage. In the same manner it embraces cases of violent course as well as the slowly progressive or even stationary cases. Thus I found the blood reacting intensely positive in a case of so-called stationary paresis where the disease had already existed 23 years.

While the different stages and forms of paresis do not stand out from one another in the regular positive result of the blood reaction which they show, nevertheless differences in the intensity of the result of the reaction can be noticed. The strength of the result of the reaction is in no way the same in all cases, and further, the latitude of the reaction is very different. I have collected cases with nearly the same result into separate groups, and have tried to determine whether the cases of one group have in any way uniform clinical points, and it was evident that this was not at all the case. I can therefore say that the intensity of the reaction does not coincide in any way with a clinical grouping of paresis.

For differential diagnosis the negative result is of more importance than the positive. While a negative finding, according to our experience thus far, excludes a diagnosis of paresis, the positive serum finding proves absolutely nothing concerning paresis, but shows simply that the person has had syphilis. The psychic disturbance which exists in certain cases need not in any way be connected with syphilis. Hence we must be on our guard against laying too much weight on the positive blood reaction in doubtful cases.

In the consideration of doubtful cases in which there is only the remotest possibility that paresis can exist, we have developed the custom of not performing spinal puncture immediately, but first making blood tests. If the result is then negative, the patients are usually spared spinal puncture. With a positive result in the blood reaction we regularly perform spinal puncture for the purpose of biological and cytological examination of the cerebro-spinal fluid.

The investigation of the spinal fluid showed the following results :

The spinal fluid was examined in 147 cases. The result of the reaction was: positive in 139 cases, doubtful in 2 cases, negative in 6 cases.

It was observed that in the 8 cases in which the results must 
be put down as not surely positive, or as negative, the sera, in contrast to the spinal fluids, reacted positive without exception, that thus also syphilis could be proved in these cases.

It is evident that a negative reaction of the spinal fluid is very rare in paresis. The cases with negative reactions represent exceptions, and we shall discuss later how these cases behaved clinically. At all events I cannot agree with the French authors on the ground of these results, and acknowledge a superiority of the spinal fluid over the serum in respect to the frequency of the presence of the reaction. In speaking of the difference of the grades of intensity of the reaction in serum, I have shown that the strength of the reaction of the serum bears no known relation to the clinical behavior of the case. The same holds true of the absolute content of reacting substances in the spinal fluid. There are all grades of reaction strength in the spinal fluid in cases coinciding clinically, and one cannot say that any group at all, either fresh or agonal, progressive, or slowly progressing cases, shows a certain reaction degree either more or less frequently. The question of the relation that the spinal fluid and serum of the same patient bear one to another in the intensity of the reaction is different. Concerning this we have already remarked that conclusions, concerning the place where reacting substances are formed, can be derived from the relation between the content in the two body fluids of these substances. The view has been suggested that in cases showing greater wealth of reacting substances in the spinal fluid one can accept that such substances do not come into the spinal fluid from the blood, but are produced from the central nervous system.

This consideration immediately gave the idea of making comparative experiments. I will say beforehand that further quantitative comparative experiments did not result in giving a positive answer to the question of the origin of the reaction products appearing in the spinal fluid. I do not state this from any desire to prove anything in this direction, but $I$ do it rather to show what relation one can notice in extensive material between the two fluids in regard to the reaction in general, and further to determine when the absolute intensity of the reaction either in the serum or the spinal fluid shows no connection with any stage or any form of paresis, and whether perhaps the relations of the 
reaction in the two fluids to each other stand in any connection with the clinical findings.

The primary consideration for the comparative investigations of the two fluids is that the experiments should be done in the same test.

The titrating causes great difficulties here in contrast to the behavior of immune sera. Whether one takes the extract as constant and uses the serum in diminishing amounts, or inversely works with diminishing amounts of extract and the same dose of serum, one frequently obtains no regular diminution of the strength of reaction but entirely irregular degrees of inhibition can occur in the middle of the series. This depends upon the fact that the extract as well as the serum can of itself inhibit hæmolysis on the one hand and increase its action on the other. The play of the antagonistic properties can frequently influence the result of the reaction in a manner not easily understood, and thus an exact determination of its strength is rendered exceedingly difficult, but nevertheless that does not prevent one from observing, under favorable conditions, a very gradual step-like decrease of the reaction strength.

On these grounds I have renounced the titration on account of the sources of error it contained, and have compared the degrees of inhibition with the use of constant doses of 0.2 extract and 0.2 serum and spinal fluid. In the case of complete inhibition of both one is obliged to loose all quantitative comparison, but, according to my experience, this is of little importance in general.

I distinguish the following degrees of inhibition:

Complete inhibition

Strong inhibition (very large sediment, large sediment)

Medium inhibition (sediment)

Weak inhibition (incomplete)

$$
\begin{aligned}
& ++t+ \\
& ++t \\
& ++
\end{aligned}
$$

The following possible results were seen:

TyPical Formule

$\begin{array}{lrl} & \text { Serum. } \\ \text { г. }+t+t \\ \text { 2. }++t+ \\ \text { 3. }+t+ \\ \text { 4. }++t \\ \text { 5. } \\ \text { 6. }+ \text { t } \\ \text { 7. }\end{array}$

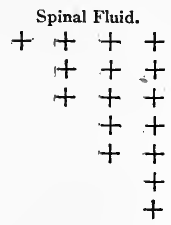




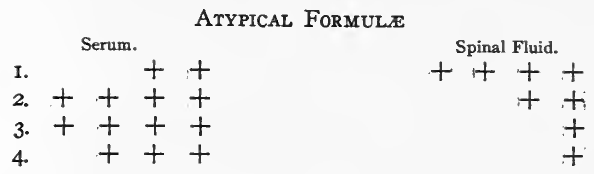

In the usual clinical forms of paresis the intensity of the reaction in the spinal fluid in general is the same as in the serum, or it is a very little below it. The reaction occurs most frequently, according to the typical form $\mathrm{I}-4$. The reaction results according to the typical forms 5-7 occur infrequently without, however, the patients who have these forms showing clinical peculiarities in any way. One finds weak reactions of both media in fresh cases of paresis, and in advanced ones, in rapidly and in slowly progressing cases.

In the cases which react according to the atypical formulæ, there are forms which vary clinically in different ways. Once it appeared to me that cases of slight progressive course and those which tend to remissions relatively, frequently show a considerable preponderance of the serum over the spinal fluid. Weak reaction of the spinal fluid with intensive reaction of the serum was shown in a series of cases which although suspicious of paresis yet could not really be differentiated from syphilitic brain disease. The same relation was observed in a few positive cases of cerebral syphilis, of which I shall speak later.

The atypical formula $\mathrm{I}, i . e$., the preponderance of the reacting substance in the spinal fluid in contrast to the serum, I have observed in only three patients, and here we had very turbulently progressing diseases which presented a picture of acute delirium, and rapidly died.

From the comparative investigations of spinal fluid and serum it was seen that a marked preponderance of the spinal fluid in its content of reacting substances in contrast to the serum extremely seldom existed; that further in paresis the two fluids reacted with almost equal intensity, and in not a small part the serum showed a reaction of higher degree. Stertz and Fraenkel-Heiden agree with this conclusion. The French authors who lately have worked on this question have come to a different conclusion. Marie, Levaditi and Jamanouchi found in 30 paretics the spinal fluid reacting positive in 93 per cent., the serum on the contrary 
in only 59 per cent, and they concluded therefrom that the serum gives less constant results than the spinal fluid and thus possesses less diagnostic importance. I am unable to explain what this difference of results depends upon.

It is astonishing that another group of French authors has had similar experience. Raviart, Breton and Petit limited themselves entirely to investigations of the spinal fluid after, as they say, they had convinced themselves in a few early tests that in paresis the serum gives the reaction much less surely than the spinal fluid. As the last named authors formed their ideas on the ground of a very few tests and neglected to follow these considerations on larger material, their contention does not appear to be sufficiently supported.

I must state the view, as I have said, in contrast to the French authors, that in paresis the reaction is shown in general surer and more regularly in the blood than in the spinal fluid.

Of course there are exceptions in which the spinal fluid of paretics reacts negative, and we shall have to examine clinically more closely the cases which lately showed a negative result since we have seen that the majority of the cases tested in Berlin with negative findings were falsely diagnosed. In the first place, as already stated, all these cases could be recognized as syphilitics positively, from the serodiagnostic investigations of the blood. They departed from the usual finding in paresis only in that the appearance of the reacting substances was lacking. One is also unable to say here that, as in all infectious diseases, and also in syphilis, there are individuals who are not capable of producing reaction products, the case is similar in a few paretics. But the positive blood reaction proves that an inability for producing the reacting substances does not exist here but that the fact that the spinal fluid remains free must have a cause dependent on the type of the disease. These cases act on the one hand like syphilitics without disease of the central nervous system, and on the other like the majority of cases of cerebral syphilis to which we shall come later.

The clinical consideration of the negative cases shows in fact that on the whole they were not ordinary forms of disease. I shall point out shortly in how far the cases departed from the usual clinical findings in paresis. 
The two cases of paresis which I consider doubtful on account of the reaction of the spinal fluid are of little interest, for I believe a positive finding could have been obtained here if only of a slight degree.

\section{ObSERVATION I}

B., captain, 40 years of age, came to autopsy. He died as a result of a suicidal shot in the head. The autopsy showed the presence of a not greatly advanced paresis.

The second case, however, could possibly have been falsely diagnosed.

\section{ObSERVATION 2}

The patient, D.A., 34 years old, painter on glass, was taken sick a few weeks before admission. His memory had rapidly failed, he talked in a silly manner, asked his wife for a hammer in order to put on his trousers; was not in condition to write anything coördinated. Fifteen year previously he had had syphilis. In the clinic he showed a confused excited condition, in which there were phases of stupid euphoria; in the periods of rest a recognizable mental weakness was present. $\mathrm{He}$ had had one epileptiform convulsion. There was a disturbance of articulatory speech, otherwise there were no somatic changes. There was little doubt of the diagnosis of paresis when the patient was taken away from the clinic by his wife in a few weeks in a slightly improved condition, against the advice of the physicians. I saw the patient again after a few weeks; he seemed psychically intact and showed full insight. He attended to his work and felt absolutely well. Physically he showed tremor of the muscles of the face, coarse tremor of the tongue and a difference in the patellar reflexes, further no disturbance. In particular the pupils reacted splendidly.

We have to do here either with a very good remission or, what is more probable, not with a paresis at all, but with a syphilitic brain disease.

Of the six cases with complete negative reaction one has died in the meantime, but unfortunately did not come to autopsy.

\section{Observation 3}

In this patient (St.) the diagnosis of paresis was made particularly with reference to a decided paralytic disturbance of the speech and writing, as well as an apparently marked dementia. No anamnesis. It was striking that there was a continuous stupor, that at times a rise in temperature to $39^{\circ} \mathrm{C}$. was observed without recognizable cause and that in spite of the advanced state of the disease the pupils reacted very well. Further there was present a general spastic stiffness as a result of which the patient fell like a stick when one stood him up. The lymphocyte increase in the 
spinal fluid was strikingly high, such as is rarely seen in paresis (600 cells to the $\mathrm{r}$ cu. $\mathrm{mm}$.). The patient was soon sent to an asylum, and died after a few weeks. While there I learned he had a purulent discharge from the left ear.

Since the autopsy was not performed it is difficult to judge this case. Possibly there existed a brain abscess or a meningitis. But since a diagnosis of paresis without reserve was made in the clinic, and a strict refutation of this idea is not possible $I$ have placed this case among the paretics. In any case the positive blood finding shows that the patient had syphilis.

\section{Observation 4}

The next case concerns a Russian lawyer, A., who eleven years previously had had a syphilitic infection. Three year ago Professor Selenew, in Charkow, made a diagnosis of cerebral syphilis on grounds unknown to me. From the beginning of the present year, 1908, symptoms indicative of paresis, made their appearance. Stuttering, changes in the hand-writing, without marked paralytic character however, retention of urine, impotence, with mild weakness of memory, distraction, change in character in the sense of a petty egoism. The patient made an impression upon us of a decided dementia. There was present, however, well-marked insight, which the patient made very evident in that he kept a diary of the state of his health. The physical signs were not grave. The speech was slurring, but not definitely paretic. Pupillary light reaction was sluggish, the tongue showed a tremor, there was no hypalgesia, the patellar reflexes were unmodified.

Neither the psychic nor the physical findings gave any certain proof of the existence of a paresis, yet the diagnosis of paresis was made, but one was not able to exclude the possibility that it could be a syphilitic brain disease.

\section{ObSERVATION 5}

The third negatively reacting patient, St., also offered much that was unusual. The infection took place 28 years previously. The disease began four years ago with paralysis of the eye movements. Shortly before the admission, June, 1908, euphoric excitement with ideas of grandeur of the most foolish nature appeared, which during his stay in the clinic continued, and even persist at the present. It is striking that a loss of the convergence reaction persists, in addition to complete pupillary immobility. The patellar reflexes are absent. No speech nor wrifing defects. There was a definite increase of lymphocytes in the spinal fluid.

Likewise here only the further course will permit a correct judgment. For the present one can think of a paresis but also of the presence of a cerebral syphilis. 


\section{Observation 6}

In the fourth case, $R$. became acutely ill after a seizure with left sided palsy, and a transitory loss of speech. In the clinic he was much excited, elaborated foolish ideas of grandeur, showed decided disturbances of speech and of handwriting. Sluggish pupillary light reaction. For many months the patient has been in an asylum; auditory hallucinations then appeared: "You have become syphilitic." At periods during the greater period of time that the patient was going along in the period of weak-minded euphoric excitement with foolish ideas of grandeur, symptom pictures appeared in which the patient seemed clear, and expressed himself as greatly surprised at his ideas of grandeur.

The presence of paresis can hardly be doubted here, since the auditory hallucination and the lucid intervals are the only things infrequent in paresis. Possibly this is a case which tends to remissions and runs a slow course and perhaps this explains the negative findings in the spinal fluid.

\section{Observation 7}

The fifth case (B.) we took to be an outspoken case of a remission in paresis. This case is also otherwise extraordinary. Syphilis was acquired fifteen years previously. Eighteen months previously, closely following a concussion of the brain, with previous perfect health, there set in on the day of the accident a state of excitement which persisted a number of months, and during which there developed a disturbance of speech, diminution in memory, reduction of intelligence, with further the expression of ideas of grandeur. For three months the patient has been out of the asylum, has worked continuously for a long time, and carried himself fully and correctly. He came to us for expert opinion as to his accident. Physically he shows a difference in the patellar reflexes, and a speech disturbance which at all events shows itself only in the repetition of test phrases. Hypalgesia, twitching in the region of the facial, and increase of cells in the spinal fluid. The writing was perfect. The pupils react well, perhaps the left a little weaker to light. Mentally there was a dull dementia of a mild grade with marked defects of attention. At the same time there was a marked feeling of being sick. Complaints of all kinds of troubles, such as an injured patient expresses. Delusion formation and hallucinations absolutely lacking.

This case shows a behavior differing from the usual one in regard to development and course.

\section{ObSERVATION 8}

The sixth and last case came to us for observation but a short time ago, so that nothing can be said concerning its later course. It was that of a former prostitute, R., with very marked physical and mental signs of 
paresis. Possibly in this case peculiarities may also appear. At the present time the condition is typical of a paresis, but it must be concluded that one observes symptom pictures apparently undoubtedly paretic which nevertheless have another significance, and which are induced by a syphilitic brain diesase and show us that we are not at times in a position to make a clinical differentiation.

When we review these cases it strikes us that, with the exception of the last case, they were all patients who did not show the usual picture of paresis. For some, one cannot think that paresis really existed, and in others again the course was long drawn out and there existed a tendency to remissions. Thus we see that exceedingly few cases of paresis lack the reaction in the spinal fluid, and that also a greater part of these are open to attack on the grounds of clinical diagnosis. It appears possible that here there may be false diagnoses just as in the negative cases of our first series of tests. Then the positive result of the reaction assumes the importance of a symptom which is characteristic in high degree of paresis and possibly even regular. However, in view of the anomalous cases, I wish to be reserved, and yet give expression to the belief that perhaps we shall obtain the positive reaction in the spinal fluid in all cases and learn to consider it as a necessary sign in the proving of the diagnosis. The positive spinal fluid reaction appears to me, as stated, capable already of being looked upon as a symptom to which there is hardly an exception in paresis. It is to be awaited whether it will some time be possible for us to refute the diagnosis of paresis on the ground of lack of reaction in the spinal fluid with accompanying positive blood reactions.

The question, however, of whether we must make a decision for paresis from a positive reaction of the spinal fluid, is an entirely different one. We will first have to investigate whether the spinal fluid as well as the serum can react positive in: (I) Syphilis without complications in the central nervous system, (2) cerebral syphilis, (3) tabes, where both serum and spinal fluid can react positively.

What the relations are in syphilis without nervous disturbances I have already explained and I will only remark here that in this case the spinal fluid always reacts negative, independent of the action of the blood. Thus we can look upon the appearance of the reac- 
tion in the spinal fluid, on the ground of this statement, as a proof of an involvement of the central nervous system. But must the type of disease of the central nervous system be of a paretic nature, and cannot a syphilitic process in the narrower sense act in the same manner? The investigations in cerebral syphilis follow later in another place, but I shall anticipate here the one fact that, in cerebral syphilis in general, the spinal fluid reacts negative in contrast to the blood, and that thus the relations are the same as in syphilis without involvement of the nervous system. The cases of cerebral syphilis in which the spinal fluid reacts positive are just as rare as the cases of paresis in which the reaction is negative. Since exceptions appear to exist on both sides we can use the reaction of the spinal fluid only with care for the differential diagnosis between paresis and cerebral syphilis, and we can only say that a positive finding speaks for paresis and a negative one for cerebral syphilis without considering it as absolute for the present.

Finally in tabes, concerning which mention will be made in another place, the spinal fluid reacts positive extremely often if not with the same regularity as in paresis. Therefore, the positive reaction of the spinal fluid speaks as much for tabes as for paresis and on this point a differentiation cannot be derived. It will later be mentioned that a difference can be met with, not in the action of the spinal fluid, but at times in the blood.

Thus when we leave tabes out of consideration we have in the positive reaction of the spinal fluid a symptom which speaks with great probability for paresis.

A very important question now arises. When does the symptom appear, and can it be used for the early diagnosis of paresis? Our experience shows that in the earliest stages of the paretic process, at least as far as one may conclude an early stage from the paucity of clinical symptoms, the reaction is accustomed to appear in clear fashion in the spinal fluid as in the blood. We have never observed that the intensity of the reaction runs parallel with the severity of the clinical symptoms. At times one finds the reaction but little appreciable in very advanced as well as in beginning cases. On the other hand clear results are just as frequent in fresh cases as in old ones. Cases are known to us which, while in full health, suddenly became sick and the test 
made immediately resulted strongly positive. Often these were cases in which the psychic manifestation first became clear while stiff pupils and other symptoms had long existed unnoticed and could have given notice of the disease. Practically the cases with insidious beginning have great importance in view of the difficulty of recognition and here the reaction gives an intensive result early.

Early diagnosis here regularly means a differential diagnosis. There are cases which show psychic or physical symptoms or both, but only to a degree, which permits of difference of opinion. Paresis here has shown symptoms or is possibly already well advanced but we are incapable of reaching a positive conclusion on the ground of clinical observations alone. It would be true early diagnosis if absolutely no suspicious signs appeared. In other words if we investigate the spinal fluid of an apparently perfectly healthy person simply with the idea of an early syphilitic infection in view, and find it reacting positive, it proves that possibly the early beginning of paresis is present. So far I have never met a case of latent tertiary syphilis in which the spinal fluid gives the reaction, but the number of cases investigated to the present is small. If in the course of further investigations, one should find positive reactions in cases of this kind, one must keep them in mind, and from the experience which one has with them it can be determined whether the positive reaction of the spinal fluid may be looked upon as the signal of paresis. At present our material only allows us to say that serological investigation may be considered a clinical symptom of paresis. The entire subject of the differential diagnosis of paresis in its relation to the Wassermann reaction is still to be worked out, as there is hardly a psychic disease which in its beginning cannot simulate paresis, and as on the other hand paresis can appear under all garbs, there exists a very large field for serodiagnosis. We shall be able to use it for the differentiation of paresis from (I) Nonsyphilitic psychoses in nonsyphilitics, (2) nonsyphilitic psychoses in syphilitics, (3) syphilitic but not metasyphilitic psychoses.

In the first group it is very easy to make a differentiation, for here a negative result of the blood reaction by and for itself excludes the existence of a paresis with the greatest probability. 
The difficulties in regard to groups (2) and (3) are greater, for here, as in paresis, the blood can react positive and the possibility of separation lies only in the different behavior of the spinal fluid. In the second group, we would expect negative reactions of the spinal fluid as in mentally healthy syphilitics. Group three would present similar relations, but not in such regular fashion, for here, if only in rare exceptions, a positive reaction of the spinal fluid can at times be observed. Thus with this group one will often obtain guidance in the right direction through the Wassermann reaction.

In almost every case where there was the possibility of overlooking or falsely diagnosing paresis, and where the differential diagnosis is concerned with it, be it in connection with the mental disease of organic origin or the so-called functional psychoses, the question immediately comes up whether the trouble cannot be traced back to syphilitic brain changes in the more narrow sense. In practically all the discussions occasioned by doubtful cases of general paresis, cerebral syphilis is the chief disease in question. The differential diagnosis of paresis becomes thereby a group differential in which on one side stand the metasyphilitic and syphilitic brain diseases, and on the other side one (or several) nonsyphilitic mental disturbances. If we succeed then in excluding a nonsyphilitic psychosis usually the further task comes before us, to distinguish between paresis and cerebral syphilis or, so to say, to make an intra syphilitic differential diagnosis.

In a large number of cases the differential diagnosis naturally is concerned with the question whether paresis or cerebral syphilis exists without there having preceded a careful differentiation of diseases of different etiology. The material has been divided in such a way, that the discussion of the differential diagnosis between cerebral syphilis and paralysis is postponed until after the report on the findings in positive cases of brain syphilis. Here also those cases are taken up, in which cerebral syphilis seemed more probable than paralysis, and where one has a better right to speak of a true differential diagnosis of brain syphilis from mental disturbances of another type.

But here other groups may be referred to, which require a differentiation from paresis. There can be no question, therefore, 
of an exhaustive differential diagnosis of paresis, because these investigations have as their first aim the use of the serodiagnosis of syphilis and I must therefore limit myself to the material which has been laid before us in the short time which has elapsed since the introduction of serodiagnosis.

The cases so far examined are of service only in so far as they have been confirmed by autopsy or by their clinical outcome. It must first be demonstrated just how serviceable the serum test for syphilis is in clinical diagnosis, and it is certainly premature to interpret obscure cases merely on the basis of their serum reactions. With these reservations, however, the value of the serum test in the differentiation of general paresis from other organic dementing mental diseases (e. g., arteriosclerotic or senile conditions, multiple and lobar sclerosis, and other unknown conditions) can be determined in the light of autopsy findings or protracted clinical observation. With respect to the conditions just mentioned which may be confused with general paresis, the factors are as a rule so complex that intra vitam perhaps not even a satisfactory probable diagnosis can be reached. For the moment, therefore, we must gather more material. It is otherwise with the cases that do not show coarse organic changes. In the latter group the clinical course offers even at present a satisfactory basis of differentiation. I will therefore present some of these case-groups. 


\section{DIFFERENTIAL DIAGNOSIS BETWEEN PARESIS AND POSTTRAUMATIC PSYCHOSES}

In the not infrequent cases of paresis which develop with more or less clear dependence in point of time upon a trauma, the serodiagnostic proof of syphilis allows one to put aside the idea, which is still accepted in some quarters, that trauma can constitute the only cause of paresis. Among my earlier described cases of paresis I cited a series in which trauma was blamed as the only cause of paresis and where serodiagnostic investigation showed that syphilis existed in the same way as in cases of paresis. Also in the paretic material which forms the basis for this article trauma was made etiologically answerable, in more or less positive fashion, for twenty cases. Here again the diagnosis of syphilis was obtainable without exception. Thus the champions of the pure traumatic origin of paresis must admit that trauma can form the "only" cause for the development of a paresis only in a syphilitic. Under these circumstances one should seek to ascribe to trauma some other rôle than that of unimportant factor. Whether this subordinate rôle really belongs to a trauma is very doubtful, especially since the beginning paretic trouble gives usually the first occasion for bodily injury either as a result of the carelessness of the patient or as a result of paretic convulsions.

Now and again, however, one meets with severe skull injuries which in themselves should be sufficient to cause a traumatic dementia. Paresis then develops in connection with the trauma. Here it is often not easy simply to ignore the trauma. A case of this sort came to us for investigation.

\section{ObSERvation 9}

Viktoria E., 5I years of age, wife of day laborer, admitted February 10, 1908. The husband denied syphilis. Patient had one child born dead, and four other children, of whom three died shortly after birth. About seven years previously, i. e., February 12, I901, the patient was struck on the forehead by an iron lever, following the breaking of a hand lever of a heavily weighted balance, and was rendered unconscious. A fracture of the frontal bone was found. After a three weeks' stay in the surgical 
clinic the patient was discharged apparently well. In the course of the next year she was often examined medically with reference to the accident, and no important mental disturbances were made out. She complained of inability to work, and of different nervous troubles, and the physicians gained the impression that she exaggerated greatly in order to continue to receive her accident insurance money. According to the husband she had become very forgetful, easily excited and during the year she had become definitely worse. Patient would sit often for hours at a time even at night, and stare in the corner. For about a year she has at times been saying foolish things, and behaves in an irresponsible manner. She loses all her money, cannot find her home, etc. At times she expresses ideas of suicide. Paralyses or convulsive attacks have not occurred. From the time of the accident the speech has become worse.

Findings.-Over the left eye there is a cross shaped scar; callus formation on the frontal bone. Cranial nerves intact. Pupillary reactions prompt to light and convergence. Patellar reflexes slightly increased. In September, 1908, study of the pupils showed a definite sluggishness of the light reaction. No Romberg. No ataxia. Distinct speech disturbances with test phrases. Writing ataxic-illegible. Sensibility difficult to test, because of lack of understanding by patient. She pulls herself together strongly on deep pin prick. She gives an intense weakminded impression, is disoriented as to time and place. On questioning only answers now and then, cannot give the year of her birth, nor the present year, etc. She knows that she has had an accident and says that it was six years ago, and also gives some hazy, in part correct, information about the kind of the accident. The mood seems weakmindedly joyful. In answer to the question, Are you sad? she answers "yes" and laughs. Spontaneously she speaks in a confused manner: thus she once expressed herself "I have gobbled five roast hares." A general feeling of sickness appears only in so far as she says she feels weak in the head. During her stay in the clinic she lay in bed all the time dull, answered questions for the most part without connection, laughed in a demented manner when one spoke to her. The patient has now been seven month in an asylum, where she has gone backwards both physically and mentally, and gives the impression of the end stages of a paresis.

The biological investigation gave positive results for both the spinal fluid and the serum.

Cytological examination showed a marked increase in the lymphocytes of the spinal fluid [I2I cells in I cu. mm.].

Here is a patient who seven years before had suffered a severe fracture of the frontal bone. Since the accident she has been an invalid physically and mentally. Extreme psychic disturbances became marked, however, only a year ago. The physical examination showed prompt reaction of the pupils but outspoken paretic disturbances of speech and writing. Psychically the 
patient offered the picture of an advanced simple paretic dementia. The biological investigation of the blood at all events made clear that the patient had had syphilis which is of importance in view of the denial of infection on the part of her husband. The statement that the patient had one still birth and lost three out of four children soon after birth was however suspicious. There is no doubt that a paresis exists here and the positive biologic finding in the spinal fluid is in harmony with this idea. We were puzzled at first at the good pupil reaction but that, in the meantime, has become considerably worse. Against the possibility that a severe posttraumatic dementia and not a paresis is present stands among other signs the clearly progressive course of the disease. The question whether the severe skull fracture, which apparently caused a slight posttraumatic dementia, did not act as preparatory for the development of a paresis in this surely syphilitic person, is a different one.

Inversely, however, disturbances caused by trauma can falsely be taken for paresis. In traumatic neuroses pure psychogenic pictures can develop which can be confused with paretic dementia. Everyone, who has had the opportunity to examine accident cases, has often learned in the study of the documents that at one time-often many years before-the diagnosis of paresis had been falsely made by a physician. The false diagnosis arises from the fact that a mental insufficiency, caused simply by psychogenic influences, combines with all kinds of important neurological disturbances, such as obliteration of a nasolabial fold, increase of knee jerks, tremor, twitching of facial muscles, slurring speech, etc., whereby a clinical picture resembling paresis can result. Serodiagnosis is here adapted to solving diagnostic difficulties most easily. In general the blood test is sufficient. If this be negative, one will be able to refute paresis. If the case be more difficult, in that one has to do with a syphilitic, one can likewise be satisfied with the negative result of the blood reaction. If the blood reaction be positive one must extend the investigation to the spinal fluid. A positive finding here would speak for paresis, and a negative one against it, without, however, rendering possible an absolutely sure differential on account of the present status of our knowledge. 


\section{OBSERVATION IO}

Josef M., 43 year old. Boiler maker. Admitted March 9, 1908.

In the year I900 the patient, while working, suffered from a squeeze of the hip region. A stiffness of the lumbar vertebræ resulted, which was referred to a chronic inflammation of the muscles of the back, and on account of this $M$. received his full accident insurance allowance, although he had previously been a hard drinker. After this he drank to excess more often, and he threatened his wife and children. He complained much of headache and dizziness, showed himself to be sexually very excitable and had variable moods. The speech and the memory had become worse. In 1902 he came as mentally diseased to the psychiatric division of the hospital, and there the diagnosis of paresis was made on the basis of the following observations. Slightly diminished pupillary light reactions left side, tremor of the tongue and hands, shaking and tremor of the muscles of the mouth, slow indistinct speech. In the repetition of test phrase the omission of syllables and of words, active increase of the patellar reflexes. M. went from the hospital to the asylum, where the same diagnosis was made. He stayed in the asylum until 1905. His brother, who was also his guardian, then took him out.

$\mathrm{He}$ continued to receive his accident insurance since it was held that there was a relationship between the trauma and the paresis.

Three years later the accident insurance company made an enquiry into the case, and learned that the patient had on his own account been working as a boiler maker for the three years, whereupon $M$. was sent again to the psychiatric clinic for a new investigation.

The physical examination showed tremor of the hands, pain to pressure on the muscles of the calf, increased patellar reflexes, swaying on standing with closed eyes, no further somatic symptoms, especially no involvement of the reactions of the pupils, the speech or the writing. Apart from definite alcohol intolerance, the patient showed no trace of any mental weakness. The clinical picture permitted one to rule out the presence of paresis with certainty. The diagnosis was that of chronic alcoholism and traumatic neurosis.

The biological investigation of the blood serum as well as that of the spinal fluid gave completely negative results. There was no increase of cells in the spinal fluid.

In the first place there were present in this case a number of physical signs to account for the false diagnosis of paresis. Sluggishness of the pupil reactions, trembling and twitching of the angles of the mouth, increase of the knee jerks, indistinct speech, etc. It is striking that the patient was in an asylum for three years without the diagnosis being corrected. The false diagnosis procured for the patient full pension for six years. 


\section{OBSERVATION II}

Wilhelm K., 45 years of age. Merchant. Admitted December 5, 1907.

On May 16, 1907, the patient, during a railroad accident, was hurled with great force against the end of the car, so that he was momentarily unconscious. After a short time he came to himself, and it was ascertained that he had suffered from no injury whatever. In the beginning he felt no pain. For the first time while in the bandaging room he became sick, he vomited and felt a sharp, shooting pain in the back of the head. Since the accident he has suffered from headache, feeling of dizziness, sleeplessness, and has become very excitable and irritable. Little by little forgetfulness showed itself, he began to talk slower, and when he told anything he had to think about it a long time; what he read he could not grasp; he was much depressed, sat around doing nothing for hours, was tearful, sensitive, and then again irritable and lost interest in his surroundings. He had very depressed thoughts concerning his sickness, spoke a great deal about becoming paralyzed. There gradually developed a characteristic disturbance of speech, furthermore he became impotent. In the fall of $1907 \mathrm{H}$. was sent to a hospital for an expert opinion, and the following was ascertained. The investigation of the internal organs gave normal findings. On the part of the nervous system there was a striking speech disturbance, combined with a flickering of the lips, also a mild increase of the deep reflexes of the lower extremities, whereas other nervous signs were not to be observed. Mentally $\mathrm{K}$. showed a deep depression. On the addition and subtraction of two to three figures a striking uncertainty was revealed. All of this awakened the suspicion that it was a case of paresis, and a physician in the psychiatric clinic could not exclude this possibility on the strength of a single examination. A biological examination for syphilis was then made, which was negative. In spite of this the opinion was rendered to the effect that there was a suspicion of paresis, but that other severe brain disease, or a neurosis could not be excluded.

Shortly thereafter $K$. was sent to the psychiatric clinic for further expert opinion. Here there was observed a strikingly marked slowing of spoken expression, and of the intellectual processes. $K$. spoke slowly as though he had to think about every word. It was hard for him to control the movement of his thoughts. This showed itself even in the answering of questions which required only the slightest reflection, such as questions about time and the circumstances of his life, of his marriage. More complicated arithmetic examples were solved only with the greatest trouble. The mood was depressed. He explained this on the ground that his condition gave him anxiety. Delusions and hallucinations did not exist. When he spoke concerning his condition, tears came quickly to his eyes. There was a decided feeling of being sick, complaints regarding difficulty in thinking; what he reads he is unable to understand; everything excites him. When he goes in the street he often becomes dizzy so that he must stand still. He must cry at every little thing, etc. 
The most striking feature that showed itself here was a most characteristic disturbance of speech. The words were spoken indistinctly and blurred. Tremor of the muscles of the lips during speech only occasionally observed. The pupils were equal in size; the left somewhat irregular, reaction to light and convergence prompt; tremor of the tongue and of the hands. Increase of the patellar reflexes, slight general hypalgesia. During his stay in the clinic the patient always conducted himself in a thoroughly orderly manner, showed himself to be completely oriented as to time' and place, never expressed anything senseless.

The biological investigation of the blood was again made and was again negative, likewise the spinal fluid, which latter, in addition, was almost free from cells.

This was without doubt a traumatic neurosis, and the further course of the disease confirmed this idea. With a superficial examination one could very well have thought of paresis at the time. In the first place one could take the psychogenic speech disturbance for paretic. This was associated with a few other suspicious signs such as tremor of the facial muscles, increase of knee jerks, tremor of the hands and tongue, and slight general hypalgesia. Likewise the psychic picture could simulate a dementia. The extreme difficulty of the train of thought brought about by psychic inhibition, the uncertainty of mental operations, the mistakes in simple psychic tasks was very marked. With this came the depressive colored mood which so frequently accompanies paresis. In this case we would have thrown out the diagnosis paresis on the ground of the biological blood finding before the patient came to us, and the further careful examination, and the findings of the spinal puncture showed this interpretation to be correct. 


\section{DIFFERENTIAL DIAGNOSIS BETWEEN PARESIS AND ALCOHOLIC PSYCHOSES}

Not alone in the beginning of paresis, but also in its later stages, alcoholic symptoms can force themselves into the foreground of the clinical picture, and obscure the signs of the paretic process to such a degree that it is difficult, and often absolutely impossible without further observation of the course, to come to the diagnosis of paresis simply from the picture at the time. These are the forms which Kraepelin has designated as alcoholic paresis, and they can be multiform. On the other side Korsakow's psychosis and other terminal states of chronic alcoholism can present the picture of the simple demented form of paresis to such a degree that the existence of paresis is falsely accepted (Kraepelin's alcoholic pseudoparesis, Bonhöffer's alcoholic paresis). According to Bonhöffer there is dull euphoria, disordered memory, decreased attention, the speech is stumbling, the knee jerks can be different, diminished or entirely lacking, decrease of the perception, dizziness, headache, weakness of memory; these are present in alcoholism as in paresis. Slight neuritic signs like drawing sensations in the legs, hypoalgesia, paresthesiæ, absence of knee jerks, and true motor awkwardness can be falsely taken for tabetic symptoms. Further, the loss of light reaction of the pupil which may be absent according to Bonhöffer, is of little value in differential diagnosis.

Finally we have seen conditions arising in connection with intoxicated states which are sufficient to awaken suspicions of the existence of paresis.

It is evident that the result of the serological test can simplify the differential diagnosis of all cases of this sort, and I shall, in the following, quote a few examples to demonstrate how serodiagnosis can be utilized in different forms of alcoholic paresis and alcoholic pseudoparesis.

Next are briefly mentioned a few cases of paresis in which delirious signs accompanied the disease. 


\section{OBSERVATION 12}

Jos. B., 5I years of age. Jeweler. The patient was admitted for the first time January 22, 1908. At that time he showed the picture of a typical alcoholic delirium; ran about with a humorously colored anxiety; tied things about his body, as though he would put on and take off articles of clothing, snuffed in the belief that he had tobacco in his hand, pulled threads, and was suggestible to all kinds of sensory illusions.

The condition lasted a few days and ceased completely after a sound sleep. The only thing which did not seem to correspond with the otherwise typical picture of an alcoholic delirium was the slight approachability of the patient, and the absence of a definite tremor. After the patient had quieted down the physical examination could be carried out, and this showed loss of pupillary light reaction, further a mild speech disturbance, and distinct neuritic symptoms.

On the mental side there was present, notwithstanding, a mild, yet nevertheless an unmistakable paretic dementia with distinct alcoholic coloring.

The biological investigation gave positive results in the spinal fluid, and blood serum and an increase of cells in the spinal fluid (73 in I cu.mm.).

We came to the conclusion that it was an alcoholic delirium in a paretic, and not a paretic delirium. The patient was discharged, but after not quite two months he was again admitted in a still further advanced condition of paretic deterioration.

\section{ObSeRvation I3}

The 40-year-old driver, Sch., came at the same time into the clinic in a delirious condition. It was reported to us that he was a hard drinker, consuming 25 liters of beer daily. Patient was much confused. The motor unrest was not marked, and showed itself only at night during a few hours. He then gets up, goes about in the room, busies himself with the beds and his clothes. In the meantime he lay in bed dull. He thought he was in an inn, but his actions did not correspond. There was a decided suggestibility. The patient permitted himself to be influenced by anything that pleased him, but did not elaborate the suggested experiences any further. The mood was not tinged with humor and there was no tremor. The delirium gradually diminished, and an undoubted paretic picture then showed itself. Speech disturbance, loss of pupillary light reaction, hypalgesia.

Biologically, both the spinal fluid and blood serum were positive, and further there was an increase of cells of the spinal fluid.

Because we heard on the one hand that the patient had drunk 
to great excess, and on the other because the anamnesis in relation to syphilis was indefinite we had at first to reckon with the possibility that this could be a severe alcoholic intoxication, even if the condition did not give the picture of a typical alcoholic delirium. The positive result of the serological tests made it possible to throw out all doubt at the outset.

Because delirious states which develop on the basis of chronic alcoholism are accustomed soon to run their course, and since after their disappearance the paretic signs are clearly recognized, the overlooking of paresis is here possible only for a short time, and the result of serological investigation is of value only in so far as it brings the matter earlier to the proper solution. On the other hand one meets states of feeblemindedness in paresis which remind one strongly of Korsakow's psychosis, and which can offer great difficulties for a long time in regard to clinical interpretation. If a simple dementia, which is characterized by very marked attention difficulty, develops in a very heavy drinker and on the other hand the definite physical symptoms of paresis are lacking, the existence of a paresis can be easily overlooked.

A case of this sort is reported here.

\section{Observation 14}

Maria A., 50 years of age. Cook. Admitted February 8, 1908.

At the age of twenty ulcer on the genitals, also an eruption; was treated with mercurial ointment. Since she was sixteen years of age has been a very heavy drinker, $6 \frac{1}{2}$ liters of beer as daily minimum, tea with rum three times a day, and two or three kümmel cordials.

She is dull and apathetic, with a high grade disturbance of attention, but knows she is in a hospital, is disoriented as to time, giving 1904 as the present year. Her grasp is difficult, she has a dull and disinterested manner. She sticks everything eatable she can find in her pockets, not confused and no delirious symptoms.

Physically the patient does not show the slightest disturbance. Pupils, speech, and writing undisturbed. Patellar reflexes present. No tremor and no neuritic symptoms.

Biological investigation, spinal fluid and blood serum positive. Lymphocytes in the spinal fluid increased ( 26 cells in I cu.mm.).

After a few months a definite speech disturbance developed, the light reaction of the pupil became very slight, and the entire picture allowed of no doubt that one had to do with a paresis. 
With regard to the entire lack of physical signs in this case we had no doubt that, in the simple dementia which was marked by very high grade attention difficulty, we had an alcoholic feeblemindedness, and we did the biological tests only because the patient had once had syphilis. When then beside the serum, the spinal fluid also reacted positive we were puzzled and the further course showed that a paresis really existed.

Another case brought up similar differential diagnostic considerations.

\section{OBSERVATION 15}

G., 46 years of age, railroad worker, admitted June 7,1908 .

The patient has been a heavy beer drinker, and admits having once had a venereal disease. A year previous he apparently had ideas of persecution, took a shovel handle to bed at night and permitted no one to enter. The last weeks previous to his admission he showed a characteristic unrest, ran around nights and seemed entirely broken up.

In the clinic the patient showed a marked mental weakness, with distinct euphoric coloration, but yet without delusion formation. Orientation as to time and place was very defective. It was striking that, whereas his memory for long past events, for instance his military service, was relatively good, there was a high grade attention defect. Numbers and words that were given him to be remembered were forgotten in a few minutes.

- Physically he showed a tremor, sluggish pupillary light reaction, articulatory speech disorder, disturbance of writing and hypalgesia.

Biological investigation showed positively in the spinal fluid and blood serum. Lymphocytes in the spinal fluid increased.

This case is distinguished through the fact that, while disturbances existed on the physical side which pointed to paresis, the psychic picture reminded one of Korsakow's psychosis, especially on account of the marked involvement of attention. The fact that ideas of persecution were present one year before the outbreak of the present disease, which ideas had a strong alcoholic coloring, and possibly also really depended upon the chronic alcoholism of the patient, contributed to our not entirely excluding the existence of a Korsakow's psychosis.

Another case of paresis which offered the symptoms of alcoholic paranoia is of especial interest.

\section{ObSERVATION I6}

K., 37 years old, chimney sweep. Admitted May 30, 1908. Hard drinker, 6-8 liters of beer daily, and schnapps in addition. While drunk, years 
before, wanted to jump out of the window. For three years in an excited condition, threatened wife and children, became very forgetful and made many mistakes. Of late he takes almost no interest in his family, has ideas of sinfulness. $\mathrm{He}$ is the greatest criminal, sees himself followed from all sides. When the clock strikes he says, "Now they are coming, now I must go to prison." For three years loss of the feeling of shame. On the day of his admission a convulsive attack with loss of consciousness. One year before entering the military service a chancre.

Physical examination shows a marked articulatory speech disturbance. Tremor of the hands and tongue. No defect of writing. Pupillary reactions prompt. Patellar reflexes present. No distinct neuritic symptoms.

Patient is completely oriented as to place, but time orientation is defective. After a week the latter was practically perfect, calculation was also better. School knowledge slight; arithmetic poor. In general approached with difficulty, for the most part depressed, but the emotional tone superficial. Nihilistic delusions. Inside he is "all rotten," "everything is getting smaller." "Nobody is like him." Further ideas of sinfülness, he has killed many millions. Hears voices. Men call out from the garden he is to be brought to the house of correction.

Biological examination positive for spinal fluid and blood serum Lymphocytes increased in the spinal fluid ( 28 cells in I cu.mm.).

The patient was taken to an insane asylum, and a recently made examination (end of September, 1908) showed, the disease in the meantime made slow progress. The depression had given way to a feebleminded euphoria. The statements as to time are now completely senseless and contradictory. Delirious states have not appeared. Auditory hallucinations are gone. The speech disturbance is marked, the pupils are pinhead size, but still react to a certain extent.

The condition which the patient showed at first must have awakened the suspicion that it was an alcoholic hallucinosis. In favor of this was the development of the trouble, which went back three years, the characteristic ideas of persecution, and the auditory hallucinations. The convulsive attack which happened before admission could have been looked on as an alcoholicepileptic one.

Among the physical signs only the speech disturbance spoke for paresis, while the other characteristic signs, especially on the part of the pupil reaction, were wanting.

Among the psychic symptoms, only the nihilistic delusions made probable the existence of paresis. A certain improvement towards the end of his observation in the clinic appeared on the contrary to speak more for an alcoholic disturbance. 
The further course showed then that it was a paresis. The biological investigation here early permitted the acceptance of a paresis, with great probability at a time when the condition did not make a certain clinical differentiation possible.

While in the above mentioned cases, the positive result of the biological test was of great weight in the recognition of paresis, two cases of alcoholism, which seemed suspicious of paresis, are now considered, wherein the negative result of the reaction differentiated them from paresis.

First a case of Korsakow's psychosis, with neurological symptoms suspicious of paresis.

\section{OBSERVATION I7}

M.O., 60 years of age. A re-toucher. For two years the patient has had transitory attacks of unconsciousness. Of late the memory has failed rapidly, and he makes small perversions, speaks foolishly at times. Concerning an infection his wife does not know, nevertheless, of seven children six have died, and the patient himself later stated that he was greased with a gray paint for some time after a military campaign. Admitted he was a fairly good drinker of schnapps.

Physically the patient showed flattened facial expression, sluggish pupillary light reaction, loss of the patellar reflexes, and a somewhat indistinct speech.

Patient gives no senseless answers, but shows nevertheless marked gaps of memory, and distinct defects of observation. No humorous mood. No insight. He was completely disoriented for time and place, without appearing confused properly speaking. Notwithstanding the fact that the mental picture was not characteristic for paresis, we were inclined to the belief that this was a case of paresis, in view of the physical symptoms (sluggish pupillary light reaction, absent knee jerks), and because of the probability of an antecedent syphilis.

The biological test was completely negative, likewise no cell increase in the spinal fluid, and we were, therefore, induced to consider the existence of a Korsakow's psychosis probable. The psychic picture developed then in such clear fashion that the diagnosis, "Korsakow's psychosis" could no longer be doubted.

In conclusion, I shall report in brief that we have at times observed speech disturbance in connection with severe intoxication states, which can be very similar to the paretic, and as a result can make one think of paresis.

The following case serves as an example. 
OBSERVATION 18

There appeared in a 48-year-old cabinet maker, who was a dissolute, rabid, drunkard, after a severe state of intoxication lasting many days, a very marked articulatory speech disturbance, which, with somewhat diminished pupillary reaction, was the only symptom suspicious of paresis.

The other physical findings and also the mental condition spoke for chronic alcoholism. The biological investigation gave absolutely negative findings, and there was no increase of cells in the spinal fluids. The speech disturbance was lost later, and at the same time all grounds for considering it as a paretic symptom also disappeared. 


\section{DIFFERENTIAL DIAGNOSIS BETWEEN PARESIS AND MANIC DEPRESSIVE PSYCHOSIS}

Depressive states which so frequently accompany paresis as the initial psychic disturbance are the most frequent cause for not recognizing it. There are, at least according to the clinical pictures, early states of the disease, states in which the mental weakness has not yet clearly developed and likewise the neurological signs are often but scantily marked, and therefore the diagnosis cannot be made. A special difficulty for differentiation exists in that an apparently distinct intellectual insufficiency, which expresses itself in the difficulty of the flow of ideas, in the inability to perform any complicated operations, in the incapacity to group the events of life in correct order in relation to time, need not depend on mental feebleness, but can be caused by the retardation as we see these so frequently in phases of manic depressive psychosis. On the other side striking delusions can be almost completely lacking in paretic depression; clear disease insight and feeling of sickness can be present. Disturbances in the field of orientation for time and place need not appear, and social forms can be wholly retained in the beginning. Even if a few features appear suspicious of paresis one will often not become suspicious and leave the diagnosis in suspense and the differential must depend on the further course. That it is of great importance to reach a correct interpretation early is obvious, and it appears that we have in serological investigations an aid which can show us the right way.

As illustrations I shall quote a few such cases in which the results of the serological tests made the diagnosis certain.

\section{OBSERVATION I9}

A 30-year-old merchant, St., had business cares during the last two years, lost considerable money, but did not thereby lose all of his property. About eight days before his admission a sudden change in his deportment occurred. He thought he could not help himself, everything was lost, he must die. He cried a great deal and expressed suicidal ideas. 
Previously he had always been well, only at all times somewhat excitable. He had never been a drinker. His wife had never had children.

In the clinic the patient showed a picture of a severe depression. $\mathrm{He}$ cried and complained continuously. He had destroyed everythingthe business was ruined-he himself was to blame for this, because he had not done any work and had neglected the business. Everything was upside down. He was anxious about his living, had no moral will power, could not work any more. His orientation for time and place was excellent, and there were no signs of intellectual impairment. Somatically there were also no suspicious disturbances, but a somewhat blank facial expression was observable. Luetic infection was denied by the patient. In spite of all this, after a time, a slight suspicion arose that he was a case of paresis chiefly because the depressive affect became superficial, and a characteristic weakness of the will developed without any definite appearance of retardation. A blood examination was then made, which gave positive findings. On searching questions the patient now admitted that several years previously he had had a suspicious ulcer which he did not know whether it was syphilitic or not; at any rate he was not treated for it. Spinal fluid examination was then made. The fluid showed, in addition to increased cellular content, a Wassermann reaction equally as positive as the blood. Dr. Weiler then observed a suspicious reaction of the pupils which show that whereas the reaction to light was prompt and ample, the consensual light reaction failed, $i$. $e$., the absence of an increase in the myosis of an illuminated eye when the opposite eye was illuminated, a symptom which Weiler has observed only in paresis. The diagnosis of paresis was then made and inunctions given, which were however without any recognizable results.

In another case anxious retardation was very prominent whereby a positive opinion concerning the presence of mental weakness was made difficult, and on the physical side no important disturbances were present.

\section{ObSERVATION 20}

Schi. twenty-two years of age. Chancre admitted, but when was doubtful. No children, no abortions. Patient is a fireman. Six weeks previously a locomotive was derailed because of his fault and he was fined one mark. He took this greatly to heart, lost his appetite, was tired, slept little and reported himself sick. After eight days returned to work. $\mathrm{He}$ ran into a gate, because he was dizzy, and had ringing of the ears, so that he did not know what he was doing. He then had to give up his work. He was very much depressed, felt very tired, feared all would go badly with the family. Complained of ringing in the ears. Neither foolish expression nor conduct were present. He was well oriented as to time, committed no foolishness with his money, and conducted himself well in general. 
In the clinic the patient showed an anxious, repressed expression, spoke in a mild hesitating voice, complained continuously of the misfortune he had had with the machine. He was well oriented as to time and place. $\mathrm{He}$ admitted having had an attack of dizziness in which he was unable to speak, and anxious, excited conditions occasionally had occurred. The pupils were somewhat unequal, the right reacting somewhat more sluggishly than the left. Further somatic disturbances were absent. The speech was good, the writing however was somewhat uncertain, but not characteristically disturbed. The cell content in the spinal fluid was increased ( 83 cells in cu.mm.).

Biological findings in spinal fluid and serum were positive.

The diagnosis of paresis was made, and the further course showed this idea to be correct. One year after the patient showed unmistakable paretic signs, even if the progressiveness is not to be put down as very evident. The depressive affect persists but now however clothed in senseless nihilistic delusions.

In another patient, likewise with the help of serodiagnosis, a very early stage of paresis was ascertained, and here the investigation was of still greater importance because syphilis was denied, and there was no lymphocytic increase in the spinal fluid.

\section{OBSERVATION 21}

Merchant, M., 48 years of age. Infection denied. He has three healthy children. No miscarriages. With complete insight and marked recognition of his illness he says that for eighteen months he has been different. His ability to work has been diminished, he suffers from weakness of memory, makes mistakes in reckoning, feels cast down and has no hope that he will ever be well again. In contradiction to these complaints he can multiply numbers remarkably fast, gives logical answers quickly, reproduces five figures after three minutes correctly. The mood is distinctly depressed. Suspicious somatic symptoms are present. The pupils react properly, but there is an absence of knee jerks. He has a Romberg and slight ataxia of the hands. Further, the speech, although not disturbed so far as the articulation is concerned, nevertheless is somewhat slower and at times halting. Sensibility is intact.

Biological examination gave positive results in the spinal fluid and blood serum.

The patient deteriorated as a paretic very rapidly. It is worthy of notice that in this patient the intellectual ability was much greater than he himself believed, a condition which in general speaks so strongly for neurasthenia and depression, and against 
paresis. The mild tabetic symptoms in themselves were naturally not indicative of paresis, and it might as well have been a state of depression in a tabetic, a differential which is not to be made with absolute certainty by serodiagnosis.

I could enlarge the discussion of cases of this sort from our material considerably although patients in these stages come to the clinic relatively seldom. Practising physicians and neurologists have the opportunity of seeing such patients much oftener.

Just as in so many cases we are brought to the opinion, through the positive result of the reaction, that we have to do with paresis, inversely we exclude paresis in depressed patients, with symptoms suggestive of paresis, when the serum reaction results negative, and so far we have never seen ourselves deceived. Since in our opinion the negative reaction of the blood alone speaks in high degree against paresis, we are generally satisfied with it, and omit the spinal puncture, and thus we can spare many patients an unnecessary spinal puncture.

An especially characteristic case is recorded here.

\section{OBSERVATION 22}

F. Leonhard, laborer, 39 years old. Venereal infection was denied. Alcohol up to 4-5 liters of beer daily admitted. The wife had had two miscarriages and two healthy children. The patient has been different for four weeks. He cries a great deal, is anxious, and self accusatory. $\mathrm{He}$ imagines that the workers whom he has to supervise do not obey him any more, despise him, spit in front of him, and believe he has done wrong.

In the clinic similar fears were expressed in tearful tones, but everything was founded on a characteristic delusional, apparently weakminded basis. He said he believed that a gypsy was responsible for everything; she had prophesied it when he was a child. He would die in the workhouse. Orientation as to time and place were uncertain. Grasp was diminished. His arithmetic examples were clumsily handled. There was slight articulatory disturbance, logoclonia, thus, brigadede. The writing was not ataxic, but showed transposition of letters, for example, weindeder Schafe instead of "weidender." Tremor of tongue. Patellar reflexes increased. Pupillary reaction unmodified.

One received the impression that it was paresis, and for proof the biological test was undertaken. The result in the spinal fluid as well as the serum was completely negative, and there was no cell increase in the spinal fluid. In spite of this we left the diag- 
nosis in suspense, because the patient appeared so suspicious of paresis, on account of the writing and speech disturbance. The patient was taken out, made two attempts at suicide, and was again admitted in a very depressed condition. After the course of a few months he was discharged cured from Eglfing where he had been transferred from the clinic.

Not quite so frequently, but still not seldom, serodiagnosis came to our aid when it was necessary to differentiate manic colored states in paresis from manic phases of a manic depressive psychosis. It would be going too far to quote these cases in detail. The suspicion can falsely be linked to paresis, especially when a clear manic mood is lacking, and hypomanic states develop in which the patients neglect themselves, go to excesses, sexually conduct themselves shamelessly, commit social follies, etc. We so frequently see a marked change of personality in the beginning of paresis. In outspoken manic excitement ideas of grandeur, of senseless grotesque formation, which in general are lacking in the manic, can be observed now and then, in so very marked fashion that they lead to the false idea that it is paresis.

We succeeded repeatedly, in cases of both sorts, in overcoming arising doubt by the negative biologic finding in the serum. Inversely we could decide for paresis by, the positive result of the reaction, where many things spoke for the presence of a manic excitement. I wish to quote a truly remarkable case of this sort.

\section{OBSERVATION 23}

First Lieutenant J., 36 years old. One brother was epileptic, otherwise no heredity. Patient was always healthy, never had any marked emotional variations; as a student was a heavy beer drinker. In I9or he had chancre, following which he took five injection cures, the last in 1906. After 1906 was married, one healthy daughter, no miscarriages. Three months previous had an attack of herpes zoster. Since this time patient has committed many foolish acts. He absented himself from the garrison without leave in order to visit his wife, and took his battery by other ways than he was ordered to do. When he wished to give a command to his battery he would lie down on the floor in front of his command and look up into the sky. He lied to his superiors in answer to questions which he had given his word of honor to answer. He was inapproachable and roughly repellant for ideas of all kinds, and when he was suspended for the time being during manœuvres because of his conduct, he telegraphed to his wife-"Hurrah-Hurrah, I'll come home sooner." 
During observation at a private institution the patient showed a continuous, careless happy mood. He had no insight. When he was questioned about having lied to his superior, he answered laughingly, "It is allowed for the accused to lie," and showed great happiness that he was enabled to lie to his superior. In sexual matters he was especially uncontrollable. When his wife visited him he grasped her by the breasts in the presence of the physicians, and fondled her buttocks, and took off all his clothes. To a young girl who was introduced to him he made advances in a striking and insulting manner, and made gross allusions to sexual matters. There were no definitely recognizable intelligence defects. Orientation was intact. Mental arithmetic not markedly disturbed, the memory not evidently weakened. Reports concerning target practice upon balloons were given with exactness but with striking exaggeration of their values. Patient was very self-confident, praised his abilities, but gave no definite expression of anything delusional.

Nothing suspicious in the way of somatic disturbances was recognizable, save a difficulty with the speech, which, however, was very slight. Difficult test phrases were spoken not free from defects, and further words were occasionally pronounced in a slurring manner. The pupillary reactions, patellar reflexes, sensibility, etc., showed no disturbances.

Biological investigation was positive for both the spinal fluid and the blood serum.

The case was from the start very suggestive of paresis, but on account of the hypomanic excitement on one side, and the lack of tangible physical signs and mental weakness, true leading symptoms, on the other, it was not easy to differentiate. The result of the serological test allowed the acceptance of the diagnosis, paresis.

We have also encountered another group of cases which is very difficult to judge. They are patients which show typical manic excitement states of the severest kind, and at the same time signs of paralysis and especially pupils rigid to light. Thus one gets in no way the impression that it is a paresis with manic coloring, rather the mania comes into view in its full development with all its characteristic signs, the exuberant cheerful mood, the waggishness, the keenness of observation of the assailable peculiarities of other persons. The patients do all sorts of mischief, make puns, humorous fancies sparkle from them. One has no doubt at all of the existence of true manic excitement states if at the same time sure signs of an organic brain disease are not present. Under these conditions one must say that three disease possibilities are to be weighed. First mania can have the signs of a 
syphilitic psychosis, or it is a true mania which, accidentally, is accompanied by the neurological symptoms of an already existing syphilitic brain disease, or finally one has to do with paresis itself.

In two cases there were certain grounds for considering a mania as a luetic psychosis, and I shall report these very characteristic cases in the section on cerebral syphilis. I shall quote here one case which ran a circular course, but which later developed as an undoubted paresis.

\section{Observation 24}

W. Rosina, mason's wife, 54 years old. First admission March 16, 1907. Syphilis was certainly present. The patient admitted that at the age of eighteen she had an ulcer on the privates, and the lymphatics were swollen. She had not received treatment. One premature birth. Two children died young. No hereditary taint. Patient had never been previously mentally ill, had always shown a uniformly happy mood, and only at the time of her menses had she been somewhat irritable. For same time she had become forgetful and disorderly; made many mistakes in her housekeeping, put kerosene in the soup, and would throw away the beef broth instead of the wash water. She was excited two days before her admission, wanted to make great changes in her home, threw everything about, threatened her children, stayed up all night, and wandered about.

In the clinic the patient showed a markedly maniacal condition. She jumped about, laughed, sang popular songs, talked incessantly in a confused flightly manner. After two days she was temporarily quieter, the mood remained happy, the flight of idea like talk continued, but it was possible to fix her attention for a time when it could be seen she was completely oriented as to time and place. She admitted she had exaggerated things, but that she thought had passed, at the same time she showed great joy that she had sworn so much. Regarding her personal history she gave correct answers, showed good memory, reckoned with striking accuracy, read rapidly, and gave correct information concerning what she had read. She showed no noteworthy intellectual disturbances. She related experiences she had had the day before. The Prince Regent had been there and appeared completely black. The Mother of God had appeared to her, had sat upon her shoulder, and had taken out her teeth so that she would not bite the Prince Regent. She had looked into heaven where her dead parents and her husband had danced.

She was greatly amused that the doctor should write it all down; struck him on the shoulder, thought it would make a fine novel, the priest should read it and the whole city would become faithful to the cross.

A physical examination could now be made, and this showed that there 
were Argyll-Robertson pupils. Stuttering over syllables appeared in the pronunciation of test phrases. The patellar reflexes were active, the sensibility intact, otherwise there were no apparent disturbances.

Spinal fluid and blood serum were positive. The spinal fluid lymphocytes were increased (II5 cells in I cu.mm.).

After about twenty-four hours of definite tranquility, a strong excited stage set in which lasted about four months and a half. The mood was uninterruptedly happy, the patient laughed, shouted, made faces, danced about, said "du" to the doctors, called them her "Little George," did all kinds of foolish things, made jokes about the other patients, pulled their hair, etc. During this excited phase the body weight diminished rapidly, she emaciated almost to a skeleton, finally weighing only 70 pounds.

At the beginning of August an increasing quieting set in, she became more friendly and approachable, but there still remained an appreciable hypomanic mood. It was striking that the patient maintained an excellent acquaintance with everything that had taken place. She knew the patients, the physicians, and the nurses and their names.

She gave, however, a mildly weakened impression, tired rapidly, refused difficult test examples, and showed a disturbance in writing, though not very characteristic.

The patient then went to a private institution, from which she was soon discharged, apparently cured.

On January 18 , 1908, the patient was again admitted. Physically she had wonderfully improved. Her weight had doubled (64 as compared with 32 kilos.). The somatic findings were the same as those at the first admission. The pupils were pin-head in size and did not react to light. The speech was somewhat slurring and stumbling with test pharases, the writing showed certain omissions, and was also ataxic. The manic mood had entirely disappeared, and given place to one of depression. The patient was not really sad, but suffered from a marked feeling of insufficiency without delusional hypochondriacal coloration. Nothing was as it should be. The memory was impaired. She could not work because her strength failed. She was sorry because she was unable to care for her husband and children and could attend only to little things in the household.

She conducted herself correctly, showed good understanding for that which was diseased in her excitement during the first stay in the clinic, but appeared to have gone backward intellectually. She reckoned badly, made at times contradictory answers concerning the past, she was also not exactly oriented as to time. In the asylum where she was transferred, they observed a very gradual decline. A weakminded tendency to weep developed, and the speech disturbance became very marked.

We were long in the dark about this case. The excited state was so plainly manic that we would have had no doubt of the presence of a mania if there had not existed such clear signs of a 
syphilitic brain disease. We were even inclined to think of a simple complication of brain syphilis with mania, and naturally also considered whether the psychosis could not likewise be the expression of a syphilitic brain disease. The further course showed that we had to do here with a paresis. The appearance of the Wassermann reaction in the spinal fluid had earlier confirmed this idea. 


\section{CONCLUSIONS CONCERNING THE NATURE OF PARESIS}

If we ask ourselves how far the results of serodiagnostic investigations, up to the present time, give us an insight into the nature of the paretic disease process, we must confess that so far it has not led us very far. We find ourselves at the present time further removed from the goal than we believed ourselves to be at the conclusion of the first investigations. Then we had at least an approximate idea of the nature of the reacting substance which appears in the serum and spinal fluid. We considered it an antibody in distinction from the antigens which stand in close relationship to the syphilitic infection. This idea, if not altogether discarded, has nevertheless been so shaken by a series of surprising observations that one cannot use it as a foundation for a programme of further work. In its place has come a series of likewise hypothethical and contradictory views, which just as little afford an understanding of the peculiarity of the disease process in paresis. Before the nature of the substances which cause the reaction is known one can draw no conclusions from their appearance as to the kind of pathological process as accompanying phenomena of which they appear in the body fluids. We shall advance further only when the biological meaning which the phenomenon has is explained. We must confess that the way, which in the beginning seemed so practicable to us for arriving at conclusions as to the origin of the antibody from organ investigation and comparative quantitative investigation of spinal fluids and sera, thus making possible a localization of the disease lesions, can no longer be trodden with results on account of the prevailing lack of clarity. Thus we are forced to the limits of our knowledge, and can only conclude from the fact that a clinically specific reaction for syphilis exists without exception in paresis, that without syphilis there is no paresis.

We are also not going too far when we further accept that 
paretics at the time of onset are still syphilitics, and we hold these conclusions therefore as justified because paretics behave, in regard to the reaction of the serum, like patients in the florid stage of syphilis, and differ clearly from the latent tertiary syphilitics.

It is further proven without doubt that the reaction stands in close relationship to syphilitic manifestations; that it appears with the first signs of general infection; that it is found most regularly in clinically manifest syphilis, and that it disappears again in about half the cases in the last stages. If paresis has for a supposition only that the patient once had syphilis, independently of whether at the beginning of his disease he is still syphilitic we should expect no higher percentage of positive results in paresis than we find in late syphilitics without symptoms. But on the other hand the behavior of paretics is not completely in accord with that of florid syphilitics. In the latter the positive blood reaction is the rule, but it knows exceptions, while in the former exceptions apparently do not exist. The biological action of the paretic coincides completely only with that of those florid syphilitics which-sit venia verbo-are capable of reacting.

Therefore, as has been mentioned before, we approach the idea that the appearance of the reacting substance represents a predisposition for the development of paresis. To draw conclusions from these observations concerning the toxic character of the reacting substance would however be premature. The peculiar clinical position which paresis and tabes assume in contrast to the true syphilitic diseases finds its expression biologically in the reaction of the spinal fluid. In paresis and in tabes we see the reacting substance appearing almost always in the spinal fluid as well as in the serum, while in syphilis in the narrower sense and also in that of the brain, we meet it very seldom in the former. Upon this, if not very regular at least striking, difference, the difference of the pathological processes is without doubt founded.

We are not able to go further into this at present, on account of the ignorance in which we find ourselves in regard to the meaning of the reaction. It is not worth while to go back to the already discussed question whether the substance comes in from the circulation, or is passed out direct to the spinal fluid from the cen- 
tral organ. For, if one, for example, takes the stand of Elias and his co-workers, and accepts that it is not a foreign compound at all but rather that the reaction is brought about through a peculiarity in the precipitation capacity of the serum albumen, one must consider the above-mentioned question as illusory in itself. 


\section{CEREBRAL SYPHILIS}

At present it is not possible to give a very definite opinion concerning the behavior of syphilitic brain diseases toward the Wassermann reaction. The cause for this lies in the fact that the cases of greatest psychiatric interest offer important difficulties in the clinical diagnosis on account of their psychotic polymorphism, and therefore they can be counted among the syphilitic brain diseases in vivo only with greater or less probability. The greater number of my cases are not clinically clear enough to allow a final judgment of the value of the results obtained by serodiagnosis in brain syphilis. On the other side benefit can be expected from serodiagnosis in the judging of clinically doubtful cases, especially since the need for increasing our present aids in diagnosis is an exceedingly great one. The only way to make any advance is to follow all cases of this sort as far as possible, and to confirm the diagnosis by autopsy. Then, retrospectively, the clinical behavior of these patients will be brought into relationship with anatomical changes on the one hand, and to the results, which the serological tests give, on the other, and thus on the ground of material confirmed by anatomical study one will leas $n$ by degrees how far one can rely on the serodiagnostic findings, and how far it can contribute, in vivo, in explaining certain clinical symptoms along set lines. A number of the cases investigated by us have died in the meantime, and they have been histologically studied, in part, by Professor Alzheimer. These cases constitute for us an exceedingly valuable material. Besides this we report also a not very small group of patients in whom, on the ground of clinical observation, we can arrive at a definite opinion, if not concerning the type and extent of the syphilitic changes, at least concerning the presence of the same.

$\mathrm{U}_{\mathrm{p}}$ to the present time, communications concerning the use of serodiagnosis in the field of syphilitic brain diseases, have been published only in very limited number, and a uniform judgment of the published cases is very difficult. The majority of authors have published their results in brain and spinal cord diseases en 
bloc and have grouped cases of paresis, tabes and syphilitic brain and cord diseases together. Hence it is quite impossible to be able to judge the cases of cerebral syphilis in particular.

Others have made known their findings in cerebral syphilis without giving clinical notes, and often it is not apparent whether spinal fluid or serum was investigated by them.

Thus I shall limit myself first to making mention of our earlier investigations, and further to considering the investigations of a few other authors, as far as their communications permit the forming of an opinion.

When we began our first investigations in paretics, we had already examined a small group of syphilitic brain diseases, and had gathered a not immaterial impression concerning the behavior of cases of this sort. There were eight cases of cerebral syphilis at our disposal, and among these few cases we found very different forms. We investigated four simple syphilitic feebleminded forms, following brain softening, a case of syphilitic endarteritis of the small brain vessels (autopsy), a paranoid psychosis of undoubted syphilitic nature, a chronic syphilitic leptomeningitis, and a case in which accurate clinical data were not available. In seven cases the spinal fluid was investigated, and gave findings different from our results in paresis, in so far as the spinal fluid reacted positive in no case. Five spinal fluids reacted entirely negative, two showed a trace of retardation which on account of its smallness did not permit a sure judgment. In five càses the serum was investigated, and found positive only twice. However, the cases which were negative in respect to the serum were old hemiplegics, patients in whom for many years no syphilitic process was taking place.

The results of other authors were in the main corroborative. On the basis of two cases of cerebral syphilis, whose spinal fluids reacted negative, A. Marie and Levaditi believed it was right to hold the negative reaction of the spinal fluid in cerebral syphilis as something very important. I have already taken a stand against this statement, made with apodictical positiveness on the ground of two cases, and have claimed that in order to settle the question the results of extensive investigations are to be demanded. Later Marie took a more conservative position. In conjunction with Levaditi and Jamanouchi he re- 
ported investigations in six hemiplegics but unfortunately clinical data were not given, so that it is not evident on the grounds of what observations the syphilitic genesis of the trouble was assumed and paresis excluded. In two cases syphilis was said to have been determined anamnestically. The spinal fluid reacted negative in five cases, and positive in one; of the sera three reacted positive, three negative. Frenkel-Heiden in seven cases of cerebral syphilis spoke only of the investigations of the spinal fluid, and reported negative findings five times, and positive twice. Förster had in five cases two weak positive and three negative reactions in the spinal fluid. Stertz investigated eight cases; all the spinal fluids reacted negative. The serum was investigated in only three cases, of which one reacted negative and two positive. Nonne obtained negative results in the spinal fluids in ten cases of cerebrospinal syphilis, with outspoken positive reaction in the serum.

It is not to be forgotten that the above-mentioned investigations, so far as number is concerned, come within very narrow boundaries, but that the infrequency of the positive reaction in the spinal fluid is so clearly general that one must gain the impression that perhaps it is possible in this way to make the differential diagnosis between syphilis and paresis.

The cerebral syphilis material which in the meantime has been available for investigation by us amounts to 50 cases, not counting cases of cerebral syphilis on a hereditary syphilitic basis. These will be discussed more fully in a special chapter.

Of the fifty cases, I can speak of only a part (22) as belonging, without doubt, to this form. The remaining 28 cases makes a motley group of different clinical pictures in which, without exception, there exists a strong suspicion of the presence of a syphilitic brain process, but which however cannot be used as a foundation for solving the question what results are to be obtained with serodiagnosis in cerebral syphilis. For the present, therefore, we shall confine ourselves to consideration of the first group of twenty-two patients which further leave nothing to be desired in symptomatic polymorphism.

Spinal fluid and serum together were investigated in 18 cases; in two patients only the spinal fluid, and in two others the serum alone. The cases in which both body fluids were investigated fall into three groups with regard to the reaction: 
I. Cases with negative reaction of the spinal fluid and positive of the serum. This group comprises almost the whole material; namely fourteen cases.

2. Cases with positive reaction of the spinal fluid as well as of the serum: 3 cases.

3. Cases with negative reaction of the spinal fluid as well as of the serum: I case.

I have never encountered cases whose spinal fluid reacted positive while the serum was negative.

Added to this are the four cases in which only one of the two body fluids was examined. Two spinal fluids reacted negative, and two sera reacted positive.

The combined results then show that of 20 spinal fluids, I7 reacted negative and 3 positive, and of 20 sera, I9 positive and I negative.

Thus there appears an almost uniform reaction type for cerebral syphilis in the fact that, as a rule, the spinal fluid reacts negative, and the serum positive. Neither the negative reaction of the spinal fluid, nor the positive reaction of the blood occurs in thoroughly uniform manner. In general one can say that cerebral syphilis differs serologically in very clear fashion from paresis, in that in the latter a positive reaction is found, almost without exception, in the spinal fluid, and on the other hand it absolutely corresponds with the florid stage of syphilis without involvement of the nervous system. Thus there is no characteristic reaction type for cerebral syphilis as a special group of the syphilitic disease forms as is the case, cum granu salis, in paresis. The use of serodiagnosis in syphilitic brain disease must be limited to establishing the fact that syphilis is present, without allowing any conclusion to be drawn as to the localization of the syphilitic process. Therefore, it is often difficult, when the patient is proven syphilitic by serodiagnosis, to ascertain clearly whether his psychic disease is caused by syphilitic changes, or whether it is not simply a psychosis of some sort in a syphilitic. But the proof alone that syphilis is present can influence the considerations in marked degree, and it will later be shown in how far this alone can promote differential diagnosis.

So far, I have spoken of cerebral syphilis "categorically" and it is naturally of the greatest importance to know in what forms 
of syphilitic brain diseases the investigations were made. It must be said at the start that, while all forms are represented, still there was a marked one-sidedness to the material. They were in reality psychiatric cases of cerebral syphilis in the true sense, and those of more or less chronic course, that is, vascular forms, cases of chronic meningo-encephalitis, or combinations of the two disease forms, a differentiation that, in vivo, is for the most part very difficult to make. On the contrary, the true neurological material-in which I shall not restrict myself to affections limited to the spinal cord-namely, acute and subacute basal meningitis and gummata of the brain, is only very sparsely represented. As far as such cases were investigated, they showed no differences from the larger group of cases, but their number was so small that one could not count them in if one wished to formulate absolute rules based on the material investigated.

I shall first describe the few cases which went under the guise of acute meningitis, or of brain tumor. All the patients came to autopsy.

In two cases the clinical diagnosis of syphilitic meningitis was made, and in two others of cerebral gumma. Of the two meningitic cases, one is remarkable in that the meningitis intervened in a very early stage of the disease, i. e., at a time when the primary lesion had not completely disappeared. The autopsy showed a nodular syphilitic meningitis, limited to the base. In the other case the meningitic changes were less clearly marked. In both cases the spinal fluid reacted negative. In the last-named case only the serum could be tested, and it gave a positive result.

Of the two patients in whom gummata were diagnosed from the clinical findings, one showed a gumma in the pons at autopsy. The spinal fluid reacted negative. The serum was not tested. The other case brought surprises in the microscopic investigation, and showed the great difficulty of clinical diagnosis in even apparently the simplest case. Let it be known that here the spinal fluid, as well as the serum, reacted negative.

\section{Observation 25}

This concerns a woman who four years previously had had a convulsive seizure. Intellectually she had gradually gone backward, and had of late become confused. Her husband had had a hemiplegia at the age of 46 , and showed immobile pupils. Syphilis was denied, although against 
this she admitted a miscarriage at the age of five months. The patient showed very slight pupillary light reaction, a disturbance of the eye muscles, loss of the patellar reflexes, definite tumor symptoms, and a marked lymphocytosis of the spinal fluid. A diagnosis of cerebral gumma was made. Autopsy (Dr. Alzheimer) showed a large tumor behind the splenium which had completely encompassed the fornix and had penetrated into the substance of the hemispheres. The macroscopic character of the tumor left no doubt that it was a gumma. The microscopical investigation showed however that it was a glioma. The diagnosis of cerebral syphilis was then overthrown, but it was not so, for an investigation of the spinal cord showed a marked syphilitic meningomyelitis.

Here then was a combination of glioma with a syphilitic disease of the spinal cord, a finding which naturally could not have been made during life.

From the serological standpoint the case is of interest, since it was the only positive case of cerebrospinal syphilis with a negative blood reaction.

Such an experience teaches us very clearly the uncertainty of clinical diagnosis, and shows how important it is to get the largest possible number of anatomically proven cases of cerebral syphilis as a ground-work for the judgment of serological investigations. Besides these four cases we have at the present only three others in which histological examination by Professor Alzheimer has established the presence of syphilitic changes in the brain. These cases are especially valuable because the anatomical control makes possible an impartial judgment of the serological findings observed during life, and therefore I shall anticipate them, and for the present mention them briefly.

The first case showed, besides extensive arteriosclerotic vessel changes, a syphilitic endarteritis, limited to a few vessels with slight infiltration of the pia. Biological finding: spinal fluid very weak positive, serum strong positive (relationship $+:++++$ ).

The second case showed a chronic meningoencephalitis, with considerable involvement of the spinal cord, and small areas of softening in the basal ganglia.

Biological investigation: spinal fluid negative, serum positive.

The third case showed diffuse degeneration of the cortex. No plasma cell infiltration, but, on the contrary, in places considerable endarteritis. Here and there giant cells were found in the adventitial lymph spaces and in areas where very marked vessel changes were present, one found little areas of softening. In the 
pia was considerable infiltration, chiefly of lymphocytes. According to the opinion of Professor Alzheimer it was a syphilitic disease of peculiar form, at all events not a paresis.

Biological investigation: spinal fluid negative; serum positive.

These cases were very difficult to interpret clinically. The first resembled arteriosclerosis. The second showed bulbar symptoms. The third was hardly to be differentiated clinically from paresis, and the result of the biological investigation here was a valuable diagnostic point, which will be gone into later.

To sum up shortly, the results that serodiagnosis gave in this group, weighty in so far as the cases were confirmed by anatomical control, I will say that of seven spinal fluids six reacted entirely negative, and one gave a very weak positive reaction, and that of five sera four reacted positive, and one negative. Thus it is established beyond doubt that there are cases of cerebral syphilis whose spinal fluid can react positive, if only to a very slight degree, and on the other hand in syphilitic meningomyelitis the spinal fluid, as well as the serum, may show a negative finding.

The remaining fifteen cases, which we thought it right to designate as sure cases of cerebral syphilis, on the grounds of the clinical observation, gave without exception positive reaction in the serum, and thus they can all be considered syphilitic. The spinal fluid was not investigated in two cases, but of the remaining thirteen spinal fluids eleven reacted negative, and two positive. The degree of positive reaction of the spinal fluid in one case was high; such as one is accustomed to meet with only in paresis. The relationship of the spinal fluid to the serum in regard to the reaction was $++++:++++$. In the other case, on the contrary, the reaction of the serum predominated in marked fashion and there was the same relationship between spinal fluid and serum as in the above mentioned case which came to autopsy, namely, $+:++++$. Both cases gave rise to differential diagnostic considerations in different ways. The one which showed the weak positive reaction will later be described conjoined with one very similar in regard to the psychic disorder, but reacting negative. I shall report here the patient whose spinal fluid reacted strongly positive. 


\section{OBSERVATION 26}

Pr. Anton, 65 years old, admitted April 20, 1907. Information relative to infection not obtained. Eleven years previously the patient had an apoplectic stroke, with right-sided paralysis. He had been unconscious four to six weeks. Since the accident the patient had been weakminded, and in the course of time the mental weakness increased somewhat, although not markedly so. There were no further attacks, the paralysis of the right side remained, the speech and the writing was, and remained, much disturbed. The patient was in a permanently helpless state.

The physical examination showed a right-sided ptosis, which was said to have been present since childhood. The right arm and right leg were paretic. There was a strong general tremor, Romberg, ataxia, patellar reflexes without marked difference, hypalgesia, pupillary reactions present.

Speech stumbling, lolling, characterless. Mentally the patient showed a high grade of dementia, with marked euphoric coloring. $\mathrm{He}$ confabulated to suggestive questions, confused experiences, lay for the most part in bed, listlessly looking ahead of him. Foolish delusional ideas not produced. Orientation was good occasionally, and it was striking that there was some definite insight.

Cytological examination positive. Seventeen cells in I cu.mm.

One could well have taken this case for a simple demented paretic, if one did not know the development of the trouble. But after one knew that the condition had already lasted eleven years, without clear progression, and had been brought on by an apoplectic attack, one must exclude the existence of a paretic process. On the other side, such a severe psychic disturbance must be put down as a very unusual result of a one-time syphilitic softening, and it cannot be known offhand that a later increase of the mental deterioration had not taken place which possibly was not clearly remarked by the relatives. Pathological anatomy will have to speak the last word here and it must be awaited whether it will show perhaps a syphilitic vessel disease of peculiar type on a combination of syphilitic and metasyphilitic changes.

Of simple syphilitic feeble-minded states, based on areas of syphilitic softening, there were six cases among the patients, and in not one of these did the spinal fluid react positive. In contrast to this the reaction of the serum was clearly positive in all. This group was very simple in clinical course. The beginning of the mental weakness in part antedated the paralysis, in part it was of later date. The mental weakness was here more, then less strongly developed, but always so characteristic in its formation 
that there were no differential diagnostic difficulties especially from paresis.

In three cases, on the ground of the clinical symptoms, we diagnosed an extensive involvement of the pia with extension to the brain substance. In a fourth cases, autopsy showed such a finding. They were chronic cases which had gone on to deterioration. In the course of time, here and there, paralyses of the eye muscles had occurred, and in two cases optic atrophy was present. Further a series of epileptiform convulsions without paralyses were observed, and the spinal fluid showed a considerable cell increase. In how far endarteritic changes also existed must be left undecided. As biological finding the reaction of the spinal fluid was always negative, while that of the serum was positive. The only case from this group of patients which has so far come to autopsy, and whose anatomical findings have already been mentioned, showed very complicated clinical conditions.

\section{OBSERVATION 27}

Tr. Anna, 60 years old, admitted May 22, 1908. Nothing known of syphilitic infection. Patient had had no miscarriages, but had had a premature child who died after three days. Two living children who had also been premature births. For six years there had gradually developed a disturbance in the patient's gait, the legs had become weaker and weaker, so that finally she could make short steps only with the help of crutches. She had no convulsive attacks. Occasionally she had urinary incontinence. Within the past six months some difficulty in swallowing had developed. For some years the patient had mentally changed in that she had become anxious and wept easily, and her memory had become impaired. Other psychical disturbances were not observed, but it was striking that she had occasional attacks of impulsive crying, and impulsive laughing. She was anxiously excited shortly before her admission.

In the clinic the patient showed herself to be well oriented and gave sensible answers to everything. The most striking feature was the frequent, marked, entirely unmotived attacks of crying. No marked intelligence defect could be ascertained; a high grade of memory defect was present, but there was an absence of any kind of psychotic symptoms. In general the mood was that of mild depression.

Physically there was a suspiciously syphilitic disseminated choroiditis. The gait was spastic, paretic, the right leg being dragged somewhat behind. The right arm was weaker than the left, there were no spasms. Ataxia of the hands and legs. No disturbance of the position sense. No stereognostic, nor apraxic disturbance. Eye muscles free. Tongue protrudes somewhat to the right. Fauces symmetrical. Horizontal nystagmus. 
Pupils unequal. Light reaction slight, but prompt. Tendon reflexes greatly exaggerated in all extremities without marked differences. No ankle clonus. Right-sided Babinski. Speech showed some imperfect articulation. No aphasia. Writing was not materially disturbed, showing only occasional displacements.

Cytologically positive.

Biologically. Spinal fluid negative, blood serum positive.

After fourteen days, during which the patient showed no changes, a condition of coma developed, with increasing weakness from which after several days she died. Autopsy showed, as already reported, a chronic syphilitic meningoencephalitis, meningomyelitis, and areas of softening in the brain stem ganglia.

There remain still four cases, which we classed with the undoubted cases of cerebral syphilis. They were very instructive to us in regard to the clinical diagnosis, because we did not easily obtain the proper conception. One case had been taken for an epileptic at a previous admission; in one case the separation from arteriosclerosis was exceedingly difficult; in the third case we departed from our original conception, that it was a Lissauer's paralysis, only after many years of observation, and finally in the last case we could not make up our minds for a long time, whether we had to do with a manic excitement, allied to manic depressive insanity in a syphilitic, or a syphilitic psychosis disguised under the picture of a mania. I wish to describe these cases in connection with similar ones, which however have not been wholly made clear in the meantime, in contrast to a few other patients who showed similar clinical pictures. These took on an entirely different value partly from what we learned by serodiagnosis. The biological reactions of only the four known patients is mentioned here. All the spinal fluids reacted negative; all the sera positive.

From this sketch of the investigated material the multiplicity of the clinical appearances and the great difficulty of clinical diagnosis becomes very convincingly evident. Often only autopsy or observation of the further course made it possible to reach a definite conclusion.

In contrast to the symptomatological variance, the biological investigation gave very uniform results.

Much more instructive than these cases, which were capable of explanation, if often not without trouble, is the clinically still 
unexplained material, $i$. e., the group of 28 patients concerning which we have not as yet progressed beyond a strong suspicion of the presence of syphilitic brain changes. However, we cannot, as yet, make use of the lesson which these cases could teach us and we must await the development which these various cases will go through. But serodiagnosis has brought here one not unimportant benefit in so far as often the positive biological blood finding lets one think of the possibility that syphilitic brain changes can lie at the bottom of the troubles. It is a motley collection of disease pictures which is here collected. In a series of cases a differentiation between paresis and cerebral syphilis was not possible. Others showed depressions and excitements or paranoid psychoses, partly with and partly without symptoms of organic lesions, in which for the present one is unable to explain in how far the psychosis is combined with syphilis or is caused by it. Further are to be mentioned hemiplegics, arteriosclerotics, cases reminiscent of multiple sclerosis or of Korsakow's psychosis, etc. Likewise, the judging of single neurological symptoms confronted us, such as absence of pupillary reactions, the patellar reflexes, without other accompanying physical or mental disturbances. The biological reactions will be thus ascertained in a very variable material but, as we have said, the fruit of these investigations can only be harvested later. So much, however, may be said, that in these 28 patients, in 20 cases the fact of syphilitic infection could be ascertained by the positive blood reaction, and over half of these had denied the infection. The majority of the spinal fluids reacted negative, but ten were positive, and in almost all of these cases, with positive spinal fluid, the occurrence of paresis came into the question of differential diagnosis.

In how far there is an outlook towards bringing greater clarity with the help of serodiagnosis, into the much discussed and, so far, so unsatisfactorily explained field of the syphilitic psychoses, only the course of years will show. One must be satisfied at present with proving the infection serologically in all cases suspicious of syphilis, even in those of the remotest relationship, and so prepare the material for investigation by the anatomists.

The large number of cases, in which a differentiation from paresis causes difficulties, forms the greatest and most important chapter in the differential diagnosis of cerebral syphilis. 
There is no doubt that biological investigation can facilitate differential diagnosis. The investigation of the blood gives only a little aid. It is positive in paresis regularly, but not with the same regularity in cerebral syphilis, thus a negative result of the blood reaction speaks always more against paresis than against cerebral syphilis. The negative blood finding, however, is met with in both groups relatively seldom, so that too much practical importance is not to be given to it. The behavior of the spinal fluid forms a real mark of differentiation. The spinal fluid reacts negative just as seldom in paresis as it reacts positive in cerebral syphilis. From this proposition it is clear that there exists a far-reaching difference of reaction, but that it does not constitute a true differentiation between paresis and cerebral syphilis, at least according to our present experience. There are a few cases of cerebral syphilis which react positive; this I cannot doubt after such a case has been established by autopsy. On the other hand I consider it very probable, on the ground of clinical experience that there are cases of paresis that react negative. Since, however, the majority of my negative paresis cases behaved very unusually, a part even calling for differential diagnosis from cerebral syphilis, and none of the cases so far can be reported as undoubted paresis through histological examination, I do not wish to state with positiveness that in paresis the reaction can be lacking in the spinal fluid.

For the present we can only say that in the reaction of the spinal fluid a new differential diagnostic point has been added to the present not completely proven ones, which clinical observation has taught us. According to the present status of our knowledge, only a conditional force can be ascribed to this, and therefore it can contribute to the clearing up of cases only in connection with our present aids.

It is not to be contested that a series of single symptom groups and, especially, the course of the disease, renders a differentiation between paresis and syphilitic pseudoparesis possible in many cases, but it is just as true that not infrequently clinical observation fails. The many attempts which have been made in recent years to separate syphilitic pseudoparesis from true paresis on the ground of certain single symptoms and symptom groups, have brought to light much that is interesting and 
valuable for differential diagnosis, but they have also made it known that there is no single symptom which, as such, belongs to only one of the two disease forms. It is certain that an outspoken paretic speech and writing disturbance is a pregnant lesion symptomatic of paresis, and that the presence of hallucinations of hearing, and the absence of hypoalgesia speaks for a syphilitic disease in the narrower sense, but the appearance of single symptoms can not bring full security to our minds. The so-called characteristic paretic dementia mentioned in the accepted disease pictures we can see occasionally in its truest form in syphilitic pseudoparesis, while on the other side the more partial psychic defect, which does not destroy the individuality by which cases of cerebral syphilis in general are characterized, can also be occasionally met with in paretics. One often goes as far as saying, "if it is not a syphilitic brain disease it is, at least, an unusual form of paresis," and with this very little is gained. We have, to-day, no cause left to doubt that there are pareses which, by the peculiarity in the localization and extent of the paretic process can produce clinical pictures which can likewise be created by syphilitic vessel changes in hardly differential form, and since Alzheimer has autopsied a case which suffered from paresis for thirty years, and was always considered as such, and was able to show histological findings really typical of paresis, one will have to be very careful about deciding against a paresis on the absence of progression.

At present it is hardly practical to diagnose difficult cases with the aid of serodiagnosis. We know at present only about the serological reaction of ordinary cases of cerebral syphilis, and it can well be that cases of unusual course, such as pareses which stretch over a decade or appear stationary, also markedly differ serologically from the ordinary findings. First the question must be settled, whether the reaction can still be shown either in the blood or in the spinal fluid in cases which arouse a deep suspicion of syphilitic or metasyphilitic brain changes, but which show, after many years, no progression of the trouble. To decide this question I could use cases which were worked up in the Bavarian asylums by Gaupp and Alzheimer. Gaupp and Alzheimer read a paper on stationary paresis in 1907 before the annual meeting of the Society of Bavarian Psychiatrists. The 
material which formed the basis of their article consisted of all the cases included as stationary paresis in Bavarian and Würtemburg asylums. It consisted of 43 cases, and among them there was hardly one case which did not raise considerable doubt, in the minds of the authors, as to the existence of paresis. Of nineteen cases which were designated as paretics in the asylums, and whose disease had lasted more than eight years, Gaupp could not recognize one single case as sure paresis on the ground of the histories. Five cases appeared to him to be probable paretics, one of which died and proved to be really paresis.

I have been able to investigate biologically another of these cases through the friendly coöperation of Professor Specht, of Erlanger.

\section{OBSERVATION 28}

The patient B., formerly a singer, now 60 years of age, had been in the Erlanger Asylum for 23 years. His disease was from the beginning, and still is, taken for paresis. The picture is an unusual one.

Nothing is noted regarding syphilis. The disease set in with a stormy period of excitement, in which foolish ideas of grandeur were present. He commanded r,ooo regiments, was a music director of all the military bands, one of the most famous opera singers, general, king, God Almighty, etc. The expansive excitement gradually abated, the ideas of grandeur remained, but were very uniform, and the patient gradually fell into an unproductive dementia with meaningless irritability, and brutal paroxysms of swearing. $\mathrm{He}$ is God Almighty, becomes uncommonly explosive when one does not address him as such, has fed the pigeons, which he designates as God's pigeons, for many years.

He has accustomed himself to a small round of occupations-raking in the garden, making beds, laying the table-and is very assiduous in the practice of these functions. In the beginning of the nineties hallucinations of hearing apparently began. From the end of the eighties the patient suffered from in part apoplectiform attacks, with evanescent half-sided paretic symptoms, in part from epileptiform attacks. For twenty years there has occurred neither physical nor psychical changes worthy of note.

The pupils are very narrow, irregular, practically immobile. Convergence reaction is doubtful. On speaking aloud there are slight tremors of the muscles of the face. The speech is usually rapid, with difficult words only stumbling over syllables and running together of single letters. Writing is markedly ataxic, scarcely decipherable. Reflexes present throughout; Babinski both sides, left more marked than right. No gross disturbances of sensibility.

Biological investigation gave strongly positive findings. The spinal fluid also reacted positively, but in a minor degree (conditions $+:++++$ ). The cell content of the spinal fluid was increased. 
We see that a case, which extended through a decade without clearly recognizable advance, can contain the reacting substance in the serum as well as in the spinal fluid. Thus we can conclude that we may expect the Wassermann reaction in the cases under consideration, apparently independently of the duration of the disease, and also that similar rules can exist in the appearance of the reaction. Whether the same relationship obtains in regard to the degree of intensity of the reaction in spinal fluid and serum as in the ordinary forms is still to be proven. We may assume that in the very slightly progressive, clinically apparently stationary cases of paresis in general, only a very low grade result is to be obtained in the spinal fluid, since the observations have taught us, in the usual forms of paresis, that the intensity of the reaction of the spinal fluid stands in absolute dependence on the progressiveness of the paretic process.

In the foregoing cases we may limit the differential diagnosis on the ground of the positive serological finding, in so far as we can assume with surety a disease caused by syphilis. The positive reaction of the spinal fluid speaks with some probability for paresis. The clinical picture contains a series of features which make the existence of a cerebral syphilis more probable. One will have to wait for the autopsy.

Since it has become apparent that one can obtain serologically the proof of syphilis in very long-lasting cases, it would be of great interest to investigate serologically the whole material described by Gaupp and Alzheimer; the cases which were diagnosed in the asylums as stationary paretics. Here is a very valuable material for the differential diagnosis of paresis and of cerebral syphilis, and further it will be possible here and there to draw a line between the forms of feeblemindedness standing in relation to syphilis, and those of different etiology. Whether one can exclude cerebral syphilis on account of a negative blood finding appears very improbable to us. Often in mild defective conditions which were caused by syphilitic processes of years before one can no longer assume the existence of syphilis, and the biological substances which are connected with it. But when the finding is positive it naturally has a very important meaning.

I have been able to examine three patients from the material mentioned, through the kindness of Dr. Würschmidt, of the 
Erlanger Asylum. In the report by Gaupp, paresis was put down as very improbable in these patients.

The biological investigation of these cases gave completely negative results in regard to the spinal fluid. Of the sera, two reacted negative, and one positive. One can say that only one of the cases was syphilitic.

It is reported here.

\section{OBSERVATION 29}

The patient has been in an asylum for fourteen years. He is now 55 years of age. Nothing is definitely known about a previous syphilitic infection. Already at the time of his admission he was designated as a demented paretic, gives no information, looks around about him dully, is entirely apathetic. Speech is greatly dilapidated, consisting of an incomprehensible lolling. Pupils immobile. Patellar reflexes increased, tremor. For years he has not changed. According to the entries in the history one reads: " $\mathrm{He}$ is continuously unclean, often somewhat excited, cries aloud, for the most part has a silly laugh and murmurs meaningless stuff. He does not seem to have shown strange actions."

No attacks. The patient is still in the same condition.

The spinal fluid is negative, but the blood serum shows a strong positive result. The lymphocytes in the spinal fluid were not increased (3 cells in I cu.mm.).

In regard to the serological reaction of the patient, one cannot doubt that the disease has a connection with syphilis. Differential diagnosis has here to choose between paresis and cerebral syphilis, and one cannot do otherwise here than to leave the decision to the anatomists. Symptomatologically in this case everything speaks for paresis, nothing against paresis and nothing for cerebral syphilis. Of course the absence of progression gives rise to suspicions.

Of the two serologically entirely negative cases, one showed neurological symptoms, which with great probability were of syphilitic genesis, while the other showed physical and psychical disturbances, which could be considered of entirely different etiology. From the psychic picture I would be inclined to look upon both patients as deteriorated catatonics. One of them, however, had pupils stiff to light, and the patellar reflexes were absent.

\section{Observation 30}

This patient, Arnold W., 62 years old, has been in the asylum since I89o. For some years before his admission he had been distracted and anxious, 
could not take care of his business, shocked the proprieties and customs, and was careless as to his appearance. Throughout the year, while in the asylum, he showed a strikingly sulky, resistant attitude, only occasionally gave a short answer, and in general swore and threatened in the commonest manner when he was spoken to. He kept himself apart from the other patients, walked backwards and forwards in the garden for hours at a time, rarely making movements of his arms, or he would sit for hours on a bench, with a tendency to lean to the left side, bent forwards with his hands in his pockets. If one attempted to change his position he would resist, and would cry in a roaring voice, "You came from the churchyard." He would often collect stones in the garden, filled his pockets with them, and swore terribly when they were emptied. In the early years he seemed anxious at times, spoke about torturing pains, at night threw everything out of the window. Only very occasionally was it possible to get him to speak, when it could be ascertained that he was very uncertain as to time, but knew that he was in an asylum. He would then utter ideas of grandeur, the contents of which were that he had I00,000,000 Gulden. One often finds in the history "crafty expression." It was very striking that after a visit from his wife in 1898 , previously to which he had for a long time been considered as completely dementedhe was very talkative, gave evidences of a good memory of earlier times, but absolutely refused to allow that the visitor was his wife.

The physical examination from the beginning showed unilateral pupillary immobility, in 1898 both pupils were immobile, and the absence of patellar reflexes noted. Other symptoms characteristic of tabes were not to be found and did not develop later.

For many years there has been no change observable. He always shows the same sulky, resistant, completely unapproachable conduct.

Cytological and biological investigation gave negative results.

If the pupils had reacted, and the patellar reflexes were present, one would not have thought of an organic disease, but rather would have designated the very eccentric, negativistic patient a terminal state of a dementia præcox. The question now is, whether it is only a combination of cerebral syphilis with dementia præcox, or whether the psychic trouble can be ascribed to syphilis or we have not to do here with a paretic. The last appears improbable to me, from the fact that there can be no talk of progression, and besides this there are many other points which can be brought up against this idea, and because a distorted, but nevertheless in certain features characteristic remains of personality are retained. One's incomplete knowledge of the clinical possibilities of forms of syphilitic brain diseases does not allow us on the other hand to exclude a syphilitic feebleminded- 
ness, and accept a catatonia. The fact that the serum reacted negative increases the probability that it was not a paresis, but rather a cerebral syphilis.

\section{OBSERVATION $3 \mathrm{I}$}

The last case, Andr. Schl., since 1893 in the asylum, now 59 years of age, according to my opinion hardly comes in question with reference to the differential diagnosis of paresis and cerebral syphilis. He is certainly to be regarded as a terminal stage of catatonia. The reason for the initial false diagnosis probably was due to the fact that two attacks of unconsciousness were observed in the very beginning of the disease. These were obviously taken to be paretic, whereas they were really catatonic. To make a short sketch of the picture it may be recorded that the patient showed almost continuous ideas of persecution and hallucinations of hearing, that he crouched in the most remarkable and peculiar positions, constructed for himself a speech in which he used alliterations and only spoke in infinitives and participles, and that he had a tendency to brutal explosive acts of violence.

At the time, and even now, there were no neurological signs giving evidence of syphilis or of paresis.

The pupils react well, the patellar reflexes are present, etc. The negative serological findings are in accord with the clinical understanding of the case.

The biological investigation of these four cases of "stationary paresis" is not able to clear the subject. But the results are not without interest in so far as that in those cases which with some possibility could have been paretics, namely in the first two reported cases, the serum at least gave a clearly positive finding; while, on the other hand, the two cases with negative serological reaction completely lack, in their clinical picture, anything that could be considered indicative of paresis. I think that in the last case in which the serological investigation resulted negative, one can abandon the present diagnosis. One gets the impression from the serological behavior of this group that even in very old cases of unusual course, the reaction can still be obtained, and that one is not bound down by time limits, at least in regard to the reaction of the blood serum. Thus, not much is gained for the differential diagnosis of paresis from cerebral syphilis, for only the reaction of the spinal fluid can contribute to a differentiation.

When I look over the cases in our clinic, which have been investigated serologically during the last year and a half, and presented difficulties in regard to separating paresis from cerebral 
syphilis, a considerable number of cases come together. A few cases which belong here are found in the small group of cases with negative reacting spinal fluid, and these have already been mentioned. It appears idle, to me, to quote a large series of these cases here, and to show how the serological examination resulted in each, for this does not bring about a real decision; at least, at present, it cannot be looked upon as decisive. By extending the discussion of the relations of the reaction, one cannot do more than to add one more to the numerous clinical arguments of probability, but cannot give any security to the opinion. One must learn to judge the importance of serodiagnosis for differential diagnosis in these cases only when they are established by histological examination, or when a true, decisive further development of the clinical picture has banished all doubt. Only a few of our cases have become clear, so far, in one way or another, and since these alone appear valuable to us $I$ shall only consider them here. First to report a case, the only one of all that in life, according to our view, has been explained on the ground of many years' observation.

\section{OBSERVATION 32}

M. Johann, 37 years of age, tailor, admitted August 27, 1905. The patient was transferred from abroad and nothing could be learned of the previous history. He seemed demented, euphoric and entirely without interest. The facial expression was flat, and without expression. The pupillary light reactions were absent. Patellar and Achilles reactions were not obtainable. Romberg +, hypalgesia, no disturbances of motility. Mixed motor and sensory aphasia. Understands hardly anything that one says to him, repetition foolish, only occasionally with correctness. Paraphasic naming of pictures and objects with evident difficulty. Only foolish combinations of syllables produced when reading, marked paragraphia, no apraxic disturbances. The aphasic disturbances gradually disappeared, and after three months had entirely gone save for a slight trace of paraphasia.

It was then learned from the patient that he had had a hard chancre as a young man, and had taken an inunction cure. The mother of the patient had epilepsy. The patient was unable to give any closer information concerning the development of the disorder.

Spinal puncture for cytological examination was made, and gave a marked lymphocytosis ( 150 cells in I cu.mm.). At that time serological examination was negative.

A diagnosis of atypical paresis (Lissauer type) was made.

Since for a number of years the disease showed only slight progress, 
being continuously under observation in the clinic, we were surprised and began to doubt the previously made diagnosis. The patient is weakminded, the round of ideas is uncommonly narrowed, calculation is very bad, the memory on the contrary pretty good and the patient is completely orderly in his conduct. $\mathrm{He}$ is above all an industrious tireless worker. Is busy with housework from morning to night, and cares for his duties with the greatest conscientiousness.

We gradually came to the belief that the patient had a cerebrospinal syphilis, and afterwards since the serum diagnosis of syphilis had been introduced we took up the investigation. The result was that the spinal fluid was negative and the serum positive, a finding that gave further support to this idea.

In the cases that I have still to consider, diagnosis has been made by autopsy.

\section{OBSERVATION 33}

R. Anna, singer, 34 years old. Admitted February, 1908.

The patient had had a past. At the age of eighteen she had an illegitimate child. From childhood alcoholic excesses. Concerning syphilitic infection the patient could give no information. For two years she had had severe headaches, nervous irritability, cannot sleep, is very excitable, trembles and feels very tired. In contrast to her complaints the mood is strikingly euphoric, careless. She sees everything in its happiest light, believes she will soon be able to go back to the stage, tells about all of the rôles in which she has acted, of the applause with which she has been overwhelmed.

At the same time she speaks of killing herself because of her terrible headaches, her helplessness, and cries that she cannot sing another note. She expresses in the next minute weakminded plans. She will at the present time-February-go to Salzkammergut on foot. She can earn money very easily, she can earn it by means of a concert, she can have crowded houses in Vienna and the like. She is exceedingly determined, has no will. Reckoning only moderate. Defect of grasp. 5867 forgotten after a minute. Memory for the past only moderate, no gross contradictions. Slight ptosis, reported as previously having been present. Marked left-sided facial palsy. Marked, at times psychogenetically increased, tremor of the left arm. Very evident pain on pressure of the nerve trunks. Well-developed optic neuritis, especially left side. Pupillary reactions normal. Patellar reflexes equally increased, no ankle clonus, no disturbance of speech or of writing. Marked lymphocytosis of the spinal fluid ( 424 cells in I cu.mm.). Spinal fluid negative, blood serum positive to Wassermann.

An inunction cure was begun but gave no results. The patient was discharged on trial but was re-admitted after a few days, because she had a fainting attack on the street. She then went to the asylum, and while there demented very rapidly within a few months without the appearance 
of attacks. The weakmindedness could not be told from that of a paretic. There was a clumsy euphoria, with ideas of grandeur. The patient lay in bed without any spontaneity, in stupid unproductivity. At the same time she rapidly declined physically, and died in November, 1908.

The autopsy showed the presence of a diffuse syphilitic vessel disease, no paretic changes (Dr. Alzheimer).

We were at first inclined, in consideration of the severe headaches, which the patient complained of, and the cranial nerve involvement, to assume a syphilitic disease. Indeed, the faulty insight, in spite of a certain feeling of sickness, as well as the euphoric emotional tone, appealed to us. Then when the patient, without the appearance of other palsies, deteriorated, so rapidly, and in a way so characteristic of paresis, it appeared to us even more probable that we had to do with a paretic. Personally, I had already placed this case among the cases of paresis with negative reaction in the spinal fluid, until the autopsy showed that a syphilitic disease existed; a finding which was in harmony with the biological behavior.

To these two cases, in which the negative reaction of the spinal fluid made the existence of paresis improbable and, on the contrary, that of syphilitic disease probable, and which, as it was later shown, was the right conception, I wish to offer two cases in contrast, in which on the ground of clinical observation the diagnosis was left open, a false diagnosis was made, the spinal fluid reacting positive, and the autopsy findings showed paresis.

\section{Observation 34}

Catherine K., day laborer, 60 years of age. Admitted in March, 1907. Syphilis was denied by her husband. Married since 1869 . One child which died after a month. No miscarriages. In 1905 apoplectic stroke with loss of speech. No paralysis. A second attack in March, 19u6, in which she spoke thickly and fell down. From this time deteriorated mentally more and more. No paralyses, no attacks. Patient is able to utter only inarticulate sounds, reacts to pin prick. She is able to stand up but makes no attempt to walk. She makes no defense movements on being pricked, and does not react at all to noises. She is lively at night, throws her bed clothes from the bed, takes hold of everything about her, burrows in the bedclothes. On being addressed the patient looks up, reacts to being troubled with angry mutterings and defense movements, which however are purposeless. She hears and sees well, follows the hands of the examiner with her eyes, and draws back angrily at every touch. She is often angrily excited when one approaches her bed and strikes at them. 
The physical examination is rendered difficult because of the resisting conduct of the patient.

The pupillary reaction is not definitely obtainable, the pupils do seem to react somewhat however. The patellar reflexes are not obtainable, the patient holding herself very stiff. Traces of an ankle clonus are present on both sides. Gait spastic, ataxic, speech unintelligible, lolling.

The diagnosis of cerebral syphilis (endarteritis) was made.

Cytological findings. Lymphocytes not distinctly increased (7 cells in I cu.mm.).

Wassermann reaction in the spinal fluid and blood serum positive. $++t+t+t+$

The patient was transferred to an asylum, died there after a few months, and the anatomical investigation showed the typical, and from the standpoint of extension the not uncommon picture of paresis.

In this case, we were led astray by the severe aphasic disturbance, which we were inclined to ascribe to localized syphilitic softening. Likewise the nonpositive cytological finding appeared to us to speak against paresis, whereas it can be correlated, according to our experience, with the assumption of a syphilitic vessel disease. The biological finding in this case was characteristic of paresis. We considered it advisable, however, not to look upon this finding as decisive.

While here one physical symptom gave rise to a false interpretation of the disease picture, we refrained from diagnosing paresis in one of the cases in which the psychic behavior, the peculiarity of the dementia, the characteristic features of paresis were completely lacking.

\section{Observation 35}

De Anton, teacher, 37 years old. Admitted May 4, 1907. Patient had syphilis at the age of 22, was treated with inunctions and injections. Married 1897. No children, no miscarriages. Nervous for 7 months. Insomnia. Complains of dulness in the head, distrait, pains in the stomach and intestines.

For some weeks has had the feeling that one limb was paralyzed and as though he walked on rubber. Increasing weakness, slowness in speech A few days before his admission a fainting attack. Yesterday cramps in the right arm. At the time of admission by reason of the preceding attack, the patient was confused-heavy-like a patient with a brain tumor. From the following day consciousness was free, but there later appeared attack like states of confusion in which the patient confabulated freely. The physical disturbances were very slight. The eye movements were free, the pupillary reactions normal. Patellar reflexes increased. No. Romberg. Speech somewhat slow, without character (washed out). No writ- 
ing disturbances. The patient showed unmistakable mental weakness, but a dementia which did not seem to us to be characteristic of paresis.

He was extremely slow and heavy in everything that he did, very selfish, meanly selfishly conceited, did not care for anything save his own health. Complained continuously of all kinds of physical troubles, without however expressing any senseless hypochondriacal delusional ideas. $\mathrm{He}$ continuously observed his state of health with painful care. Kept a notebook in which he kept careful record of his pollutions after his admission and their relation to the occurrence of his stomach pains. He was exceedingly irritable to noises. He was always very polite to the physicians and approachable, continuously desired new treatments, and made therapeutic suggestions in a silly fashion. We observed the patient one year. He had frequent attacks with accompanying signs of paralysis, always followed by speech disturbances. The mental weakness gradually increased, the circle of ideas always narrowing, the careful self observation remained however as before, as well as the social adaptability, the irritability to noises. Delusions were never observed.

Cytological examination showed marked increase in cells (200 in I cu.mm.).

The Wassermann reaction was positive to both body fluids.

Condition of spinal fluid to serum $=++:+++$

The patient died of an intercurrent typhoid, and we were dubious to the last whether he had cerebral spinal syphilis or paresis. The autopsy gave the ordinary findings of paresis in an advanced stage.

Certainly, I am far from concluding, from the single observation which is here made, that one can differentiate cerebral syphilis from paresis on the ground of the negative reaction of the spinal fluid in the former and its positive reaction in the latter. Still I believe that it may be allowed to play some part in the diagnostic probabilities after the differential sign found in a large and irrefutable clinical material has also been tried on some cases which are quite difficult from a differential diagnostic viewpoint. After a while we will certainly be able to see more clearly.

In the differentiation of cerebral syphilis from psychoses without organic causation, we are confronted with difficulties not less than those presented in its distinction from paresis. All are agreed as to the bewildering array of syndromes that may appear in the course of cerebral syphilis, and which suggest a series of mental disorders having nothing in common with syphilis. Sometimes, however, the symptomatology is much more than merely suggestive, and it may actually lead to an indistinguishable conformity to the clinical picture. 
For a number of years attention has been called from various sides particularly to paranoid psychoses with accompanying hallucinations which have been observed in syphilitics, often with the simultaneous development of neurological symptoms, also without the same, whose separation from nonorganically induced diseased pictures-especially of the dementia præcox group-can be uncommonly difficult.

If the mental disturbances are accompanied by somatic appearances suspicious of syphilis, especially by pupillary immobility to light, in general it will be possible to come to a definite judgment concerning its etiological position much earlier than in those cases in which the nervous status affords no assistance. But even then, if for example, in such a case, pupillary immobility to light be present, this evidences only that a syphilitic disease of the nervous system is present, but not that the psychical disturbances are caused by it. A simple complication of cerebral syphilis, with functional psychoses, can be excluded only when its syphilitic origin can be recognized from the character of the mental disturbance itself. We are, however, still far from this.

According to A. Westphal, who has of recent years reported especially interesting cases of this character, there may be found, in addition to delusion formation and hallucinations, which remind one very closely of dementia præcox, catatonic symptoms in exceedingly typical form. Further, we have also seen cases of paranoid psychoses in syphilis which reminded one less of dementia præcox than of chronic alcoholic hallucinosis.

Serodiagnosis can be utilized for the elucidation of these cases in so far as it reveals syphilis, even when the history denies it and suspiciously syphilitic physical symptoms are lacking. Thereby attention will be called to cases whose clinical behavior of itself has awakened no suspicion. Some cases coming under our observation may be reported here.

I shall at first cite a case which resembled a chronic alcoholic hallucinosis.

\section{Observation 36}

One of our patients (Fr. Sofie, 34 years old) suffered for three years, perhaps still longer, from delusional ideas whose content for the most past consisted of ideas of jealousy directed against her husband. She had a great variety of perceptions, from which she concluded that her husband had sexual relations with all the females that came within the circle of her 
ideas, even with his mother and mother-in-law. She made the most painful scenes because of his supposed unfaithfulness. By reason of these ideas, that her husband had been estranged from her, there developed all kinds of ideas of persecution-she was going to be killed, poisoned, and put out of the way. These ideas were kept active by almost continuous hallucinations of hearing. At times the voices came from the outside, but in general the voice came from her breast, and told her where her husband was at the moment, and with whom he was making sexual appointments, informed her of all the missteps of her husband.

In the course of the year there developed a mild dementia, which showed itself in general in the somewhat indifferent manner in which the patient regarded her delusions.

Marked defect, inclusive of memory, was not present. Strong variations in mood were not observed. The general emotional tone was in general very happy, although not at all expansive. Patient was fully oriented and approachable in her deportment. There were no catatonic symptoms. Convulsions or other disturbances of consciousness were never present, but nevertheless the patient had suffered from headaches for many years.

Physically, nothing pathological was observable. Alcoholism could, in all probability, be ruled out. A somewhat suspicious, but not certainly diagnosticated genital affection had occurred years previously. Increased cell content in the spinal fluid is not now present but had been two years previously.

The Wassermann reaction was negative with reference to the spinal fluid, but gave a positive result with reference to the blood serum.

Syphilis is definitely proven by means of the serological examination, but whether the psychosis stands in relation to syphilis, unfortunately, cannot be concluded. One can say no more than that we have here a psychosis, of peculiar nature, which is difficult to classify in a recognized group. The entire character of the delusion formation, and the absence of any catatonic symptoms speaks against dementia præcox; against circular psychosis is the absence of definite mood anomalies; against alcoholism, the fact that no alcoholic abuse was present; against paresis the absence of paralytic signs, etc.

We know enough disease pictures, however, which we are not able for the present to bring into a system-i. e., into a purely symptomatic one-and which are certainly not related to syphilis. On the other hand the present psychosis has hardly anything in common with the syphilitic diseases known to us. The appearance of hallucinations of hearing, and the gradual development 
of a mild dementia we observe often in cerebral syphilis, but these are hardly more than external resemblances. There remains to us then hardly more than a suspicion that will however cause us to be watchful in other similar cases, and learn of their relation to syphilis. If such a relation at all exists, we shall succeed in finding it along this path.

Disease pictures which remind us of dementia præcox are often observed in syphilitics, such as in the case now described.

\section{OBSERVATION 37}

In July, 1906, a 39-year-old servant, S. Marie, was brought to the clinic, who had suddenly become anxiously excited, believed herself to be pursued and robbed. In the clinic she was clear and oriented, quiet, somewhat apathetic, and made absolutely relevant statements. She related that for months she had heard the voices of policemen say to her-" Come to the anatomy building (?)-Schmidt you must come"-and similar. People spoke badly of her; they had done something with her body. She suffered much from headaches and dizziness-there were no seizures. At times, while in the clinic, she complained of heavy feeling in the head, felt sick all over. She purposely dissimulated the complex hallucinations of hearing, but in general was thoroughly approachable. No mannerism, no excentricity, natural in her talk and expression. She admitted a genital ulcer fifteen years previously.

The pupils were absolutely immobile, otherwise no physical signs of any syphilitic nature were present.

Lymphocytes increased. Only the spinal fluid was investigated biologically with very slight positive results.

The character of the delusional ideas here certainly reminds one greatly of dementia præcox; especially the ideas of bodily influence. One should not permit one's self to be dissuaded from the idea that the case belongs to dementia præcox because of the absence of catatonic symptoms. But in the pupillary immobility to light there is present a sign of an organic brain disease, which, in all probability, is of syphilitic nature. It is very probable that the psychical disturbance is the expression of the same disease. It will be our problem to investigate in the future how to find the correct path from the character of the mental disturbance only, even if without neurological support. In the meantime we have often encountered such forms since our attention has been directed towards them. I shall report still another case of this sort. 


\section{ObSERVATION 38}

Christine B., 35 years old. For two years she has imagined that her husband wished to make her a prostitute, to make her a Catholic. Since then she has always been accosted by men; the men also came to her in the night and violated her. Then she imagined her husband was dead, her present one being another. She hears voices from above. "Everything was done to her alone." A higher being spoke to her. She believes she was "in the room with the Holy Father." Of late she has been sexually very excitable; also otherwise irritable, often pounding on the window panes. Fifteen years previously venereal disease, probably syphilis.

In the clinic the patient gave an indolent, apathetic impression. She related her delusional experiences without any apparent affect. She has, as she says, observed that she has become much more indifferent to everything. She has been approachable at all times, and shows always an entirely natural unconstrained demeanor. Gross disturbances of intelligence were not observed.

Physically she shows an irregularity of the pupils with good reactions. The patellar reflexes were increased, the left facial slightly paretic, no further pathological findings.

The cell content of the spinal fluid was increased. Wassermann reaction of the spinal fluid negative, blood serum positive.

In contrast to the preceding case the physical examination gave no positive evidence for the presence of an organic lesion and therefore it is much more difficult here to show a relationship between syphilis and the psychosis. One certainly cannot hold that the character and grouping of the existing symptoms could awaken the suspicion that an organic or a syphilitic brain disease of any kind lay at the bottom.

The slight development of catatonic symptoms is somewhat striking in these cases. But this naturally proves very little since we also miss catatonic symptoms in patients who deteriorate in a manner thoroughly characteristic of dementia præcox. If psychical differential features exist at all between paranoid syphilitic psychoses and the disease pictures of dementia præcox, they are such that we at the present time are not able to pick out as most important, but which a large material observed for years and anatomically studied may serve to reveal.

I should now like to call attention to a group of cases which are not less difficult to judge and which have aroused our attention in a similar manner to the paranoid cases. These are those psychoses which run their course under the picture of a stormy 
and apparently purely manic excited condition. It is to A. Westphal that we are also indebted for having brought together the very interesting material for this group of diseases, and for having pointed out their relation to paresis, to the syphilitic psychoses, and to manic depressive psychoses. The judging of these patients is placed upon a certain basis in so far as those of a portion of the paranoid cases, as there are here present in a definite shape the neurological disturbances which point to organic changes.

What here gave rise to hesitation to speak of the mental disturbances as of pure organic cause, was the development of the psychosis thoroughly typical of, and in no manner to be distinguished from mania.

\section{ObSeRvation 39}

Johann H., cattle dealer, 42 years old, married. Admitted to the Munich Clinic, September 29, 1906. First admission.

History from wife. No mental nor nervous trouble in the family. Married I890. In I89I, a weak boy who died at the age of seven years. In 1893 and 1894 each one abortion. Nothing known of an infection.

Patient was always mentally and physically well. Emotional anomalies absent. On January 20, 1906, he was hit on the head by a piece of coal, and was unconscious for ten minutes. Shortly after a change occurred in his nature.

He became gradually excited, irritable, sulky, complained about headache and spoke a great deal. Great desire for sleep. In spite of all this he was quiet and busy in his work until the end of August of this year. In the last weeks the memory failed. August 28 he had two attacks; he could not speak for one to one and half minutes, but showed no paralytic signs. The night following there were five to six attacks, after each of which he could not speak for a few minutes. Since then no more attacks.

After that he became more excited than ever, ran around at night in the street in his shirt, and for this reason was brought to the clinic.

Status, October 3: Active excitement, disconnected, confused talking, dejected, weeping, disoriented for time. For the most part pays no attention to questions. The grasp nevertheless seems to be good. Very powerful man. Pupils medium wide, immobile both sides, convergence reaction present. Patellar reflexes active, right stronger than left. Right nasolabial fold less marked than left. Tongue protruded in the middle linetremor. By diverting attention hypalgesia.

November 7: Exuberant, over-happy mood. Flighty talk from morning until night. Ideas of grandeur. Is guardian of the king and pope of the Alwise and the Almighty. In between times opportune, witty remarks. Today broke the windowpane in the bath-room.

October II: Expansive happiness. Sings songs the whole day long. Very quick in his repartee. (Say "electricity.") "That is gone out of me." 
Continued actively excited until the beginning of January. For the most part markedly joyous, at times also wrathful, tending to violence. Then gradually began to quiet down. Nevertheless the patient was still very active, with joyous, careless mood, but was at the same time entirely orderly in his conduct. He was fully oriented, very attentive, obedient, and gave sensible answers to all questions, but was easily diverted, careless, no true insight. Finally the excitement completely disappeared, but without there being any accompanying insight. Concerning syphilis nothing could be ascertained. He was allowed to go home.

No increase in the lymphocytes (two samples). Spinal fluid: Wassermann negative.

Since at this time we had not yet definitely recognized the significance of the serological examination of the blood we were satisfied with the negative result of the investigation of the spinal fluid. We are not able to arrive at a positive judgment of the case. There was much that spoke for the excitement being of organic causation, particularly the fact that attacks with speechlessness had previously occurred, and the pupillary immobility to light as well as the differences in the patellar reflexes would not permit one to doubt the existence of organic disturbances. But the psychosis as such showed, in so typical a manner, the picture of a pure, active mania, that we always had to reckon with the possibility that perhaps there was present an accidental combination of a manic excitement with organic brain disease.

The patient recently (September, 1908) after two years have passed returned to us and voluntarily "to recuperate-to take baths." In the meantime he has pursued his trade (as cattle dealer), took good care of his business and was in no way peculiar. Investigation showed that the physical status was as before; the pupils were immobile to light, and the left patellar reflex, which at the time previous was much diminished, now was completely absent. Extreme intelligence defects were not present, the memory in particular was excellent, but there existed, nevertheless, an unmistakable weakness of judgment. The fact alone that $H$., notwithstanding he felt perfectly well, came voluntarily to the clinic, "only to take baths," was suspicious; and the attitude that the patient took towards his previous illness showed definite lack of judgment. There was also mental weakness present which, though slight, was nevertheless without question. The blood investigation was now taken up and with positive results. 
Hereby was obtained a positive support for the syphilitic origin of the affection, and we now came to the conviction, after it had been demonstrated that the "mania" had left behind some mental weakness, that we here had to deal with an organically caused syphilitic psychosis.

We received a very similar case a year later.

\section{ObSeRVATIon 40}

Jose, Hö, day laborer, 38 years old. According to his wife's statement, a few days previously the patient became suddenly excited. For three years he has been absolutely well, but he had once, previous to that, had a psychosis, suffered from ideas of persecution, and was held in an asylum two years therefor. In earlier years he was entirely normal, his emotional tone had been uniform.

At the present time the patient shows an active manic excitement. Expansive joyful mood, flighty speech, strong motor unrest, increased self-consciousness. "Twenty-seven months able to do every kind of work, an expert in the water, and on the land industrious and honest." He has had all of the talents. Uninterrupted talking, he sprang about in the bath, laughs and sings-“"Was hätte ich für einen schonen Bloch, wenn ich Meister geworden wäre, lieb Vaterland magst ruhig sein, seid treu zu Wasser und zu Lande." After eight weeks he became quiet, remained, however, in an elated mood, self-satisfied, and showed no true insight. He continuously praised himself for his remarkable qualities, related how clever he was in any kind of work, etc. His demeanor at no time showed evidences of weakmindedness. Intelligence tests in general showed no marked disturbances.

The pupils were immobile to light, the patellar reflexes increased, otherwise no disturbances.

The lymphocytes in the spinal fluid were markedly increased (I03 cells to I cu.mm.). Biological investigation gave positive reaction of a mild grade for the spinal fluid, high grade for the blood serum. (Relation $+:+++$ +.)

We could not decide with definiteness the relationship between the manic excitement, and the underlying tissue changes which caused the neurological changes, and discharged the patient with the diagnosis "mania (positive lumbar findings, immobile pupils)."

Further investigation concerning the earlier illness of the patient gave very interesting data. In I902, five years previous to the present illness, the patient was transferred to the asylum with a diagnosis of dementia præcox. Previously he had never shown any mental trouble. He had an anxious depressed mood, expressed delusional ideas, was infected through sympathy, had consumption, the abdomen was sick. Then there came self-accusations, he had committed sin because of unchaste living, and all kinds of evil deeds. In the asylum he showed the picture of a confused anxious depression, refused nourishment, stood around praying, undressed 
himself. In 1902 the pupils reacted well, in 1903 they were immobile to light. A year later a change occurred, the patient became "definitely manic." At the same time foolish ideas of grandeur appeared, "I am God the Father, Son and Holy Ghost-the whole world, 1,000 millioms, 25 billions you can have-I have served three years, and when one said to me lick me ... I shot him as dead as a mouse with a golden sabël." As the joyous excitement progressed syphilitic ulcers appeared. An inunction cure was begun, after which the eruption disappeared. The excitement also soon subsided, and the patient was discharged, and then was apparently entirely well for three years, until the time he was admitted to us.

The patient seemed to recover from the recent attack which we observed, at least he goes to his work, and according to his wife, conducts himself quite properly.

One must here again question, is not the pupillary immobility possibly a residuum of a circumscribed syphilitic process which is independent of the mental disease? One can here, even more than in the preceding case, think of a combination with manic depressive psychosis in that the mental disturbances appeared in attacks, and in the first attack a transition took place from a depression to a manic psychosis in a very definite manner. In favor of a close relationship between the psychosis and brain syphilis is the fact that the pupillary immobility to light developed during the first mental attack. That the foolish ideas of grandeur which were expressed during the first manic attacks are evidence of a connection with an organic brain disease of a syphilitic nature cannot be maintained offhand.

A paresis of circular course certainly cannot be excluded, especially can we here observe a very slow progression and the tendency to marked remissions. But after the disease had existed five years there should have developed a recognizable intelligence defect; perhaps the fact that at the occasion of the first attack a syphilitic skin eruption appeared speaks more against paresis, which, though it may occur in this disease, is nevertheless extremely rare.

The results of the biological investigation contribute little to the explanation of this case. The presence of the reacting substances in the spinal fluid can always indicate that pupillary immobility is not the residuum of a bygone process, but that also at the time of the second attack syphilitic processes were in progress in the central nervous system. This opinion finds a definite support in 
the increased cell contents in the spinal fluid. The nature of the problem makes us abstain from a conclusive judgment.

Should epileptiform attacks appear in the foreground in the beginning of a brain syphilis, a confusion with genuine epilepsy can take place very easily, and it is an old experience that mistaken diagnoses are caused in this manner. In recent years the diagnosis of cerebral syphilis from epilepsy has taken on great importance through the work of Alzheimer, since this investigator has shown that not only the epileptiform attacks but also the psychical disturbances which resemble the equivalents in genuine epilepsy, dream states, depressions, absences, may be occasioned by syphilitic vascular disease of the brain.

I shall report two cases, in which we were led to the mistaken impression that genuine epilepsy was present, because of the appearance of conclusive attacks.

The first patient is particularly noteworthy, because in him the clinical diagnosis starting with epilepsy arrived in a roundabout way through paresis at cerebral syphilis.

\section{ObSeRvation $4 \mathrm{I}$}

The patient, William H., an engine fitter, 30 years of age, was admitted to the clinic three times in the course of two years because of epileptic attacks which occurred in the streets. The attacks have been going on $4^{\frac{1}{2}}$ years, begin with general convulsions, loss of urine and biting of the tongue and at times show a definite relationship to alcoholic indulgences. No epileptic equivalents of any kind had ever been present. The first admission was in 1906, the second in 1907 , the third in 1908 . It was reported that the father of the patient died of paresis. The patient himself said he had had gonorrhea, but no syphilis. No physical nor mental disturbance which could be referred to an organic process could be found. At the third admission the patient occasionally showed a passing state of anxiety, which he defined as a heart uneasiness during which he did not become confused. There were no doubts of the diagnosis of genuine epilepsy. One month later, in May, 1908, the patient was again admitted. He had previously had an attack. For several days the patient now showed a picture exactly like paresis. He seemed mildly confused, did not know himself, was markedly euphoric, expressed ideas of grandeur, and showed paretic, speech and writing disturbances.

The biological investigation first awakened doubts with reference to the presence of paresis, because, while the spinal fluid was completely negative, the blood serum on the contrary reacted strongly positive. The lymphocytes in the spinal fluid were increased ( 24 cells in I cu.mm.). Gradually very striking mental disturbances developed. The patient went into a con- 
fused excited state. Numerous hallucinations of hearing appeared; he heard many voices under the bed, which spoke through a telephone: “Thou belongest to me, and thy love can free thee, until then thou liest for a long time under the turf," etc. He crawled under the bed in order to hear the voices distinctly, and begged that people should be quiet in order that he might understand the voices. He believed that the attendants and patients were persecutors and wanted to kill him. Upstairs there was an apparatus arranged by which he would be made unconscious; it was a kind of induction, he would be killed by an electric current.

An inunction cure was then started, and after he had had two more epileptic attacks one right after the other, his orientation returned, whereas the auditory hallucinations still continued. The complete retrogression of all symptoms then took place. The patient became clear, the excitement disappeared, and complete insight into his disease developed. The ideas of persecution, the auditory hallucinations were corrected and designated as due to his disease. Intelligence defects were not recognizable with a renewed examination. The writing was without fault, the articulatory speech disturbance disappeared and soon in the physical field nothing but much increased knee jerks could be found. The patient, in accordance with his wish, was soon discharged in complete orderly condition.

We have here come to the impression that the symptoms are to be referred to a syphilitic brain disease. The hallucinations of hearing, among other things, and the lengthy course, speak against paresis; since the beginning of the disorder already goes back four years and a half, if it had been a case of paresis, mental weakness would have developed. We also had no occasion, with reference to the character of the disturbance, to reckon with the possibility that a genuine epilepsy formed the foundation of the disease. Since the father of the patient died of paresis, the possibility that this was a case of hereditary syphilis could not be decided offhand; and likewise the denial of infection on the part of the patient, who had been very intimate with prostitutes, should be accepted with scepticism in any case. What type of syphilitic brain disease was present, is hard to say: In addition to chronic leptomeningitis, Alzheimer's endarteritis of the small vessels, which can give rise to pictures resembling epilepsy, comes into consideration.

The biological investigation here led to the positive determination of the syphilitic infection, and further gave the first occasion to call in question the diagnosis of paresis which had been made in the meantime. 


\section{OBSERVATION 42}

Another patient, an alcoholic, who was brought to the clinic because of epileptic attacks, and stayed several days, showed no physical signs and was regarded as a simple epileptic. Six months later he was again admitted with distinct signs of a basal meningitis.

The lymphocytosis was here very high (200 cells in I cu.mm.). The Wassermann reaction showed the regular findings of a cerebral syphilis; negative spinal fluid, positive blood serum.

A further profitable field for serum diagnosis seems to exist in the differentiation of arteriosclerosis from syphilitic brain disease. Thanks to the work of Alzheimer, Binswanger and others we are in a position, on the basis of a series of characteristic psychical differential features, to diagnose the greater number of these cases during life. But syphilitic vascular disease, as well as arteriosclerosis, can evidently bring about disease pictures so slightly characteristic that a separation into one of the two groups is not possible. The position is further particularly complicated because complications of arteriosclerotic and syphilitic vascular diseases are not rare, and a peculiar mixture of clinical symptoms can therefore result, whose unravelling belongs to the most difficult, if not at time insoluble, of problems. Further the widespread, and certainly not unfounded, opinion that syphilis can lead to the development of true arteriosclerotic vascular changes, deserves attention, and this result is calculated to bring about particularly difficult differential diagnostic relationships.

Serum diagnosis is here in particular measure directed to a purely preparatory problem, preparatory in so far as it calls the attention of the anatomist to the investigation of the brains of patients who, during life, pass as arteriosclerotics, yet, from their serological behavior, must be regarded as syphilitics. Looking backwards definite new points of view are to be found, in one or another direction, which also make clinical differentiation easier. For the time being, all arteriosclerotics should be examined serologically, especially those who become ill relatively early, even when, clinically, absolutely no suspicion of the presence of syphilitic changes is aroused. We have already found among sclerotics a series of cases whose blood gave the Wassermann reaction. One of these cases has come to autopsy, and demonstrated, in a very forcible manner, how serum diagnosis may sometimes give the interpretation. 


\section{OBSERVATION 43}

George R., 48 years old, admitted January 30, 1908.

So far as the incomplete history could be obtained from the people he lived with this unmarried patient was no drinker, worked regularly and showed nothing striking up to the day before his admission. He was found one morning in a completely confused condition. $\mathrm{He}$ was half dressed, spoke disconnectedly, uncomprehendingly, gave absolutely irrelevant answers, did not know how to use his spoon when soup was placed before him. He was then brought to the clinic.

The physical examination gave no gross neurological signs. The eye movements were free, the pupils reacted promptly, the patellar reflexes were rather active, the remaining tendon, skin and mucous membrane reflexes were also present. No disturbances of sensibility, no paralyses. On the contrary there were very complicated aphasic and apraxic disturbances. The aphasia was mixed motor and sensory, preponderatingly motor however. Repetition of words was not possible; the understanding of words was more difficult, however, with repeated commands simple acts were carried out whereby distinct difficulty showed itself. He reads single letters from what is set before him without bringing them together into words, and does not understand what he reads. He can carry out simple acts with the right hand, although clumsily, but not with the left hand. He uses various objects correctly with the right hand, but often only after repeated attempts. Single parts of complicated acts were correctly performed but not in the proper order. It was very remarkable that the apraxic disturbance of the left side was much further developed than that of the right. There were no evidences of paralytic phenomena.

As a result of the aphasic disturbance it was possible to obtain only an incomplete mental status. Patient appeared to know where he was. $\mathrm{He}$ also began no actions which could be referred to a state of confusion. Nothing could be learned regarding syphilis, but a rather advanced alopecia was suspicious.

A biological examination was first tried with strong positive result. A lumbar puncture was then made, which gave a marked lymphocytosis ( 3.46 cells in I cu.mm.), biologically the spinal fluid reacted positive but in very mild degree. (Spinal fluid: Serum $=+:+++$. ) The patient belongs among the three cases of cerebral syphilis with positive findings of the spinal fluid.

The patient died a short time after being transferred to the asylum, and Professor Alzheimer found, as has already been detailed in the previous summary of the autopsy material, in addition to widespread arteriosclerotic changes of single blood vessels, a marked increase of the vessel wall cells (syphilitic endarteritis) and limited infiltration of the pia.

I should like to report still another case which is still alive, in which the serum investigation findings first afforded the motive to take the differential diagnosis, between arteriosclerosis and cerebral syphilis, into consideration. 


\section{OBSERVATION 44}

Frau Von S., 58 years old. Admitted June 27, 1908.

Concerning venereal disease nothing can be learned. The patient has had neither children nor miscarriages. Patient has had no severe disease, and mental disturbances have never been observed. Patient has lived for some time in a hotel in Munich, and a friend of hers, whom we thank for information, has assured us that there has been nothing out of the way to be observed about her. She has shown a uniform happy mood, is mentally active, and her memory leaves nothing to complain of. On the day before her admission she suffered an attack as she sat at the table. The head fell to the left, she sat looking straight ahead of her, her face was distorted. After a few minutes she came to herself, and said, "perhaps that was a stroke." Afterwards she was a little dull and after a few hours there was a repetition of the attack, whereupon the patient was brought to the clinic.

On the morning after admission the patient was completely oriented, but remembered, however, only indistinctly the details of her transfer. Intellectual troubles were not observed, especially the memory and observation were not disturbed. In her manner of speech there was a certain heaviness and circumstantiality, she ran off of the theme easily, showed a deficient understanding regarding the severity of her disease, and a distinct lack of resolution. She was completely oriented in company. In the course of further observation, the lack of insight became more evident. Thus she was inclined to refer her disorder to an empty tooth, but always had something to complain about. She was very querulous, followed the orders of the physicians unwillingly, wanted to know everything better. She showed also rare peculiarities, lying in bed, for instance, with an open umbrella, wished the room darkened all day because the light dazzled her eyes, and the like. No delusion formation, no hallucinations. Fainting, convulsive attacks, disturbance of consciousness of any kind did not appear during the time of observation.

Physically the patient showed not the slightest pathological change. Speech and writing were unmodified. No distinct peripheral arteriosclerosis.

Investigation of the blood was positive, that of the spinal fluid, however, negative. The cell content of the spinal fluid was not markedly increased ( 8 cells in $\mathrm{I}$ cu.mm.).

Here one could not maintain that the clinical picture had permitted the supposition that the patient suffered from a syphilitic brain disease. It is also in no way proven that this is the case, but on the ground of the positive blood findings, one is led to this possibility. The disturbances are so slightly developed, that they afford only the slightest support for the differential diagnosis. Following the two slight attacks, without after-symptoms, 
there developed a definite loss of critique, a somewhat stubborn peculiar manner, without any noteworthy involvement of the memory, power of attention or other intellectual faculties. Perhaps the slow advance of the disorder, the transitoriness of the paralytic symptoms, which appeared some time past, the absence of any attention disorder permitted one to think of it more as a syphilitic than as an arteriosclerotic affection. The change in character, however, with the appearance of a selfish querulousness, bore the senile stamp. After all we must content ourselves with directing greater attention to the further course, especially with regard to eventual appearance of suspiciously syphilitic disturbances, and if the course of the disease affords no light we must leave the differentiation to the anatomists. 


\section{TABES AND TABES PLUS PSYCHOSES}

A. Schütze was the first to report concerning the use of the Wassermann reaction in tabes, and after this author, who in the beginning, from a relatively small amount of material, had obtained his principal proof that the spinal fluid in tabes contained reacting substances in the same manner as in paresis, he later extended his researches to a much larger material including the study of the blood serum in tabes. No systematic studies of tabes have been undertaken, although other authors have reported concerning their findings in small groups of tabes which have occurred in mixed material.

In addition to Schütze the work of Citron should be reported, as he had studied a greater number of cases than the former. ${ }^{1}$

For the most part the results of Schütze are standard. $\mathrm{He}$ investigated 100 cases of tabes, in $7 \mathrm{I}$ the serum, in 21 the spinal fluid and in 8 the serum and spinal fluid at the same time. It is to be regretted that the investigation of both body fluids should have been done in so small a number of patients. Independent of the medium in which the results were obtained 69 cases reacted positive and $3^{I}$ negative. Individually of 78 per cent. sera $5 \mathrm{I}$, $i$. e., 65 per cent., and of 29 spinal fluids, $23, i$. e., 80 per cent. reacted positive. From this it would appear that in tabes the spinal fluid gives a positive reaction more often than the serum. One cannot, however, draw this conclusion with certainty from Schütze's material, because, the blood findings were obtained almost exclusively from other patients than the spinal fluid findings, and it is further to be observed that the results of the blood investigations were obtained from a much larger material. According to Citron the conditions are reversed. With him, of I5 sera 12 reacted positive, while of 9 spinal fluids only 2 reacted positively. The answer to the question in how far general laws concerning the relation of the reaction in the spinal fluid to that of the serum in tabes may be present can be made only after

${ }^{1}$ Nonne found 90 per cent. positive findings in the blood and 50 per cent. positive findings in the spinal fluid in tabes. 
further and more extended independent investigations. Even at the present time, however, it is certain that as in paresis so also in tabes the spinal fluid, in addition to the serum, can contain the reacting substances, and when we follow the investigations of Schütze the majority of the cases show it. By means of the agreement of the biological behavior there is brought forward a further confirmation of the close relationship of tabes and paresis which gives new support to the view of Möbius that they are similar processes, but having different localizations. On the other hand, tabes in company with paresis from the standpoint of biological behavior, is separated in a very striking manner from the syphilitic diseases-in the narrow sense-in that, as has already been pointed out, the latter generally show a negative finding in the spinal fluid, whether the central nervous system is involved or not.

My own material of tabes, without psychic symptoms, is small, and comes for the greater part from the general hospitals of the city. In all, 16 cases were investigated, of which, it may be observed, the majority were in the beginning of the disease.

Spinal fluid and serum were studied simultaneously in Io patients. The spinal fluid reacted positive six times, weakly positive (questionable) once and negative three times. The serum, positive eight times, negative twice. The spinal fluid alone was investigated in one case with positive findings, the serum alone in 4 cases, in which 3 reacted positive and I negative. In all II spinal fluids were investigated of which 7 ( 64 per cent.) were positive, I (9 per cent.) questionable, and 3 ( 27 per cent.) reacted negatively. Further, I4 sera, of which II (79 per cent.) were positive, and 3 (2I per cent.) negative. Of the 16 cases $3, i$. e., 19 per cent., reacted entirely negative, independent of the medium used in the investigation. According to our experiences then, it is learned by means of the Wassermann reaction, that the majority of tabetics are syphilitic. I can further confirm the statements of Schütze, that a positive reaction is usually yielded by the spinal fluid in addition to the blood serum; so that similar conditions prevail in tabes and in paresis. However, in so far as conclusions can be based upon my scanty material, most of which I was moreover unable to examine clinically in person-it would seem that in tabes as opposed to my findings in paresis, cases do 
occur which present a negative behavior of the serum. In the spinal fluid also, the reacting substances are evidently not met with as frequently in tabes as in paresis. In those cases in which both body fluids reacted positively, so far as the grade of reaction was concerned, the serum surpassed the spinal fluid.

Among the small number of patients that I could observe one case is worth relating, in so far as he showed that it is possible, by means of a positive reaction of the spinal fluid, to arrive at an early diagnosis of tabes.

\section{OBSERVATION 45}

This refers to a 44-year-old alcoholic, a broken-down piano teacher, who was sent in because of drunkenness. She showed no other mental disturbances. The physical examination, however, showed an inequality of the pupils and left-sided immobility. The patellar reflexes were active. Further objective or subjective tabetic symptoms could not be elicited.

The spinal fluid gave negative cytological evidence, but gave the Wassermann reaction. We saw the patient one year later, with a fully developed tabes; absence of knee jerks, Romberg, general hypalgesia, lancinating pains, paræsthesiæ, etc.

This observation suggests the importance of ascertaining, by means of serodiagnostic methods, the significance, as an individual symptom, of pupillary rigidity to light, or absolute fixation, respectively; first in its relation to syphilis in general, and next in regard to the part played by it as an initial symptom of metasyphilitic disease.

I have made two further observations in which pupillary immobility to light was present on both sides as the only symptom of disease to be obtained; cases which in the psychic field gave no evidences of disturbance. They concern an eighteen-year-old, mentally sound anæmic girl, and a twenty-year-old man, otherwise completely well, who had been brought into the clinic in a drunken state. Concerning acquired infection, or syphilitic heredity nothing could be learned; all signs of syphilis were absent. The blood of both reacted positive, and this finding shows very surely that the pupillary immobility has a syphilitic genesis. In contrast to the other patient the spinal fluid of both of these cases reacted completely negative, and up to the present time no tabetic symptoms have developed, which naturally does not prove that they will never appear. But one should count upon the possibility that the difference in biological behavior of the spinal fluid is 
evidence of a difference in the significance of the symptoms, and supposedly in the direction that a pupillary immobility with negative reaction of the spinal fluid rather points to a syphilitic process, in a narrow sense-which possibly has run its course-whereas in the other case one has to deal with a metasyphilitic process already advanced in its grasp. In order to differentiate these questions it will require at least a great amount of material which must be followed for years.

What the combination of brain disease with tabes indicates I had opportunity to investigate in three directions.

Once, in my paresis material, I came upon six cases of true tabo-paresis, $i$. e., cases in which distinctly recognizable disease of the posterior cord was allied with paretic symptoms. They behaved like ordinary cases of paresis, gave positive reaction of the spinal fluid, and of the serum. Nevertheless, in four cases the serum reaction preponderated. In this far there was agreement with the cases of simple paresis, which showed a slowly advancing course, and where also the spinal fluid gave a slighter reaction than the serum. Apparently the similarity in behavior of both groups is explained by reason of this slight tendency to progression.

Further I should like to call attention to two cases where tabetic symptoms developed after syphilitic brain disease had taken place. The cases behaved differently biologically, and this difference may have its cause in a difference in the fundamental underlying changes of the disturbances.

\section{OBSERVATION 46}

The present patient is now in his fifty-eighth year and had acquired syphilis 2I years previously. Three years after the infection there appeared a paralysis of the eye muscles, and a syphilitic optic neuritis with total blindness following. Seven years later tabetic symptoms developed; lancinating pains, girdle sensations, gastric crises. At the present time there is loss of pupillary light reactions, and absence of knee jerks. Ataxia is distinct only in the hands, Romberg is not characteristic. Patient was admitted because of attacks of præcordial anxiety. Mental disturbances, at least such as might permit one to think of paresis, were not present.

Cytological examination positive ( 30 cells in $\mathrm{I}$ cu.mm.). Biological investigation-spinal fluid and blood serum positive. 


\section{ObSERVATION 47}

The other patient is 47 years old and had syphilis twenty years ago. Twelve years ago left-sided hemiplegia. For ten years, incontinence of urine. No subjective tabetic symptoms. The pupils are practically completely immobile. Patellar reflexes somewhat exaggerated. Romberg slight. Mild ataxia of the extremities; general hypalgesia. Apart from mild weakness of memory, no psychical disturbances.

Cytological investigation positive ( 46 cells in I cu.mm.). Biological investigation; spinal fluid negative, blood serum positive.

The cases are different biologically in so far as that in the first case the spinal fluid reacted positively, in the second negatively whereas there was no difference in the blood reaction. Clinically the cases are quite different with reference to the type of the brain disase. The first case was a syphilitic basilar meningitis, in the second there was a vascular disease. In regard to the spinal cord disease, the clinical picture of the first case is that of tabes, whereas in the second it is very questionable whether there is a tabetic change at all. It is much more probable that this is a case of spinal syphilis. It is quite interesting that in the positive case of tabes the reaction appears in the spinal fluid, while it does not in the other case, and it is quite probable that this makes possible a differentiation in the sense already mentioned. It will require further investigation to determine whether serodiagnosis will be called upon to differentiate syphilitic from metasyphilitic diseases of the cord in the same way as in diseases of the brain.

On the other hand it seems to me highly improbable that serodiagnosis will be called upon to clear such a difficult question as the nosological position of psychoses occurring in tabes. If tabes be present, it will show itself biologically by means of a positive reaction. Tabes of itself can cause a positive result of the reaction in the spinal fluid as in the serum. One can hardly conceive, however, that the disturbances due to the underlying psychosis can at the same time produce a recognizable influence upon the serological behavior. It is, therefore, not possible to conclude, from the reaction, whether, in any particular case, there exists a syphilitic, metasyphilitic or other type of psychosis.

Two cases occurred which I should like to report in brief. 


\section{Observation 48}

In this case, that of a 35-year-old woman, the tabes had developed for seven years in an exquisite manner. There were all of the possible subjective symptoms, Argyll-Robertson pupils, loss of knee jerks, high grade ataxia, incontinence of urine, etc. The mental disorder showed itself in a mild dementia, not at all paretic, and a peculiar character development. The patient was very peevish, irritable, quarrelsome, suspicious, uncommonly difficult to manage. On the other hand there were no delusions, nor hallucinations. Since we could obtain no history from the relatives, we were unable to judge when the mental disturbances had begun. The psychical condition of the patient was taken to be hysterical in another place, which does not seem to have been justified.

The cytological examination showed mild positive findings (II cells). Biologically the spinal fluid behaved negatively, the blood serum weakly positive.

The case shows that in a completely developed tabes the spinal fluid may be free from reacting substances.

In conclusion I should like to report one case which is an excellent example of a combination of tabes with a paranoid psychosis, showing itself in the form to which Cassirer has called attention.

\section{OBSERVATION 49}

The patient, E.W., a 34-year-old writer, was admitted to the clinic November 24, 1907, following a suicidal attempt. He stated that he wished to take his life because he could no longer bear the persecution to which he was subjected. It began eight months ago and all came from the magistrate in Bozen, who wished to take vengeance upon him because he had criticized an order of the judge in an editorial. He was charged with all possible crimes, theft, house breaking, triple murder, shameful acts with boys and girls and impotence. $\mathrm{He}$ is constantly surrounded by disguised policeman. He hears all kinds of voices, knockings, noises, all of which refer to him. For some time it has seemed to him as if a frightfully bad smell came out of his nose whereat he had had the feeling as though he had passed through a dream state, and everything that he had previously experienced he had now clearly seen and heard; it was as if a cinematograph exhibition were unrolled before his eyes. They wished to poison him with vitriol, even now he tasted the frightful taste. Everything was done by the order of the Bozen magistrate.

The patient brought all of these ideas forth in orderly language with a strong affective accent. Orientation for time and place were excellent, the memory splendid, and in general there were no signs of mental weakness. $\mathrm{He}$ was absolutely natural in his bearing, most approachable, showed great need for expression of his thoughts.

In the clinic the delusion formation developed further, took on more 
and more fantastic character. He believed he was pregnant with twins, felt very clearly how the children moved in his body; later the foetuses passed with his fæces which he referred to the fact that someone had put something into his apple sauce. He hears voices practically without interruption, at times insulting, at times praising him. Thus they would call out he was Christ, king, director of the Klinik. Everyone must listen to him. He continuously endeavored to further his release in an energetic manner, because everything here was bewitched.

Physical findings. Pupils unequal, almost completely immobile to light. Knee jerks weak, Achilles reflex absent, no Romberg, no disturbance of the bladder. Band shaped hypalgesia in the region of the nipples, lancinating pains, hypalgesia of the legs, speech and writing undisturbed.

Lymphocytes in the spinal fluid hardly increased (6 in I cu.mm.). Biological finding spinal fluid weakly positive, blood serum strongly positive.

The case is peculiarly characteristic because of the ideas of bodily influence. Whether, and in how far the tabetic sensations may have been used in the delusion formation is not to be clearly determined. The nosological position of such a case is certainly uncommonly difficult to judge, and, before careful histological studies has brought clarity, one can have various views. Undoubtedly paranoid psychoses, which symptomatically show complete similarity, occur in nonsyphilitics, without the presence of any kind of disturbances indicative of organic changes, and on the other hand similar pictures may be found in syphilitic brain disease without involvement of the posterior columns. Examples of this variety I have already cited.

From the biological findings, which find a sufficient explanation by reason of tabes, one naturally obtains nothing essential for the judgment of the psychoses. 


\section{E. FEEBLEMINDED FORMS ON A HEREDITARY SYPHILITIC BASIS}

Among the diseases which may affect the brain in younger years, and which may lead to dementia, syphilis plays a very important rôle. It is a knowledge of this fact which has gradually opened the way, though still in individual cases we are far from being able to definitely separate certain demented children on a hereditary syphilitic basis from the great mass of other forms of feeble-mindedness. This difficulty is in accord with the more general fact that in the idiocy group itself we are not able to make a classification, at least for the majority. In recent years small groups have been set off with definiteness; thus cretinism, which Krepelin refers to a disorder of metabolism, amaurotic idiocy, Mongolian idiocy, and, primarily among the progressive forms, juvenile paresis. The undivided remainder, however, makes up an overwhelming majority of the material. One is satisfied for the time being to make a division according to the grade of the weak-mindedness present, separating idiots, imbeciles and debiles, a classification whose external characters offer no prospect in futhering our insight into the character of the actually existing processes.

In the forms of idiocy which are accompanied by paralytic symptoms, neurologists are accustomed to found their divisions upon the clinical form of the motility disturbances. When one takes into consideration that for the most part one here has to do with destructive processes that have involved the brain in its development, and that here the most varying causes, such as embolism, thrombosis, etiologically quite different forms of meningitis, and encephalitis, traumatic hemorrhages, etc., can lead to similar widespread defects, it cannot be wondered at that etiologically different processes may lead to similar defect symptoms and that a classification which places the neurological symptoms in the foreground can hardly lead one to the goal. When one looks through one of the latest summaries from the neurological side, as for instance that of Zappert, one can soon recognize that the neurological is no more effective than the psychiatric arrange- 
ment, in that they both can encompass only a portion of the cases. Cases with a syphilitic genesis can be intermingled in all of the thinkable neurological forms without one's being in a position to pick them out with any certainty.

Even anatomical investigation must be satisfied with the demonstration of the destruction and with its localization since it concerns, in the majority of cases, a long since gone-by process and one is often unable to judge as to the character of the previously existing brain disease. I may here state an observation of Alzheimer's. In the brain of two patients with juvenile paresis Alzheimer could demonstrate, in addition to the paretic changes, foci of disease which had caused delimited retardation of development. The form and arrangement justified the conclusion that they had been brought about by primary changes in the blood vessels and the history left no remaining doubts that they were cases of syphilitic vascular disease. But the anatomical picture, because of the age of the process, did not permit any signs of syphilitic vascular disease to be recognized: here also was only indirect demonstration possible.

In his well-known scale, which expresses the frequency with which hereditary syphilis involves the individual organs, Heubner has placed the nervous system as last. When, following him, we admit that syphilis of the nervous system does not belong to the commoner hereditary syphilitic affections, we cannot conclude at all from this that, in the genesis of congenital, and feeblemindedness acquired in childhood, syphilis plays a subordinate rôle.

In looking through the literature up to 1904 which Bresler carefully collected, one recognizes the great difficulties which are met with in the recognition of syphilitic feebleminded forms, and which must lead to markedly divergent judgments of syphilis as an etiological factor.

According to Rumpf, 13 per cent. of the hereditary syphilitic symptoms are distributed in the nervous system.

Jullien observed that of 162 children of syphilitic parents onehalf suffered from inflammation of the meninges or from convulsions, and he concluded from this that syphilis involves the nervous system in 50 per cent. of hereditary syphilitic children. Investigations into the syphilitic antecedents of weakminded children have been made from various sides. English and American 
authors show the lowest percentages. In I,000 idiots Shuttleworth found only four cases of positive and ten cases of probable syphilis. These figures seemed even to him to be too low, and he says that the parents do not readily tell the truth relative to syphilis. Down, in his idiot material, found only 2 per cent. and Brown only I-I.5 per cent. of syphilis.

Wildermuth reckons the frequency of hereditary syphilis in idiots at II. 8 per cent. Binswanger in an institution exclusively for imbeciles of the better class endeavored to search for syphilis, and here 9.5 per cent. certain and 12.2 per cent. probable syphilis of one of the parents was determined. König found, in simple idiocy not complicated by motor disturbances, hereditary syphilis certain in 6.5 per cent. and very probable in 4.2 per cent. further, thus a percentage of 10.7. Bourneville held syphilis to be an extremely rare cause for idiotic conditions. Heubner's recent statistics are in striking contrast to Bourneville's opinion. According to Heubner, of 25,000 children treated in the Charité there were 230 cases of idiocy. In 87 of these etiological information was obtainable, and in these there was 23 per cent. of syphilis in the parents, nervous hereditary taint in 20.7 per cent., symptoms of fever in 16 per cent., alcoholism in 13 per cent. and in ro per cent. other causes existed. According to him, syphilis leads the list as to etiological factors.

From these statistical results it is readily seen how the opinions regarding the syphilitic genesis of idiocy are at variance.

On the other hand all are agreed that the clinical manifestations of syphilitic brain disease in childhood are exceedingly plentiful, and therefore gives occasion to difficulties in differential diagnosis from the great number of brain diseases which frequently take place in childhood. It would go far beyond the range of this summary were $I$ to enter into a detailed discussion of these clinical pictures and their relation to syphilis. I must content myself with singling out certain forms which, by reason of their frequency, claim our interest.

Above all should be pointed out the great group of feebleminded children who at the same time suffer from paralytic symptoms of the type of Little's disease, or from symptomatically related motor disturbances. The etiology which was originally postulated for Little's disease was very precise and narrowly cir- 
cumscribed. It consisted of meningeal hemorrhages which were occasioned by the act of birth. Abnormal positions, difficult labors because of the resistance of the maternal parts, instrumental pressure in birth, versions, breach presentations, premature birth, prolapse of the cord were causes. Asphyxiation during the delivery was regarded as especially important for the origin of intra-meningeal hemorrhage by later workers. Injuries of a purely mechanical-traumatic nature were also referred to as causing the disease picture. This viewpoint was specially upheld by Virchow (cit. according to Freud) who looked upon the hemorrhage as due to the overriding of the cranial bones which caused a tearing off of the veins which go from the pia to the large sinuses. Thus the disturbances occurred as a result of interruption of the circulation. Further, it was a striking fact that a large per cent. of such Little's disease cases were premature births. This led to the possibility of thinking that syphilis here played a rôle. Weyhe then found 23 cases- 12 per cent. of hereditary syphilis in 122 autopsies-of infants with meningeal hemorrhage. Later Mracek, in view of the frequency of meningeal hemorrhage in hereditary syphilis, postulated a syphilis hemorrhagica neonatorum which he referred to a syphilitic disease of the blood vessels. Fischl could not find this vascular disease following syphilis, but took the position that one could speak of a clinically established hemorrhagic diathesis in hereditary syphilitic children.

Freud, from whose most excellent monograph on cerebral diplegia I have in part taken the foregoing data, expresses himself carefully regarding the rôle which should be ascribed to syphilis as an etiological factor. He does not go further into the matter, and advances only the following statement which at any rate shows that he regards hereditary syphilis as very suspicious in this regard. After he has explained that in all probability a number of cases of Little's disease may be regarded as congenital disturbances in a narrow sense, he further says: "The second point whose extended treatment I later abandoned, concerns a factor of the congenital etiology which to me, as to other authors, seems called upon to fulfil an important etiological rôle. I mean the factor of hereditary syphilis. I have momentarily abandoned the gathering together of the sparse and not yet available material 
which speaks in favor of a special hereditary syphilis of the nervous system, and for its valuation in the etiology of cerebral palsy in children, because I entertain the hope that such a collection will be able to give a positive result in a few years. I personally confess to the expectation that in this question as in the tabes-paresis problem, we shall all come to the standpoint which Fournier long ago anticipated.

Later the general spastic diplegias of Little, as well as the paraplegias have been grouped under the general conception of infantile cerebral palsy. This is done on good grounds, because under the influence of different disease processes quite similar disturbances can develop also in the later years of childhood, and because on the other hand it is understood that one is not always in the position to determine whether paralytic symptoms, which may be observed in children of one to two years of age are to be referred mainly to parturition and not to disease processes which attack the child brain in infancy. One would consequently work much more profitably, if one investigated, in how far syphilis is concerned etiologically in cerebral palsies of children in the widest sense. A separation of the cases referable to lues from those of other etiology seems at the present time hardly possible from clinical standpoints. Zappert is correct in his statement that the cerebral palsies of children, in general, are not nosological entities, but are only to be regarded as the terminal stages of different forms of brain disease. Dementia with paralyses, in the sense of cerebral infantile palsies, can have as a cause an infectious encephalitis following scarlet fever, measles, whooping cough, as well as an embolus, a thrombosis, also a syphilitic endarteritis, or a meningoencephalitis. One knows that here syphilis plays no slight rôle as one has frequently observed children with hereditary syphilis among these patients. In any individual case it will naturally be very difficult to determine a relationship with syphilis when other syphilitic symptoms are absent, and the history denies it. According to Zappert, a subdivision according to etiological standpoints is rendered further difficult because either by reason of the indolence of the parents, or by the variability of the initial symptoms, all descriptive history is lacking and nothing can be learned concerning the beginning of the paralysis.

Hence it is not very promising to prepare statistical collec- 
tions concerning the rôle of syphilis in infantile cerebral palsy. One should start not from the children but from the positively syphilitic parents and seek to determine how frequently one finds the symptom complex of infantile cerebral palsy in the descendants of syphilitics. So far as I know this has never been done. König was formerly of the opinion that syphilis played no rôle in the origin of infantile cerebral palsies, and he designated as causative moments only severe, $i$. e., asphyxic parturition, trauma to the head, and infectious diseases. Later he published three cases of infantile cerebral palsy with syphilitic genesis, and recognized hereditary syphilis as a fourth etiological moment. Still later he calculated the rôle of syphilis as causative for these known forms of weakmindedness at 7 per cent. Fournier did not miss syphilis in any of his cases, also Althaus. On the other hand, Wachsmuth found in 185 idiots 22 with cerebral palsy, and in no case could syphilis be proven in the parents.

Such statistics, when not derived from the parents, or when they concern a large material from the higher classes, have scarcely any conclusive force. The necessity for an objective method of determining hereditary syphilis, exists here in large degree, and it will be taken up later, whether, and in how far, serum diagnosis can be utilized here.

In addition to infantile cerebral palsy, which is further an object for psychiatric consideration, because in the majority of cases it is accompanied by mental weakness, there are still groups which, if I may so express it, are purely psychiatric and where for the one the influence of hereditary syphilis is to be regarded of importance, in another, syphilis is to be valued as of less importance, and finally another in which syphilis plays no part at all. I have here in view cases of pure psychical defective states, beginning with the mildest debility and psychopathic inferiority, and rising to the most severe forms of deepest dementia; cases, which are separate from those just spoken of in that they run their course without any paralytic phenomena.

Whether there exists a form of congenital feeble-mindedness of severe grade due to hereditary syphilis is at the least questionable, and not very probable. It is improbable because we must here introduce as a cause a syphilitic brain disease going on in utero, which, as is well known, takes place often, but which, at 
the same time, almost regularly leads to the death of the fœtus. One can therefore scarcely reckon it as a notable factor in the origin of idiocy. Idiocy of a marked grade in children may be regarded, so far as syphilis comes into consideration, as the result of an extra uterine syphilitic brain disease undergone in infancy. In the majority of cases the disease sets in with the unmistakable signs of a severe brain disease, as the result of which can be claimed without difficulty the later demonstrable, more or less marked weak-mindedness. It does not seem necessary, however, for a brain disease which leads to mental enfeeblement to show itself in every case as an acute disease. I shall later come to speak of cases, which developed very gradually, without convulsions or fever, altogether without signs of organic disease, which arrived at a definite termination, and which left behind, as a result, entirely stationary, perhaps even educatable and improvable idiots. Should such a disease set in early, and the afflicted child not be carefully observed, one would in such a case have no possibility of separating a congenital from an acquired feeblemindedness. Finally a separation of hereditary syphilitic weakminded types into those with and those without motility disturbances can only be purely symptomatological and have absolutely no nosological significance. I have lately been able to study such a case in which this is made very evident. Here the disease showed itself in infancy in the form of a hemiplegia; the paralytic signs however disappeared completely after a few weeks, whereas the intellect suffered a severe and permanent injury.

The pathological processes, whose expression can be such different clinical forms, do not differ essentially in their nature from those of cerebral syphilis of adults. We find syphilitic endarteritis with its highly variable localizations, isolated gummatous growths, gummatous infiltrations, meningitis, and meningo encephalitis. In the majority of the cases, however, numerous diseased forms exist side by side. That the results clinically are more marked than in syphilis of adults is due to the fact that here the syphilis attacks the developing brain, and that there results, in addition to the destruction, a retardation of development.

While we now have to deal with specific syphilitic diseases of the nervous system, hereditary syphilis as a predisposing 
moment in the origin of a number of other diseases of the nervous system should come into consideration, and particularly in the sense that it brings about a diminished resistance of definite tracts. The portions involved show themselves not to be developed to the demands which normally are put upon them, and early become functionally incapacitated. Syphilis comes into consideration here as an etiological factor only in a wider sense. These are the hereditary forms which Fournier has brought together under the parasyphilitic diseases of the nervous system.

Whether and how far syphilis plays a rôle certainly cannot be stated without hesitation. It is for the time being a purely hypothetical statement founded on certain clinical impressions. The forms belonging here show a family type. There come in consideration the spastic family affections of purely spinal or cerebrospinal type, the hereditary ataxias, the muscular atrophies, etc. One can here conceive of an injury to the germ, and the affections must be regarded as endogenous in the truest sense of the word. The boundaries of the parasyphilitic diseases are at the present time much widened by many and are extended to diseases in which true syphilitic processes cannot be excluded. I mean here, among others, the well-known cases of spastic paralysis with idiocy published by Homén. Here the "para" is more the expression of caution, in view of the absence of certain signs of hereditary syphilis, than a truly grounded scientific consideration.

These cases lead over into the uncommonly important, and for the present in no manner solved, questions concerning psychical degeneration on an hereditary syphilitic basis.

The type of the hereditary syphilitic child without any tangible disease has been formulated by Fournier on the basis of his great experience. It includes children who are backward mentally and physically_ “les enfants arrièrés." Fournier describes them as unintelligent, simple, silly, limited children. They develop slowly and with difficulty both physically and mentally. They get their teeth late, remain small, anæmic, stunted. Further than this they begin to talk late, learn to read and write with difficulty, their vocabulary is small, their memory faulty. At the age of ten or twelve their pleasures and plays are those of little children. When grown up they are poor scholars, weakly en- 
dowed, make no true advances, are always behind their companions, "toujours en retard." They are dull, stupid, in a word, not adapted to mental culture. Thus they stay, develop scarcely any further, and are finally inferior creatures with limited mental capacity, but such a child, as Fournier himself has expressly shown in another place, "is not an incapable, an imbecile or an idiot." These are the mildest forms of Fournier's purely mental form of hereditary syphilis. From these relatively slight disturbances severe weak-minded forms may suddenly develop. The cases which Fournier describes further awakens the suspicion that, in part, they may have been juvenile paretics. As Alzheimer has convincingly shown, juvenile paresis not infrequently develops in imbecile syphilitic children. From Fournier's description it appears that there existed pure intellectual inferiority.

According to Ziehen's experience cases of mild weak-mindedness develop not infrequently on a basis of hereditary syphilis. Ziehen reports that he has made a careful statistical study in mild congenital weak-mindedness. He found hereditary syphilis probable in 17 per cent. and certain in Io per cent., a truly astonishing high percentage. Here also pure intellectual inferiority is involved.

Other forms of congenital syphilitic weak-mindedness in which the intellectual inferiority is only a portion of the difficulty or is much less marked than disturbances in the development of the moral and emotional qualities are not described by Fournier, but on the other hand have been observed by others. Pieper describes two hereditary syphilitic children which apparently belong here. One case is that of a boy who from early youth showed a striking, over excitable, choleric, destructible nature, since his eleventh month, convulsions, no paralytic phenomena. The second case is that of a boy whose father suffered from syphilis and had a psychosis (paresis?). As an infant he showed definite signs of syphilis. Between the first and third years he had convulsions. When grown up he went to school but without success, committed all kinds of foolishness, attempted suicide in which he endeavored to poison himself with oxalic acid.

Kowalewsky describes neurasthenia on the basis of hereditary syphilis. According to him the children are anæmic and scrofulous, are highly excitable, nervous and moody. Kraemer also 
reports hereditary syphilis as an etiological factor in the origin of nervousness in children.

Not infrequently, hereditary syphilis, according to Nonne, shows itself in the form of a general irritable weakness of the nervous system. He reports two observations of this type. The first child came from a father who was infected with syphilis six years before the birth of the child, and two years before the birth was treated with inunctions because of a specific iritis. Neither parent was nervous, and no neuropathies were present in the ascendants of either. From the beginning of his life the child was strongly excitable, later suffered greatly from headaches, from anomalies of mood, obstinate insomnia and irregularity of appetite. External signs of syphilis could not be found. Large doses of potassium iodide were given with the result that the child slept again, became much quieter, lost the pathological irritability, and at the same time began to grow. Concerning the other child Nonne further reports, that he came likewise from a syphilitic father, but developed normally both mentally and physically. $\mathrm{He}$ learned, however, with difficulty, notwithstanding marked effort -he could fix his attention only with difficulty. The child was very active and easily frightened, slept restlessly, was a bad eater, and had chorea at the age of six years. Rapid improvement of all the symptoms followed the use of potassium iodide.

According to the observations of well known authors, it seems also that there is a psychopathic inferiority in syphilitic children in which the involvement of the intellectual field is not the most important. Such observations, at the present time, so far as the literature is known to me, have been made only in isolated cases.

This short summary should limit itself to disturbances which, at the time of the investigation, do not show any disease process proper, but only defective states which result either from a past specific affection of the nervous system, or which may be referred back to an injury founded in the germ cells. As a matter of fact, as has already been noted, it is almost impossible to make a distinction, for there are syphilitic processes which set in in infancy and because of the slight symptoms which they show cannot be looked upon as definite diseases.

Wherein then can one recognize that a weakminded child, with 
or without paralytic signs owes this disturbance to hereditary syphilis?

Does the psychic behavior, or do the eventually present disturbances of motility show such characteristic signs as to permit a differential diagnosis from similar forms of other etiology? There is hardly any doubt that the disease picture for the most part does not show anything which may be regarded as of differential diagnostic value, or at least we are not yet in a position at the present time to recognize peculiarities of psychical disturbances as syphilitic. On the other hand the motility disturbances which are found in many cases are so various and agree so completely with the results of other and different disease processes, that they also only very occasionally admit the possibility of recognition as being due to syphilis. Properly speaking only the behavior of the pupillary reactions gives valuable diagnostic support. If there is marked disturbance of the pupillary reaction, chiefly isolated immobility to light, we may assume with some probability that a syphilitic process is at the bottom of the disease picture. An absence of pupillary disturbances naturally is not evidence against the syphilitic etiology.

Consequently, since the essential psychical and neurological disturbances present do not place us in the position to form a judgment concerning the cause of the disease in question, we must rely, as far as syphilis is concerned, first on the history, and then upon the existence of the so-called syphilitic stigmata.

The history, directed to the proving of syphilis, will include the parents, the brothers and sisters, and then the child itself. The course of the pregnancies with their characteristic progress, will give valuable indications-abortion-dead child-full-term syphilitic child-syphilis-free child. At times the anamnesis findings are so striking as to prove hereditary syphilis, while again on the contrary they leave us entirely in the dark. In the first place we can, without any further question, conclude that a weakminded child is such on the basis of hereditary syphilis when we prove only that the father once had syphilis. If the child itself has never had any signs of syphilis; if in the series of births there have been no abortions, and no dead children, nevertheless one may always hold the possibility of a relationship between the disease and hereditary syphilis; but one cannot yet avoid con- 
sidering the possibility of the condition. How often is one deprived entirely of the possibility of obtaining a reasonably reliable family history and must support one's self entirely upon the symptoms which the disease picture itself shows, and that at the time of the investigation. When one learns that the child had an eruption as an infant, one will not be able to discover in many cases in which a medical examination has not taken place whether one has to deal with a syphilitic exanthema.

There will further be an especial difficulty because in early childhood syphilitic brain disease can run its course without necessarily showing external manifestations of syphilis, either before or after. And now as to the individual characteristic stigmata of hereditary syphilis. It cannot be disputed that they are present with such clearness in many cases that they constitute a certain guarantee. But difficulties are also present here. Take for instance the classical Hutchinson triad-cresentic rounding of the upper middle incisors-interstitial keratitis-deafness. None of these affections are found in young children. The Hutchinson teeth belong to the second dentition, and also the other two signs first develop, according to Heubner, between the tenth and twelfth years, much less often about the fifth to sixth years. The first periods of childhood do not offer these important criteria at all. Further it is to be observed that not all authors consider the Hutchinson triad as decisive hereditary syphilis signs. The Hutchinson tooth is designated as entirely uncharacteristic, for instance, by Hochsinger who most certainly has had a great deal of experience. Hochsinger lays stress upon the fact that this dental anomaly is the result of a disturbance of nutrition which affects the tooth germ during its quiet period in the jaw; not syphilis alone, or not only the inherited, but every severe general disease (rachitis, scarlet fever, typhoid, etc.) which affects the child during the period of development of the roots of the resting incisors can give the same effect.

If there is anywhere a need for a sure objective method of diagnosis that need is especially great in the diagnosis of syphilis from all that has been said. Can serum diagnosis be utilized at all here, and if so, in how far is its use possible?

It can be said, once for all, that the reaction shows hereditary syphilis in the same manner as the acquired-and that often 
the reaction is very strong. Furthermore, as Bauer has shown, the blood gives the reaction even in infancy.

Besides it naturally is limited to the same boundaries as in acquired syphilis. Only a positive finding is evidence. A negative finding may be found, although certainly rarely, in florid syphilis, still oftener in latent syphilis. A negative blood finding permits one to rule out the occurrence of a juvenile paresis fairly positively, even as the same is the case in paresis due to acquired syphilis.

In the forms which make up the most important portion of the present observations-the stationary forms of feeble-mindedness -we have to consider defective states on the basis of syphilitic brain disease. The feeble-minded children may be healthy so far as syphilis is concerned when we have studied them-it may have left the body entirely or naturally it may as well be present in a latent condition. With reference to syphilis itself we are concerned for the most part with cured or latent cases. Therefore, we may expect only the same percentage of positive results in the blood reactions as one finds in the tertiary latent stages of acquired syphilis, $i$. $e$., about 50 per cent.

In single cases a positive blood finding permits only a diagnosis of syphilis independent of the fact whether at the time of investigation syphilitic processes are going on or not. One also finds here positive reactions in cases where, for years. specific processes have no longer appeared, where also no clinical evidence of the continuance of the infection is present. Conclusions regarding the localization of the syphilitic process, for instanceconcerning the syphilitic origin of the present weakmindedness can also be drawn here under certain precautions. A hereditary syphilitic child can dement just as well following a scarlatinal encephalitis as following a syphilitic meningo encephalitis, and if,- - and this is questionable-an external syphilitic manifestation is required for the appearance of the reaction so can the remains of an interstitial keratitis or any other specific alternation be completely satisfactory to explain a positive finding. If one then would deal so carefully with the valuation in single cases it is certain that the assurance of syphilis diagnosis represents an uncommonly valuable assistance in the series of clinical methods for the etiological interpretation of disturbances in the field of 
the central nervous system in childhood. One should not blindly explain a weak mind as due to syphilis if the blood reacts positively. One should, however, consider in large degree the probability in such a case, provided that no other indications of any other form of etiology are present.

In the following I shall describe the first series of observations made with the Wassermann serum diagnosis of syphilis in psychic defects of childhood.

The material is not large, but it is valuable in that accident has given me a series of entirely different forms. The differential diagnosis between acute syphilitic and metasyphilitic disease processes is of little moment and in reality it comprises the diagnosis of stationary forms of mild and severe grades of weakmindedness in children. The material was drawn from three sources. A few cases were received in our clinic; we are under obligations for the friendly coöperation of Professor Pfaundler, of the University Clinic for Children for a second group. I further investigated a series of children who were under treatment for skin affection in the Reisinger Polyclinic, and among the few that could be found, there was a high percentage of children with nervous disturbances. In this place Professor Seitz should also be thanked for his kindly passing over of the cases. As for the rest of the material, I studied without choice the descendants of a number of paretics of our clinic. Concerning these serological methods for family research I will say something later in this connection. In the majority of the children the investigation had to be limited to the blood, and only in a few was the spinal fluid tested at the same time. Finally in a few cases the spinal fluid only was available.

I should like once more to call attention to the fact that the blood serum is the body fluid, by means of which the Wassermann method for the diagnosis of syphilis has to be made. The spinal fluid in general shows itself to be free of syphilitic reaction products, even when the blood serum is positive. It reacts positive only in paresis, and occasionally in the-in the narrow sense-non-metasyphilitic diseases of the central nervous system. A negative result, so far as the spinal fluid alone is concerned, proves nothing against the presence of syphilis, and in general does not allow of any conclusion concerning the behavior of the serum in the particular case. 
The cases in which I investigated the spinal fluid alone, so far as the result was negative, are therefore, for the reasons given, not to be considered entirely negative biologically, but one must decide the question in how far the negative result should be valued in regard to its speaking with some probability against the presence of juvenile paresis.

In all, $5^{8}$ children came to hand for investigation, as follows: In 48 cases only blood serum, in 6, serum and spinal fluid, and in 4 the spinal fluid alone was examined.

With the exception of one case of infantile cerebral palsy there was definite support given for the possibility in all cases that hereditary syphilis was present. To be sure the children who were treated by us in the children's clinic, or the polyclinic, for nervous or other appearances of hereditary syphilis, and who therefore were used for study, made up only a small portion of the cases. The majority of the children showed no certain signs of hereditary syphilis but nevertheless came from families in which, by reason of paresis in the father, the possibility of hereditary syphilitic taint was present. Because of this one finds in the material many cases which showed on the part of the nervous system, either insignificant disturbances or none whatever. In the first place I shall speak of those cases which evidenced nervous affections. Completeness with reference to the clinically possible forms cannot be thought of in the least. There is at my disposal only a series of cases which $I$ have brought together into separate groups for the sake of clearness.

\section{Juvenile Paresis}

I cite these cases only because, for the sake of completeness, it seems desirable to use clinical material to present also the relations of the Wassermann reaction to juvenile paresis.

\section{ObSeRvation 50}

Previous History.-Ludwig Z., I5 years old. Admitted December I0, 1906. Illegitimate child, mother waitress. Concerning the infection of the mother in relation to the unmarried father nothing is to be learned. Previous to the birth of the patient three abortions, four other children died young. Patient himself was born with an eruption. He developed normally both mentally and physically, learned to walk and speak at the 
normal time. Up to his twelfth year he did well at school. In the year 1905 a change in his character occurred. He could learn nothing more, his memory failed, he became unclean, ate everything he could get hold of, talked foolishly, and convulsive attacks occurred.

Physical Status.-A strongly developed boy in good state of nourishment. Eye grounds, right, advanced optic atrophy, left, not observable because of the opacity of the cornea. Pupils immobile, right wider than left. Patellar reflexes not obtainable. Hypalgesia. Distinct paretic writing, speech slurring, monotonous.

Mental Status.-Far advanced dementia. Foolish euphoria. Gives irrelevant answers to most questions. Name and age correctly given; orientation for time and place lost. The patient gradually became absolutely helpless, blind and could no longer speak connectedly. Finally he had convulsive attacks from which he died June 18 , 1908.

Cytological Findings.-Increased lymphocytosis. Biological findings: spinal fluid and blood serum positive.

The autopsy confirmed the clinical diagnosis.

\section{OBSERVATION $5^{1}$}

Otto P., I5 years old. Admitted May 8, I906.

Previous History.-Infection on the part of the parents denied. Patient is the only child. No mental disease in the family. The patient developed normally, physically and mentally, up to the seventh year. $\mathrm{He}$ did very well one year in school. In his seventh year he had general convulsions with loss of consciousness, following which he remained behind physically, could not advance in his studies, and gradually became more and more demented. He remained in school until his thirteenth year, but advanced only up to the second grade of the common school. In 1905 he had more attacks without convulsions. He fell down, could get up himself and it appeared as though he fell from carelessness. A further psychic change now developed in that he was very easily angered, and was ill natured, cried and screamed. For three weeks he has soiled himself, is unable to walk, crawls around on the floor.

Physical Status.-Moderately well nourished, weak muscles, knees bent at an angle of $100^{\circ}$, developed marked rigidity in attempts to straighten. Patient can reither walk nor stand. Grasping movements slow and with mild ataxia. External muscles of the eye and facial muscles show no disturbance. The pupils are dilated, equal, immobile to light and convergence. Hutchinson teeth. General hypalgesia. Active knee jerks. Patient does not speak, only occasionally uttering inarticulate sounds.

Mental status.-Patient is in a state of deep dementia. Soils himself with urine and fæces. Grasps at objects held in front of him without paying any further attention to them, or sticks them aimlessly in his mouth. In the course of further observations the contractures increased more and more, and the patient has had a series of attacks. The patient is still in the clinic.

Cytological Findings. -28 cells in I cu.mm. Biological findings positive for spinal fluid and blood serum. 


\section{OBSERVATION 52}

Ludwig Schw., I3 years old. Admitted April 25, 1908.

Previous History.-The parents deny syphilis. Before the birth of the patient three miscarriages in the sixth month afterwards a seven months child that did not live, then a weakminded child; following this three living children, the last of whom required treatment for a syphilitic eruption. Patient himself was born at the normal time. Immediately after birth cold in the head; at the age of six weeks an eruption (inunction treatment). Later no further eruption, however he had a wet eczema of the head. He then developed very well physically. No attacks of anger nor fainting spells. Mentally the patient was well endowed, studied with much eagerness and advanced well in school. He was a good boy, tractable, and not nervous. The patient first showed bad signs in the summer of 1907. In contrast with his former state he learned with difficulty, took this to heart, bemoaned that he could not advance. In September, 1907, he had a convulsive attack with loss of consciousness, generalized convulsions without biting the tongue. After the attack, for an hour, he could only loll; the next day also the speech was bad. Since the attack it has not returned to its former state, other paralyses were not observed. A few days after the attack he again went to school, but he could no longer grasp anything and could not observe. He became very excited because he could no longer work, cried a great deal, was not as ambitious as before, and was afraid of bad marks. Since then he has had no further attacks but has complained often of headaches. Patient deteriorated mentally more and more, one had to direct him repeatedly if he had anything to attend to. Externally he kept himself clean as before. Emotionally he was excitable, which he had not been previously, kept to himself, was at times dejected, and cried a great deal.

Physical Status.-Thriving exterior. Very strong and normally developed for his age. Pupils are unequal, react slightly to light, left somewhat better than right. Reaction to convergence present. Patellar reflex very active on both sides, left stronger than right. Ankle clonus present on both sides. No Romberg. Trembling of muscles of the face on speaking. Speech somewhat slurring; with difficult test phrases, stumbling. Eyesight normal, hearing good. Teeth mostly carious, upper incisors with straight cutting surfaces.

Mental Status.-Oriented for time and place. Gives correct answers to the majority of questions. School knowledge still passably retained. A marked difficulty in the answering of somewhat complicated questions is striking; after long reflection these are for the most part answered relevantly. $\mathrm{He}$ is very quiet, indolent, shows no interest in his surroundings, lies down stupidly without doing anything. Should one read something to him, he can reproduce the contents only incompletely. The writing shows no gross changes.

Cytological Findings.-Lymphocytes markedly increased. 273 cells in I cu.mm.

Biological Findings.-Spinal fluid and blood serum positive. 


\section{OBSERVATION 53}

Alfons D., I I years old (University Children's Clinic). Admitted October, I907.

Previous History.-Concerning syphilitic infection nothing can be obtained. The mother noticed nothing strange with the child in the early years. In his fourth year it was determined by the physician that the patient was nearly blind in the right eye. He was always an apathetic - boy and did not play with other children. In August, 1907, attacks first appeared, as often as six in one day. After about one minute he would stand up, somewhat dazed, and begin to walk about; became soon completely clear. At times while eating he suddenly stretched his hand out so that the object which he held in his hand was thrown out. At these times consciousness was not disturbed. A speech disturbance was observed from the time of the first attack.

Physical Status.-A delicate and weakly boy, behind his age. Distinct appearance of the veins of the skin in the region of the back and sacrum. No deformity of the skeleton. Both active and passive movements freely performed. Pupils much dilated, scarcely contracting on exposure to light. Mild convergent strabismus. Borders of optic disc somewhat obliterated. Plaques of chorio-retinitis in the region of the papillæ and in the periphery. On the margin of the papillæ there is a change in the pigment which must be interpreted as due to an old meningitis of the optic nerve. No double vision. All of the reflexes were markedly increased. No ankle clonus.

Definite changes in sensibility were not in evidence. The gait is somewhat stumbling-spastic, ataxic. The lips tremble in speaking. Speech is indistinct and slurring.

Mental Status.-Knowledge very slight, writes and reads a few letters, fails in the simplest arithmetic examples, names of the months impossible, the days of the week in part only. He gives his own age correctly. Is very irritable. Often grabs hold of other children, makes a fist and hits them on the head with it. In the clinic a number of attacks were observed, with involvement principally of the right side.

When the patient was again admitted in January, in the meantime having gone home for a month, he seemed to have gone backwards, both bodily and mentally. He could not then even give his age. $\mathrm{He}$ has numerous attacks, and in the time between has frequent outbursts of anger with crying and screaming.

Biological Investigation.-Spinal fluid positive. Serum not investigated.

With reference to the results of the biological investigation, juvenile forms of paresis behave the same as paresis in the adult. The spinal fluid as well as the blood serum reacts positive. In the last case described the investigation of the serum was not made. However, the result here would probably have been positive since, according to our experience, when the spinal fluid reacts positive the serum does not vary. 
The difficulty of obtaining anamnestic proof of syphilis in children is here shown very distinctly. Only in one case could infection be determined with complete certainty.

The first two and the last case were in advanced stages of the disease, the third in a relatively early stage.

With reference to the strength of the reaction in the blood, all of the cases behaved very nearly alike. In the second case, which ran such a strikingly long course (it lasted nine years) the serum reacted distinctly stronger than the spinal fluid-an observation which is often made in the slowly advancing cases. On the other hand, it is of importance to call attention to the fact that in the third case which was in the beginning of the disease, the spinal fluid reacted very intensely, and was scarcely less marked than the reaction of the serum.

Clinically it may be observed that the first three children were not imbecile before the disease-only in the fourth case was there a congenital feeblemindedness present. In all of the cases there were paretic convulsive attacks.

\section{Infantile Cerebral Palsy With Feeblemindedness}

\section{ObServation 54}

\section{Marie M., 13 years old. Admitted February 28, 1908.}

Previous History.-Patient is the oldest of five living children. One child born previously, from another father, died one hour old, no abortion. Mother is not married. Has never observed anything suspicious of syphilis upon herself or her lover. The father has a stomach complaint, has had "typhoid in head" (?) but no alcoholic abuse. After the patient's birth and until she was a year old, the patient had a strong tremor of the eyes. Up to the fourth year she was sickly, began to speak and to run at the age of two years, and then developed well both physically and mentally. Information relative to syphilitic symptoms not obtainable. She was always very peculiar in her manner, did not play with other children. Was however bright. At the age of six she entered school, studied exceedingly well and obtained good marks. At the age of nine while out riding she fell out of the wagon; the accident was however very slight, the child was not injured, was not unconscious and showed nothing striking. The day following she had a convulsive attack. It began with convulsions in the arms and lasted six hours. She was unconscious and soiled herself. Afterwards she gradually retrograded mentally. The teachers told the mother that the child was no longer normal, she could not write and could not observe. In November, 1906, she had a second attack following which the right side was paralyzed, she could not speak and vomited. The condi- 
tion lasted eight days and was designated by the attending physician as hysteria. Exactly one year later there was another attack which began with vomiting. After the attack the child could not raise her right arm, the leg was apparently not paralyzed. In January, 1908, another attack with loss of speech and paralysis of the right arm. The speech which up to this time had recovered after the attacks was now worse, and the child became increasingly more demented.

Physical Status.-Fairly good condition of nourishment, hardly at all behind her age. General stiffness of all the extremities. The disturbance is a little more marked in the legs than in the arms. No distinct paralyses; however, in addition to the increased tonus of the lower extremities, there is a fairly uniform paresis observable. The feet are extended, the gait is spastic-paretic on the balls of the feet. Choreic unrest of the entire body. No distinct ataxia. Gross muscular force still well preserved in all extremities and without noteworthy differences. Pupils do not react to light or to convergence. Skin and mucous membrane reflexes still present. All of the tendon reflexes extraordinarily increased. Patellar reflex obtained on striking the periosteum. Marked ankle clonus on both sides. Babinski reflex distinct on both sides. Tests for sensibility not possible; at any rate there is no diminution to pain; rather a mild hyperalgesia. Speech lolling; no external signs of hereditary syphilis.

Mental Status.-Very confiding, obedient, cleanly, but at the same time very querulous and anxious. Knowledge very slight. Simple objects correctly named for the most part. She cannot tell time and only the simplest arithmetical questions can be solved with the help of the fingers. She busies herself by the hour alone with building blocks, claps the hands and laughs like a little child when the physician comes. Keeps herself clean and shows much tenderness to her mother and brothers and sisters.

An inunction treatment was given without showing any improvement. Cytological findings mildly positive (Io cells in I cu.mm.).

Biological Findings.-Very weak in spinal fluid, strongly positive in blood serum. (Relations: $t: t+++$.)

The chief features of the picture are as follows: Neither the history nor stigmata gave evidence of hereditary syphilis. Up to her ninth year no marked disturbance physically or mentally. Then there occurred an attack with paralysis, then three more attacks and gradually increasing dementia. At the present time marked feeblemindedness, spastic paresis of the lower extremities, the same, though less in the upper limbs, absolute immobility of the pupils, increase patellar reflexes, ankle clonus, Babinski, lolling speech. The external picture is that of an infantile cerebral palsy of the spastic paraplegic type. The diagnosis here is between cerebral syphilis and paresis. A definite differentiation is at the time not available. A great probability exists, how- 
ever, that a syphilitic process is here present because of the marked disturbance of the motility, the loss of light and convergence reactions, and finally because of the character of the mental enfeeblement. In spite of marked intellectual deterioration, there is no marked alteration in character. The child has a good manner, is clear and shows a marked tenderness to her family. It is noteworthy that the history completely denies syphilis. Nevertheless, the blood of the mother and that of the younger sister is positive.

\section{OBSERVATION 55 .}

Marie G., nine years old.

Concerning infection nothing to be obtained. No abortions. Before the patient was born three children died of convulsions a few days to a week old. They were all delivered at term and did not suffer from eruptions. After the patient no further children. Patient had a syphilitic eruption at the age of three months (diagnosed in the pediatric polyclinic). At the age of 12 months she had a right-sided paralysis. From this time on convulsive attacks often in series of from ten to twelve attacks one after another. In the fourth year paralysis of the left arm, which disappeared after eight days. After this attack the child was blind for three months.

Status.-Spastic paralysis of the right extremities. Right leg and right arm somewhat shortened. Patellar reflexes, both sides active, not different. No ankle clonus, no Babinski. Hydrocephalus, saddle nose, Hutchinson teeth, pupils maximally dilated, immobile to light and accommodation. Pin prick felt everywhere.

Mentally, the child shows advanced idiocy-speaks only a few words, and these only for the past year.

Biologically the blood serum is positive.

We have here a syphilitic disease of the brain which had already set in by the first year, and which had produced a hemiplegic form of infantile cerebral palsy. One cannot, as in the first case, speak of any progression. We have the results of an already finished process. Here also, the loss of the pupillary reactions speaks for a syphilitic genesis, but in contrast to the first case, hereditary syphilis became manifest soon after birth, and at the present time the child shows many manifest stigmata of hereditary syphilis. As a common opposing factor in both cases, the parents knew nothing concerning an infection. The blood of the mother did not give the Wassermann reaction. 


\section{OBSERVATION 56}

Therese W., $4 \frac{1}{2}$ years of age.

Father died of tabes, had syphilis in his military time, was treated by inunction. He died the same year the patient was born. Mother reported to have always been well, nothing suspicious of syphilis observed.

Children as follows: (I) Alive, 22 years of age, at the age of $I$ an eruption (syphilis?) ; (2) died at the age of six weeks; (3) alive, 20 years old, nervous, sickly; (4) abortion; (5) died at age of three months; (6) abortion; (7) died at the age of six, of whooping cough; (9) Therese (patient).

The patient, ninth in the order of birth, came two weeks before her term. At the age of three weeks she had vesicles on her hands and feet, and later an eruption appeared; spasm of the glottis at the age of nine months. Following this the right arm was weak, probably also the right leg. At the age of two years and a half meningitis, following which the right leg was less movable. For a few months she has begun to run and speaks only one word "Mama."

Physically.-Spastic paralysis of the right leg with contractures of the knee joint. Right arm slightly paretic, with slight amount of spasm. Marked hydrocephalus; defective teeth. Tendon reflexes somewhat increased, no ankle clonus. Pupils react slightly to light, somewhat better to convergence.

Mentally.-Severe grade of idiocy. The biological investigation unfortunately could not be made as the withdrawal of blood was not permitted.

I cite this case because, like the preceding, it shows the hemiplegic form of infantile cerebral palsy which is highly probably the result of a syphilitic brain disease. This case is also noteworthy because the father was already tabetic at the time of procreation, and notwithstanding this such severe syphilitic symptoms appeared in the child.

In conclusion a case of infantile cerebral palsy is cited in which neither the history gave anything suspicious of syphilis, nor the child herself showed any proof in this direction. Here, however, the disturbance of the nervous system had developed following a disease with fever.

\section{ObSERVATION 57}

Anna Tr., Iot years old.

Previous History.-Syphilis of the parents denied. Patient is a single child. No abortion, no further births. Patient was not born prematurely, had no eruptions, no appearance indicative of syphilis. At the age of six months, in connection with vaccination, she had a high fever, and could not raise the right arm. Later, as she made her first attempts at 
walking it seemed as though the right leg were also paralyzed. The paralytic signs gradually improved. Convulsions or fainting attacks were not observed. The child is very nervous and easily frightened, and in earlier years suffered from pavor nocturnus. Mentally she is far behind those of her age. She advances in school only with trouble and care and not without repetition of her classes.

Status.-Weakly, not developed up to her age. Right arm and right leg show distinct spasm and choreic movements with mild paresis. Patellar reflex exaggerated on the right side, no ankle clonus, no Babinski. Teeth grooved, carious. Pupils react promptly to light and to convergence. No disturbances of sensibility. Dull, slow, abstracted. School knowledge very slight, anxious at the examination.

Biological examination of serum negative.

\section{Summary}

These four cases show three different types of infantile cerebral palsy. In the first case there was an unhealed syphilitic disease at the base, probably a meningoencephalitis; the second and third cases were very similar. The disturbance was to be traced back to a hemiplegia in the first year of life, probably due to syphilitic vascular disease. In the fourth case a hemiplegia had developed following an acute infectious disease. Probably here a nonsyphilitic infectious encephalitis had played a part. With reference to the serological findings, case 3 must be eliminated, since the investigation could not be made. Cases I and 2 reacted positive, case 4 negative. The results of the reaction agree with the clinical findings. In case 2 syphilis is certainly shown through the tabes of the father, and by other unquestionable hereditary syphilitic symptoms in the child. In case $I$, on the contrary, the history is lacking, and the child showed no hereditary syphilitic signs, so that here the positive serum reaction was of great importance for the etiological explanation of the case.

The fourth case which showed itself negative serologically clinically also gave no evidence of a syphilitic genesis. The three syphilitic cases separate themselves uniformly from the fourth nonsyphilitic case through the difference in behavior of the pupillary reaction. In all of the syphilitic cases there was marked involvement of the pupillary reactions; in the nonsyphilitic case there was prompt reaction of the pupils. 


\section{Acquired Feebleminded Forms Without Motor Disturbances}

\section{OBSERVATION 58}

Josef Sch., 9 years old. Admitted April 28, 1908.

Preliminary Note.-Patient is the brother of observation No. 52 (juvenile paresis). Concerning the other members of the family, a summary will be given later.

Previous History.-The parents deny syphilitic infection. Patient came at full term. The delivery was easy and required no artificial aid. Following birth the child was very weak. At the age of six months had an eruption over the entire body (not observed medically). Developed well during the early years, was very strong and looked robust. Mentally also he seemed to develop well, began to speak before one year old, was active and confiding. At the age of $\mathrm{I} \frac{1}{2}$ years a very striking change took place in the child's manner, without the appearance of any fever, convulsions or other sign of bodily illness. He ceased to speak, was anxious, shy and repressed. Although he had previously always been cleanly, from now on he comenced to soil himself continuously. Up to the age of five he was entirely demented; could not speak, understood nothing, soiled himself. Physically he developed well. From his sixth year a gradual improvement was noted. He learned to speak a little, knew his relatives, found his way about the streets correctly. He was taken to school, where for three years he remained in the lowest class. He learned to write some, and to read, but only very little. He never had any convulsions. His character is somewhat sullen, irritable, wants everything he sees, and becomes very much excited when he cannot have it.

Physical Status.-Exceedingly strongly built boy in excellent condition. No signs whatever of syphilitic infection in the eyes, teeth, ears or elsewhere. No lymphatic enlargements, no paralyses. Sensibility intact. Pupils react to light and to convergence. Patellar reflexes active. Ankle clonus occasionally obtained. The speech is that of a child of two years. The words are constructed in a childish manner: "Gummiball," "Dummiball:" "Schwan "= "San." Very incomplete articulation, monotonous tones. Grimacing movements, twitching of the angles of the mouth, holds his head bent forward.

Mental Status.-A few objects in his primer are rightly named. His ability to read is limited to small words such as "ein," "ist" and the like, and to single letters. Connected reading is impossible. $\mathrm{He}$ cannot multiply at all; addition of the smallest numbers possible with the aid of the fingers. He gives his age correctly. He has no idea of the divisions of time, the years, the months, etc. His vocabulary is very limited. He is cleanly, tractable, quiet, stupid and expresses no wishes.

Cytological examination negative. Biological investigation of spinal fluid negative, of blood serum positive.

The case is of special interest in that it showed the exact pic- 
ture of a congenital idiocy. If the child had not been well observed in his infancy and the mental changes, which developed without any severe signs of disease, noted, one would have believed as in many similar cases which have developed gradually, that the child had always been feebleminded. The case is a pure example of the "forme mentale" of Fournier's hereditary nerve syphilis. There were never any physical disturbances; the nervous system showed nothing indicative of syphilis; the pupillary reaction, this delicate reagent for syphilitic processes of the nervous system, never showed anything pathological. The child gave no certain signs in support of a syphilitic etiology. All suspicious stigmata were absent and the eruption which the child was thought to have shown at the age of six months had not been observed medically. The parents denied infection, but the numerous abortions which the mother had had as well as the fact that one of their children had juvenile paresis, allows with certainty the acceptance of a very insidious syphilitic brain disease which had run its course without any alarming symptoms. The positive finding in the serum gives further support to this view.

Whereas, biologically, the behavior of the two brothers was the same in regard to the serum, they are different in that the spinal fluid of the first case (Observation 52) was positive, whereas in this case it was negative. This finding agrees with our previous experience in that paresis is characterized by the almost invariable appearance of the reaction in the spinal fluid, while in the true syphilitic brain processes the reaction is rarely found. In the present case one can scarcely speak of the present existence of a cerebral syphilis: the process has run its course and the syphilis is latent, possibly even healed.

I have also observed in later childhood dementing processes which set in without any recognizable signs of an acute brain disease and which led in a comparatively short time to a marked mental weakness.

\section{OBSERVATION 59}

This concerns the eight-year-old boy of a general paretic, Josef $\mathrm{E}$. The father acquired syphilis fourteen years before the birth of the child, was treated for years with mercurial injections, and developed general paresis in 1907. The mother had never noticed anything syphilitic about herself, 
is apparently absolutely well. Her blood, however, reacted positively to the Wassermann reaction. No abortions, none of the children died. Patient himself was healthy and strong. Eruptions or other appearances suggestive of syphilis were not observed. He learned to walk and talk at the proper time, was a very clever, good and in no manner a peculiar child. He had an aural discharge for some time; no eye disorders, no scarlet fever, no fits, and further no convulsion. Up to his first year he developed very satisfactorily both physically and mentally. Then a sudden change set in. He spent a vacation in the country with relatives, and from the time of his return was quite transformed. The relatives had noticed nothing peculiar. The child had had no fever and no convulsions during the vacation. Since then he has kept on going down hill. He can no longer observe, cannot follow in school and suffers much from headaches. $\mathrm{He}$ is stupid, uninterested, does not play, sits alone by the hour staring in front of him, then again he is sulky and obstinate, which formerly had never been observed with him. He continues to be clean as before, and in his conduct is passably orderly. There have been no attacks in the meantime, although his mother noticed at times that he spoke his words with difficulty.

Physically the patient is well nourished, and gave a robust impression. No hydrocephalus. No syphilitic stigmata. Teeth of the first dentition not characteristic. Left pupil larger than right. Reaction to light prompt but not very ample. Patellar reflexes present, not increased. Romberg absent. No disturbance of sensibility. Speech not striking. Writes his name and "München" without mistakes. The patient gives the impression of mental weakness. Cannot tell the present year, and shows little knowledge. He seems quite dull and uninterested, but is quite natural in his conduct and his movements are performed without any peculiarities. Hallucinations do not seem to have been present.

Biological investigation of blood serum positive.

One would naturally first think of paresis here, and that there is a paretic process is not to be ruled out. It is certainly striking that after the disease has lasted now a year somatic symptoms have not yet developed in a distinct manner and also that no attacks, which are rarely absent in juvenile paresis, have occurred. Perhaps it is an insidiously progressing syphilitic dementing process not connected with paresis. In my opinion hebephrenia can be ruled out. It is noteworthy that the child has never shown any syphilitic signs. The positive blood reaction which the child shows, nevertheless, evidences that the certainly syphilitic parents have transmitted syphilis as such to the child, and not that the parental syphilis somehow has caused an indirect, remote injury to the child.

The child of another paretic showed related disturbances. 


\section{OBSERVATION 60}

Anton B., I4 years old.

Father died of general paresis in 1906. The first child is twenty years old and is healthy; then followed four children who died after a few weeks, the last child, the patient, was an eight months' baby. The mother is unable to say anything about syphilis. The child has never shown any external signs suspicious of syphilis. He developed well, learned to walk and talk at the age of one year, at the age of five years he had an eye disease, since which time he squints. He learned very well in school in the first years, then became gradually poorer, and from the age of ten his inability to learn, which apparently was due to weakness of memory, became very marked. For the past year the child has been able to understand nothing. It was also observed that for a number of years the child had bad and exciting dreams, and often gnashed his teeth at night. Convulsions were not observed. Apart from the mental weakness which had developed of later years he showed also a changed character, he became irritable and untruthful. Further peculiar states of anxiety were apparent at times, in which he seemed slightly confused, and almost regularly had the same anxious ideas, namely that the butcher came and was going to stick him. These states last only a minute and the mother is unable to state how much the child remembered of them. For one year he has been quite dull, and without interest. He goes about the streets as though he were blind, as though he knew no danger; one has to pay attention to him to keep him from being run over.

The boy cannot be called very strong, nor yet truly weak. The head measurements are not striking. Left-sided convergent strabismus. No characteristic signs pointing toward hereditary syphilis. The pupils react promptly, patellår reflexes in order, no disturbances of sensibility. Speech and writing undisturbed.

Biological examination of blood positive.

We have here an exquisite chronic progressive dementing process in a child who is suspiciously syphilitic solely because of the paresis of his father. Upon the child himself there was apparently never any syphilitic disease in the sense of hereditary syphilis, and nothing suspicious could be learned by any examination. We must here again think that we have to do with a juvenile paresis. This opinion has, however, less probability in itself than in the previously reported case. Here the disease has been in progress for a number of years without there having developed any signs characteristic of paresis. Pupillary reactions, patellar reflexes, speech and writing are normal. Formerly one would have thought of an epileptic dementia. To support this opinion the grinding of the teeth which appeared at night time may be 
assumed to be attacks as likewise the short dreamy states. The child is, however, certainly hereditarily syphilitic, as the serological examination shows, and with this in mind we may regard as highly probable the possibility that the psychical disturbances are the expression of a chronic progressive syphilitic brain process, especially as we know from Alzheimer's investigations that endarteritis of the brain vessels may bring about disease pictures very similar to genuine epilepsy.

A case of stationary feeblemindedness, following an apoplectic attack, may here be added.

\section{ObsERvation 61}

Josef W., I5 years old.

Preliminary History. - The father had an ulcer on the penis in 1890 , concerning the syphilitic nature of which he did not know, and which was not treated. He claimed never to have had any general symptoms, but came to the clinic with cerebral syphilis. The mother claims never to have observed anything suspicious of syphilis, but had at the time on her neck a tertiary syphilide as big as the palm of the hand, and which she designated as "a harmless spot."

Order of children: (1) Died at the age of I4 days; (2) patient; (3) born dead; (4), (5), (6) miscarriages.

Patient was not prematurely born. At the age of one week he had a right-sided paralysis, which completely disappeared after eight weeks. During the next two years repeated, short epileptic attacks. No eruptions. No snuffles, no eye or ear affection. Was always weakly, began to walk and speak at the age of two years. Mentally he was badiy endowed, did badly in school, grasped with difficulty and paid very little attention.

Status.-Pale, badly nourished, physically deficient. Teeth almost absent. Absolutely immobile pupils (light and convergence). Patellar reflexes increased on both sides, no ankle clonus, no Babinski, no Romberg. No signs of paralysis, also no spasms in the previously paralyzed extremities. With reference to movement, motor force and reflexes, no differences on the two sides. Behaves himself quite orderly and civilly, but shows, however, with the simplest questions a marked intellectual weakness. He does not know the year of his birth, his school knowledge is very faulty, arithmetic very bad, but can read and write to some degree.

Biological investigation of the blood serum positive.

The case is of particular interest in so far as he shows that, in infancy, hemiplegias induced by syphilitic brain disease may entirely disappear so far as the motor symptoms are concerned, whereas the mental weakness caused by the same process remains. The end result is the same as in the preceding case in which no 
paralytic symptoms had appeared, notwithstanding the difference in the beginning. Such cases cannot, in principle, be differentiated from those which result in feeblemindedness with motor disturbances; $i$. e., in infantile cerebral palsies on a hereditary syphilitic basis.

\section{Imbecile Children}

I should now like to turn to a group of children which seem to possess great practical importance. It concerns children all from syphilitic families, mostly the children of paretics-some were also found as brothers or sisters of syphilitic children-who were not regarded by their parents as really sick, and therefore never went to a physician, and whom I only found because in certain families where I had found the father, mother, or one child syphilitic, the remainder of the family was examined. They were children who showed absolutely no neurological signs of syphilitic brain disease, yet nevertheless showed mild grades of feeblemindedness. The question here is a difficult one, whether it concerns children who have inherited syphilis in the strict sense and if so, whether the syphilis as such has caused changes in the brain by which the mental development has been retarded, or whether the syphilis without localizing itself in the central nervous system only involves the development of the mental faculties in the sense of a general injury. On the other hand one could also think that in such cases the syphilis has not been transmitted to the child but that nevertheless "parasyphilitic" influences of a hereditary nature can play a rôle in the sense that syphilis of the father leads to a degeneration in the seed. Finally it is not necessary that mental inferiority should have any relation whatever to syphilis in a child springing from a syphilitic family even when syphilitic himself.

Suppose that we find a positive blood reaction in a child. We can then say that in all such cases, and they are certainly quite frequent, that the child is syphilitic when no syphilitic signs can be observed. Among other things this position has the value, that when one would infer a causal relationship between feeblemindedness and syphilis in particular cases, one can at least negative a distant relationship in the sense of a parasyphilitic influence.

Now take the other situation. When in such a child the reaction is negative, what can we conclude from this? Certainly 
something less definite than in the first case. We know that the reaction can in rare cases be negative even in manifest syphilis; it is also negative in a high proportion in latent syphilis. Therefore, one cannot conclude that in a mentally inferior child, whose blood is serologically negative, but springing from a syphilitic family, the deficient psychical development stands in no relationship to hereditary syphilis. One cannot designate such a child as free from syphilis.

It is also not always easy to come to a positive judgment be it that the serum is positive, or be it negative, whether and how far syphilis may be made responsible. In the course of time, however, experience will accumulate which will make the conclusions easier when the first beginnings of-if one may so call it-family serological investigations have been carried on to greater proportions.

A thorough clinical study of these cases will of itself lead to the obtaining of possibilities of differentiation, and if serological investigation has given the motive to turn the attention in greater measure to such forms, and when here and there it will help to show the way for the discovery of suitable cases it will have served us not without purpose.

I shall here cite some cases which may serve as examples.

In the first place I mention a brother and sister of ten and fourteen years of age respectively. Both parents deny infection. No abortions were present. The series of births was commenced, however, by a seven months' dead child. In addition to the two children under consideration there were two others living, while a further child died at the age of six months.

\section{Ella and Robert Pr.}

\section{OBSERVATIONS 62 AND 63}

The girl was born at term, developed slowly, was always languishing and weakly. She had rachitis, and began to walk and speak at the age of eighteen months. She had an ear affection for a long time, and six years ago had an inflammation of the eyes. Mentally she was always slow and dull, did not take much notice and advanced in school with much labor. She was always somewhat obstinate, nervous, irritable, did not sleep quietly, no eruptions or convulsions. In addition to her physical weakness, and poor intellectual development she had carious, but not otherwise characteristic teeth, and the remains of an interstitial keratitis. No somatic disturbance of the nervous system. 
The brother as an infant had an eruption, hoarseness and snuffles. At the age of six months an inflammation of the cornea. Learned to walk and talk at the age of three. Still wets his bed. In I906 was treated with inunctions for a syphilitic affection of the throat. He was always weakly, and is very poor in his studies; went to a special school without making any noteworthy advances. Has always been nervous, excited and restless; his bringing up was always difficult. He had a saddle nose, Hutchinson's teeth, and the remains of an interstitial keratitis. Neurologically nothing pathological is in evidence. $\mathrm{He}$ is backward in his physical as well as mental development without being an idiot.

The blood serum of both children reacted positive.

We have in both of these cases very suspicious somatic symptoms of hereditary syphilis, and both children are slightly feebleminded without there ever having been observed any clinical signs of brain disease, and without showing anything suspicious in the nervous status. The positive blood reaction makes syphilis objectively certain in these children, whose parent would not admit ever having had syphilis. The parents reported that the children were not only weakly endowed, but were nervous and excitable, and we shall further see that this combination is found quite often in similar cases.

Josef E., 8 years old.

\section{OBSERVATION 64}

Father general paresis. Mother has one pupil immobile to light, otherwise no tabetic symptoms, and is mentally healthy. Both parents deny the infection. Six children died in their first year. No abortions or premature deliveries. The child learned to walk and talk normally, was always weakly. Never any eruptions, no convulsive attacks, never any headaches or the like. The year previous had a corneal inflammation after measles. Intellectually moderately endowed, advanced in his school work with diffculty, is very distrait and weak in his memory. Shows himself to be an anxious, shy, excitable child, uncommonly easily frightened, cries at every opportunity. Pavor nocturnus.

Examination shows the absence of any hereditary syphilitic stigmata. The child seems quite atrophic, has the face of an old man, nervous system intact. School knowledge lacking; slight intellectual power, without there being the question of a high grade imbecility. The child seems uncommonly anxious and peevish.

Biological investigation of serum positive.

Here is also a marked erethistic coloring to the imbecility. This child did not give the slightest evidence of syphilis which the serological investigation uncovered. One can have no doubt of 
syphilis of the parents, despite denial, since the father had paresis, and the mother an immobile pupil.

I shall here follow with a boy whose two brothers have already been reported (observations 52,58 , juvenile paresis with stationary dementia).

Otto Sch.

\section{OBSERVATION 65}

The child was strong at birth, developed physically very well, and is a robust well-appearing boy. He has had no eruption nor anything else suspicious. Examination also showed the absence of any signs pointing to hereditary syphilis. Likewise no pathological symptoms on the part of the nervous system. On the contrary, however, mentally he is very backward, learns very badly. Although he takes pains he does not advance in school, and according to the reports of the mother he has a memory like a sieve. He is also very nervous, cries aloud in his sleep, is afraid of everything and has "no rest in him."

Biological investigation of blood serum positive.

We have here a new variation since the physical condition is splendid, and the defect seems to exist purely in the psychical sphere. The child shows nothing syphilitic. The parents deny infection, and we have a proof of the etiology only through the disease of both older children. Here also is a child not only intellectually but emotionally strange.

In the four cases just described, we found without exception a positive result of the Wassermann reaction. I shall now add two examples that one can find in the children of syphilitic families who show exactly similar conditions, but whose blood does not give the reaction.

\section{ObSERVATION 66}

Josef W., 7 years old.

Mother general paresis. Father denies syphilis; his blood reacts positive. Patient is the first born and only living of five children; the others died in their first year; furthermore two abortions interspersed among the other births. One of the children that died had vesicles on the hands and feet and was treated for syphilis. Patient had no eruptions, no snuffles during infancy, no inflammation of the ears or eyes, and in general nothing suspicious of syphilis. He was very weakly, developed extremely slowly, first began to walk at the age of three and a half years, and to speak at five. In recent years he has become somewhat more dextrous. He was sent to school where he did not seem to advance with the others. The teacher wrote to the father that nothing could be done with the child. Otherwise he is very excitable, suffers from night terrors, has attacks of rage, scratches and bites. Still wets his bed. 
The child is pale, weakly, about two years behind his age. No syphilitic stigmata. The speech is dull and clumsy. The nervous status shows no pathological changes.

Mentally he showed, on examination, a distinct imbecility, not however of high grade.

Biological examination of blood serum negative.

Josef K, II years old.

\section{ObSERVATION 67}

Father general paresis, mother immobile pupils without other tabetic symptoms, and without mental disturbances. Father infected before marriage and was still under treatment after marriage. Shortly after marriage he infected his wife, who was also treated with mercurial inunctions.

Children one to five abortions between the third and eighth month. Then twins, the living one of which is our patient. Later no further births. As an infant the child always had "a stopped-up nose," otherwise never showed anything suspicious of syphilis; no convulsions. Development was entirely normal, only he was always weakly. He suffered from headaches and had a growth in the nose. He understood badly, got bad marks at school, and is nervous and excitable.

A delicate, physically poorly developed, weakly endowed boy. No syphilitic stigmata. Nervous system without pathological findings.

Biological examination of blood negative.

Both of these children, who sprang from families in which syphilis had caused desolation, in which both parents became paretic and the descendants were destroyed, with the exception of these two, are feebleminded, and further have a striking excitable nervous constitution, which we have nearly always encountered in earlier cases. In contrast to the other cases the blood gave a negative reaction. The children bore no external stigmata of hereditary syphilis. Should we then infer that syphilis, as infectious agent, had not injured the brain, or should the disturbance be referred back to hereditary influences, which only stand in loose relationship to syphilis, such as secondary, indirect, or parasyphilitic disturbances, or whatever else one may wish to call them? As has already been shown, for the time being no satisfactory answer can be given, but one must always bear in mind that a negative result of the serological investigation in no manner negatives the fact that the children really have syphilis hidden within them, or at the least were syphilitic at an earlier period, and that the injuries resulted from the direct influence of the virus. 
I must abstain from bringing out still further detailed casuistics and must content myself with bringing the entire material together in a tabular summary, and to complete it in brief.

\section{Psychopathic Children}

One more group appears to me to require special report. In my later researches I met with cases in which, in contrast to the cases thus far cited, intellectual inferiority did not rule the picture, but where the psychopathic constitution stood in the foreground. The feebleminded syphilitic children were also designated throughout as "nervous," and in this regard already afford a hint of the possibility that a diseased course of the emotional processes may be met with in a definite form.

As a matter of fact I found a strikingly large number of simply nervous children to which I shall revert in connection with the conclusion of the tabulation of the entire material. In the meantime reports of two children, whose psychopathic make-up showed marked criminal traces, may be more exactly detailed.

Bernard L., nine years old.

The father was infected with syphilis in 1870 , and still showed syphilitic signs eight years before the birth of the child. Before the birth of the patient the mother had an abortion, and, directly following, two more. The boy has never shown any signs suspicious of syphilis. Up to the age of five years he suffered from convulsions of childhood. He was always a sharp and precocious boy, learned well in school, but was extremely lazy, uncommonly rude, and hard to bring up. $\mathrm{He}$ stole, lied, pulled the heads off living fishes and birds, and threw them at the heads of his school mates, struck at his parents and used the most vulgar abusive terms. Threats or blows create not the slightest impression. At night he often had peculiar states in which he left his bed, stood at the window, or lay on the floor without waking. Apparently he also had nocturnal fits. At times he rolled his eyes up and his body shook. He often suffered from headaches. $\mathrm{He}$ is a pale weakly child. Degeneration stigmata are absent, and no remains of syphilitic infection are to be found. The teeth also show nothing characteristic. The nervous status shows nothing pathological, with the exception of the extremely striking fact that the patellar reflexes are entirely absent. The investigation of the patellar reflexes was made with the greatest care also by Dr. Weiler with his knee jerk apparatus, and there was not the slightest trace of a muscular contraction in evidence. The pupils, however, reacted to perfection.

The serological examination was negative. 
We have here before us a case of "moral insanity" with lost patellar reflexes. The child comes from a syphilitic family, and we can well conclude from the fact that both before and after his birth abortions had occurred that his intrauterine development had been influenced by syphilis. He had never shown anything definitely syphilitic, and notwithstanding the fact that his blood showed a negative reaction the suspicion could be entertained that here syphilis had done its work at least indirectly.

I would like to choose still a second case, which also shows an irrecoverable degenerate whose hereditary syphilis had injured the nervous system in a distinct manner.

Josef W., I6 years old.

\section{OBSERVATION 69}

Syphilis of the parents and infection of the patient was denied.

The mother gave birth to a dead child before the patient was born, later no further children. Patient was born at term. Rachitis, but otherwise a good strong physical development. Previously, and even at the present time he wets his bed. During dentition, mild convulsions, which did not show themselves later. At the age of three years and a half he was blind in the left eye for three months. No eruptions or the like and no noteworthy acute diseases. He learned with difficulty and was extremely unamenable to discipline. He was sent to a special training school. He ran away from there, and at the age of eight years went-auf die Walz-slept in hay stacks, stole what he could not obtain, broke open cash boxes to obtain money. He commenced to steal at the age of five years. Later his father tried to train him for a piccolo, but he was absolutely no use.

Investigation showed immobile pupils both sides, and in the left eye the remains of a parenchymatous keratitis. No other stigmata of hereditary syphilis. Patellar reflexes and nervous system in general without pathological findings.

Lymphocytes in the spinal fluid increased ( 44 cells in I cu.mm.).

Biological investigation of the spinal fluid negative. Blood serum positive.

One cannot very well doubt that a syphilitic brain disease had here played a part. The history in support of this, however, is lacking. There is here no question of a highly developed intellect as in the previous case. There is a not insignificant feeblemindedness present. There stands in the foreground here, however, and in this respect both cases agree, complete incorrigibility in consequence of a deeply seated disturbance of the moral constitution. 
The children material that I have studied is collectively arranged in the following table. It is composed in part of cases which became the objects of hospital treatment, either for syphilitic or other disease condition not recognized as such. The greater portion however were found out in the investigation of syphilitic families, for the most part as descendants of paretics. In all, 58 children were concerned.

TABLE VI

\begin{tabular}{|c|c|c|c|c|}
\hline \multirow[b]{2}{*}{ Diagnosis. } & \multicolumn{2}{|c|}{ Spinal Fluid. } & \multicolumn{2}{|c|}{ Serum. } \\
\hline & $\begin{array}{l}\text { Posi- } \\
\text { tive. }\end{array}$ & $\begin{array}{l}\text { Nega- } \\
\text { tive. }\end{array}$ & $\begin{array}{l}\text { Posi- } \\
\text { tive. }\end{array}$ & $\begin{array}{l}\text { Nega- } \\
\text { tive. }\end{array}$ \\
\hline Syphilis (not cerebral) II manifest. ............ & - & 2 & - & - \\
\hline Syphilis (not cerebral) III latent ...... & - & - & 2 & - \\
\hline Paresis, general $\ldots \ldots \ldots \ldots \ldots \ldots \ldots \ldots \ldots \ldots$ & 4 & - & 3 & - \\
\hline Progressive feeble-mindedness (non paretic) . . . . . & - & - & 2 & - \\
\hline Immobile pupils without mental disturbances. .... & - & - & $\mathbf{r}$ & - \\
\hline Immobile pupils with feeble-mindedness. . . . . . . & - & - & 2 & - \\
\hline Feeble-mindedness with motor disturbances. . . . . . & - & - & 2 & - \\
\hline Feeble-mindedness without somatic disturbances .. & - & - & 5 & 4 \\
\hline Hemiplegia without feeble-mindedness $\ldots \ldots \ldots \ldots$ & - & - & - & i \\
\hline \multicolumn{5}{|l|}{ Meningococcus meningitis with manifest hereditary } \\
\hline Acute cerebral syphilis. $\ldots \ldots \ldots \ldots \ldots \ldots \ldots \ldots \ldots$ & $\overline{2}$ & 2 & $\overline{\mathbf{r}}$ & 二 \\
\hline 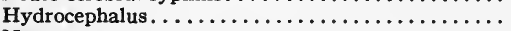 & $二$ & - & I & 2 \\
\hline 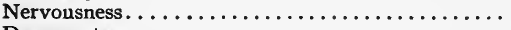 & - & 一 & 2 & 7 \\
\hline Degenerates. . . . . . . . . . . . . . . . . . . . . & - & - & 2 & $\mathbf{I}$ \\
\hline \multirow[t]{3}{*}{ 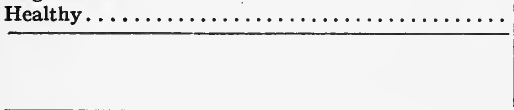 } & - & - & - & 14 \\
\hline & 6 & 4 & 23 & 29 \\
\hline & \multicolumn{2}{|c|}{ ro } & \multicolumn{2}{|c|}{52} \\
\hline
\end{tabular}

The spinal fluid was studied in ten cases only, a number which is too small to judge, in general, the behavior of the reaction on the part of the spinal fluid in hereditary syphilis, and to compare with the behavior which syphilitics with acquired syphilis show in this direction. It is noteworthy that of the six positive spinal fluids four came from juvenile paretics, and that this diagnosis is certainly not excluded in the fifth case, and that among these cases only one certainly not paretic child-he had syphilitic meningitis-was found. That, on the other hand, all of the juvenile paretics reacted on the part of the spinal fluid is to be expected, since here the same conditions prevail as in paresis due to acquired syphilis. In the four children with negative spinal fluids the sera could not be investigated at the same time, 
and it is therefore not possible to determine if these children were at all capable of reaction, that is, whether the negative reaction of the spinal fluid could not be explained simply from a similar negative behavior of the blood serum.

The serum was investigated in 52 children. The reaction was positive 23 times, $i$. e., in 44 per cent. of the cases. Among these children were fourteen whose fathers were paretic, or who had syphilitic brothers or sisters, who themselves, however, evidenced neither physical nor mental disturbances of any kind, especially no syphilitic signs. These children all reacted negative. After deducting these children from the entire material, and paying attention to those who from the standpoint of healthiness were not free from objection, the percentage of the positively reacting cases was not materially increased. There remained then 38 children of whom 23, i. e., 60 per cent., reacted positively.

It is of great interest that so many simply nervous children were found in the descendants of syphilitics. Of nine of such children two reacted positively, without their having shown the slightest signs of hereditary syphilis. Both were children of paretics. The findings in both of these children were similar. They were girls who were four to five years of age. They were delicately formed, without, however, appearing strikingly weakly. With good intelligence, they were taught with difficulty, showed a striking restlessness, were very irritable, and were also easily frightened, anxious, and slept restlessly. How far these disturbances stand in relationship to hereditary syphilis one cannot determine offhand. We always recommended a specific therapy, and we hold ourselves all the more justified since Nonne, as has already been stated, has seen prompt reaction to mercury in apparently similar cases. On the other hand, one cannot say that the remaining nervous children that reacted negatively had no hereditary syphilis, since we know that about one half of latent syphilitics fail to give the reaction.

If one wishes to go more intimately into the question of how far a family is saturated with syphilis, and if one would solve the problem by means of serum diagnosis, one must above all make it clear to himself that a differentiation between syphilitic and nonsyphilitic children, according to the result of the reaction, can be made only within narrow limits. That the positive children 
are syphilitic admits of no question, but how far the negative children are syphilis-free cannot be judged. As a matter of fact, in the collective investigations of syphilitic families one does not in any case find a series of positive reactions without a gap. A positively reacting mother can have a negatively reacting child, and a negatively reacting woman can be the mother of a positively reacting child. Also one can find in a series of children positive and negative reactions. Often the older children react positively, and the younger negatively, or the reverse may occur, or in the middle of a series of positive children one child is exceptional and shows a negative reaction.

Serological family investigations give many interesting disclosures. It shows in a convincing manner how often individuals do not know at all that they are syphilitic. Thus I found five wives of paretics, and two husbands of paretic women who reacted positively without their showing any signs of a present or a past syphilis, and without they themselves ever having observed anything of an infection. I have also seen apparently nonsyphilitic children for whose positive reaction only the syphilis or paresis of the father gave an explanation, also the reverse, parents in whom the syphilis of a child gave the only support therefore that they were also syphilitic, and in whom a positive reaction was then to be obtained. I believe that one is justified in such cases in depending upon the positive results of the reaction and assuming syphilis. In the face of such experiences one should not wonder that occasionally so-called nonsyphilitics give the Wassermann reaction.

As an example I should like to cite a family that showed very interesting conditions. Concerning three children of this family details have already been given (Observations $52,5^{8}$ and 65 ).

The disease of one child gave an occasion for the investigation of this family. It was a boy, who developed very well physically, and was well endowed intellectually. As an infant he had showed transitory syphilitic signs, which soon disappeared, and left behind no changes, from which the presence of hereditary syphilis could be revealed in the child.

At the age of thirteen, while on his way to school, he had a convulsive attack, and following this he became feebleminded. The spinal fluid and the serum reacted positively. This and the 
clinical picture left no doubt but that it was a case of juvenile paresis. The parents of the child were positive that they never had had syphilis. The father would not permit himself to be examined, whereas in the mother the biological examination could be made, and gave an intense positive result. The remaining children of the family were then studied clinically and serologically. The next youngest child had never presented any signs of syphilis. He showed a high grade stationary feeblemindedness, as a result of an evident syphilitic brain disease during infancy, and his blood reacted positively. Then followed a mildly nervous girl, who was, however, neither physically nor mentally injured, and never had shown any syphilitic symptoms. She reacted negative. The next youngest child was a mildly imbecile nervous boy, in whom nothing suspicious of syphilis could be learned here, nevertheless, the reaction was positive. In the youngest boy, who is $3^{1 / 2}$ years old, appearing physically and mentally fully healthy, but who gave a positive reaction, on more searching examination it was learned that at the age of six months he was treated in the polyclinic for a syphilitic eruption. Whereas at the time of the investigation in none of the five children were syphilitic symptoms present, and in three of them absolutely nothing suspiciously syphilitic had appeared, yet by means of the serum diagnosis of syphilis it was learned that, with one exception, they all, and also the mother, who had no idea of it at all, were syphilitic.

This family, cited in tabular form, showed the following picture:

Father: denied syphilis, appeared perfectly healthy: not examined.

Mother: denied syphilis, appeared perfectly healthy: serum positive.

\section{Children}

I. Son, I8 years old, reported well, not examined.

2-4. Abortion in sixth month.

5. Ludwig, juvenile paresis-spinal fluid and serum positive.

6. Premature birth at seven months, died after one-half hour.

7. Josef, II years old, stationary dementia, spinal fluid negative, serum positive.

8. Kate, $8 \frac{1}{2}$ years old, nervous, otherwise well, serum negative.

9. Otto, $6 \frac{1}{2}$ years old, imbecile, nervous, serum positive.

Io. Marie, $3^{\frac{1}{2}}$ years old, at six months syphilitic eruption, serum positive. 
From the fact that the series of births began with an apparently healthy child, and was then followed by abortions, one can very well assume that the infection of one of the couple took place after marriage.

The serological investigation permitted the discovery of syphilis in this family in a manner that clinical observation alone could not have made remotely possible. 


\section{INFLUENCE ON THE WASSERMANN REAC- TION BY COURSE OF DISEASE AND MERCURY TREATMENT}

In a series of paretics, and cases of cerebral syphilis, the spinal fluid and serum were taken at definite periods, and quantitatively titrated to determine the amount of reacting substances. Such individuals were examined who clinically showed no changes between the intervals of examination; those who showed a greater or less definite progression in the time between, and finally the influence of mercurial inunctions on the reaction was studied. As a general result of these investigations, it was learned that the intensity of the reaction in the spinal fluid as well as in the serum is strikingly constant.

The comparative investigations were so arranged that the different withdrawals of the body fluids coming from one and the same patient were placed side by side in the same examination and titrated. Fluids that were obtained previously were in the meantime preserved with carbolic, and put in the ice box. The reaction is in no way hindered by the storing of the fluid, the sterile conserving in the ice box, provided that evaporation is prevented by the use of rubber caps. Even after years have passed the sera show the same behavior as shortly after withdrawal. I hold the results of comparative quantitative investigations to be valuable only when they are obtained in one and the same examination. Even with the same extract, examinations made at different periods do not permit themselves to be compared. When one, however, has changed the extract entirely in the meantime, and furthermore works with another complement, another hæmolytic serum and blood, which perhaps has an entirely different character, the examination conditions are changed to such a degree that an exact comparison of the grade of retardation cannot be possible. ${ }^{1}$

${ }^{1}$ Detre (Wien. kl. Woch., 1908, No. 5) fixes the results of his investigations by letting a drop of the remaining blood corpuscle emulsion dry on a piece of filter paper. The value of exact comparisons made in this 
In the following investigations, decreasing amounts of extract and constant (o.2 c.c.) amounts of serum or spinal fluid were used. As has already been explained in another place, an exact titration in the serodiagnosis of syphilis is not always possible, because extracts, as well as serum, in themselves possess hæmolytic retarding and advancing properties, and the play of these influences can involve the even decrease of the reaction strength in titration. In the following experiments cited, however, these influences do not appear.

I shall cite three cases among paretics, in whom blood tests taken at intervals were titrated side by side. Case A, in the period between, had shown clinically no noticeable change either for the better or worse. In Case B there had been a distinct mental reduction, and in Case $\mathrm{C}$ a distinct physical deterioration in the time between the taking of the bloods.

\section{TABLE VII}

Explanation of Signs: $o=$ complete retardation. Complete $=$ complete solution. The other signs indicate intermediate values.

\begin{tabular}{|c|c|c|c|c|c|c|}
\hline \multirow{2}{*}{$\begin{array}{l}\text { Syphilitic } \\
\text { Extract. }\end{array}$} & \multicolumn{2}{|c|}{ Case A. } & \multicolumn{2}{|c|}{ Case B. } & \multicolumn{2}{|c|}{ Case C. } \\
\hline & $\begin{array}{l}\text { Serum April } \\
5,1907 \text {. }\end{array}$ & $\begin{array}{l}\text { Serum July } \\
x_{3}, \times 907 .\end{array}$ & $\begin{array}{c}\text { Serum Mar. } \\
4, \text { 1907. }\end{array}$ & $\mid \begin{array}{c}\text { Serum July } \\
x_{3}, x_{903}\end{array}$ & $\begin{array}{l}\text { Serum April } \\
x_{3}, x_{007}\end{array}$ & $\begin{array}{l}\text { Serum July } \\
x_{3}, x 907 .\end{array}$ \\
\hline 0.2 & Nearly o. & Nearly o. & 0 & o & Nearly o. & $\begin{array}{l}\text { Very large } \\
\text { sediment }\end{array}$ \\
\hline $\begin{array}{l}0.1 \\
0.05\end{array}$ & $\begin{array}{l}\text { Small } \\
\text { sediment } \\
\text { Almost } \\
\text { complete }\end{array}$ & $\begin{array}{c}\text { Small } \\
\text { sediment } \\
\text { Almost } \\
\text { complete }\end{array}$ & $\begin{array}{l}0 \\
0\end{array}$ & $\begin{array}{l}0 \\
0\end{array}$ & $\begin{array}{l}\text { Sediment } \\
\text { Incomplete }\end{array}$ & $\begin{array}{c}\text { Slight } \\
\text { sediment } \\
\text { Incomplete }\end{array}$ \\
\hline 0.01 & Complete & Complete & $\begin{array}{c}\text { Small } \\
\text { sediment. }\end{array}$ & $\begin{array}{c}\text { Small } \\
\text { sediment. }\end{array}$ & Complete & Complete \\
\hline
\end{tabular}

The time interval was 3-4 months. In $\mathrm{A}$ and $\mathrm{B}$ the appearances had not changed in the least, notwithstanding a distinctly recognizable depreciation in the psychical condition had taken place. In $\mathrm{C}$ a very slight diminution in the reaction was recognizable, which, however, was so insignificant that it certainly deserved no consideration. It is hereby learned that in paresis the manner is, in my opinion, damaged by unpreventable differences in the grade of retardation which the same sera can show at different investigations. 
blood holds its titer very pronouncedly, independent of any kind of advance in the disease.

The same holds true for the spinal fluid, and for the relations of the spinal fluid to the serum, as the following protocols show:

TABLE VIII

Case W. Paresis

\begin{tabular}{|c|c|c|c|c|}
\hline $\begin{array}{l}\text { Syphilis } \\
\text { Extract. }\end{array}$ & $\begin{array}{c}\text { Spinal Fluid. } \\
\text { March 18, x907. }\end{array}$ & $\begin{array}{l}\text { Spinal Fluid. } \\
\text { July 20, rgo7. }\end{array}$ & $\begin{array}{c}\text { Serum. } \\
\text { March 18, } 1907 .\end{array}$ & $\begin{array}{c}\text { Serum. } \\
\text { July } 20, x 9 \text { ro. }\end{array}$ \\
\hline 0.2 & $\begin{array}{l}\text { Very large } \\
\text { sediment. }\end{array}$ & $\begin{array}{l}\text { Very large } \\
\text { sediment. }\end{array}$ & o & o \\
\hline 0.1 & Sediment. & Sediment. & Large sediment. & $\begin{array}{l}\text { Very large } \\
\text { sediment. }\end{array}$ \\
\hline $\begin{array}{l}0.05 \\
0.01\end{array}$ & $\begin{array}{l}\text { Complete. } \\
\text { Complete. }\end{array}$ & $\begin{array}{l}\text { Complete. } \\
\text { Complete. }\end{array}$ & $\begin{array}{l}\text { Complete. } \\
\text { Complete. }\end{array}$ & $\begin{array}{c}\text { Nearly complete. } \\
\text { Complete. }\end{array}$ \\
\hline
\end{tabular}

This case, at the time of the first lumbar puncture, had shown a marked state of excitement; at the time of the second puncture he was quiet. A very slight increase in the titer of the serum seems to have taken place here, which, however, is without significance. The behavior of the spinal fluid had not suffered any change at all. In another case, whose disease had made marked advances in the time between the punctures, there appeared neither in the spinal fluid nor in the serum the slightest change in the strength of the reaction.

It appears to us now to be particularly interesting to determine whether paretic attacks, which must be regarded as acute progressions of the disease process, bring about any influence on the titer. So far as my present examinaions permit a judgment, such an influence seems not to have been found, at any rate not in the sense of an increase in the serum titer. At all events I do not report cases in which the blood has been taken shortly before the attack for one, and during the attack, or shortly after for the second. The first tests were taken a number of days, or even months, the second several hours after the attacks; in two patients there still existed a severe stupor due to an attack.

Details are found in the following table. 
TABLE IX.

\begin{tabular}{|c|c|c|c|c|}
\hline \multirow[b]{2}{*}{$\begin{array}{l}\text { Syphilis } \\
\text { Extract. }\end{array}$} & \multicolumn{2}{|c|}{ Fr. (Paresis). } & \multicolumn{2}{|c|}{ Or. (Paresis). } \\
\hline & $\begin{array}{l}\text { Serum September } \\
\text { 14, 1907, no } \\
\text { Attacks. }\end{array}$ & $\begin{array}{l}\text { Serum February 9, } \\
\text { I908, no Attacks. }\end{array}$ & $\begin{array}{l}\text { Serum February ro, } \\
\text { rgo8, no Attacks. }\end{array}$ & $\begin{array}{l}\text { Serum February 18, } \\
\text { 1908, After Two At- } \\
\text { tacks, Confusion. }\end{array}$ \\
\hline 0.2 & Large sediment. & $\begin{array}{c}\text { Somewhat } \\
\text { smaller sediment }\end{array}$ & Large sediment. & Sediment. \\
\hline 0.1 & Sediment. & Small sediment. & Large sediment. & Sediment. \\
\hline $\begin{array}{l}0.05 \\
0.01\end{array}$ & $\begin{array}{l}\text { Sediment. } \\
\text { Incomplete. }\end{array}$ & $\begin{array}{c}\text { Small sediment. } \\
\text { Almost. } \\
\text { incomplete. }\end{array}$ & $\begin{array}{l}\text { Large sediment. } \\
\text { Sediment. }\end{array}$ & $\begin{array}{l}\text { Sediment. } \\
\text { Incomplete. }\end{array}$ \\
\hline
\end{tabular}

According to the behavior of both cases cited, it would appear as if the blood experienced a diminution of content of reacting substances during an attack. The difference is certainly not significant, and for exact judgment there is lacking the determination of the amount of titer which the blood possessed directly before the attack.

Concerning the influence on the spinal fluid during an attack I give the following example, the judgment concerning which is certainly rendered more difficult because of inunction treatment in the interval.

TABLE $\mathrm{X}$

Sch. (PAREsis)

\begin{tabular}{|c|c|c|c|c|}
\hline \multirow{2}{*}{$\begin{array}{l}\text { Sypbilis } \\
\text { Extract. }\end{array}$} & \multicolumn{2}{|c|}{$\begin{array}{c}\text { October } 4,1907 . \text { After attacks and before } \\
\text { the beginning of } \mathrm{Hg} \text { treatment. }\end{array}$} & \multicolumn{2}{|c|}{$\begin{array}{l}\text { Nov. } 21,1907 . \text { In between no attacks } \\
\text { after close of inunction treatment. }\end{array}$} \\
\hline & Spinal Fluid. & Serum. & Spinal Fluid. & Serum. \\
\hline 0.2 & 0 & 0 & 0 & o \\
\hline 0.1 & 0 & 0 & o & o \\
\hline 0.07 & 0 & 0 & 0 & 0 \\
\hline 0.03 & $\begin{array}{l}\text { Very large } \\
\text { sediment. }\end{array}$ & & Small sediment. & $\begin{array}{l}\text { Very large } \\
\text { sediment. }\end{array}$ \\
\hline 0.01 & Complete. & Complete. & Complete. & Complete. \\
\hline
\end{tabular}

The differences here, notwithstanding the taking of mercurial treatment, are extremely slight. The spinal fluid had experienced a slight diminution, the serum a small increase of titer. At any rate we observe in contrast to the two cases previously cited no disappearance of the serum titer, but a slight rise. The results are certainly quite insignificant in both directions.

When one regards the last table from the viewpoint of the influence of mercurial therapy, it appears that no noteworthy in- 
fluence is to be observed in this direction. The presence of the attacks certainly makes certain judgment harder. I have, however, investigated the influence of specific treatment on the reaction in a large series of cases of cerebral syphilis and of paresis, and in no case could a definitely recognizable influence be made out. In none of these cases, however, did the inunction treatment produce any influence upon the clinical picture.

TABLE XI

Oc. Paresis

\begin{tabular}{|c|c|c|c|c|}
\hline \multirow{3}{*}{$\begin{array}{l}\text { Syphilis } \\
\text { Extract. }\end{array}$} & \multirow{2}{*}{\multicolumn{2}{|c|}{$\begin{array}{l}\begin{array}{l}\text { October } 31,1907 \\
\text { Since June } 30,1907, \text { no Mercury. }\end{array} \\
\text { Before the Beginning of Mercury } \\
\text { Treatment. }\end{array}$}} & \multirow{2}{*}{\multicolumn{2}{|c|}{ Close of Mercury Treatment. }} \\
\hline & & & & \\
\hline & Spinal Fluid. & Serum. & Spinal Fluid. & Serum. \\
\hline $\begin{array}{l}0.2 \\
0.1 \\
0.05\end{array}$ & $\begin{array}{l}\text { Large sediment. } \\
\text { Sediment. } \\
\text { Incomplete. }\end{array}$ & $\begin{array}{l}\text { Almost o. } \\
\text { Sediment. } \\
\text { Almost } \\
\text { incomplete. }\end{array}$ & $\begin{array}{l}\text { Large sediment. } \\
\text { Sediment. } \\
\text { Incomplete. }\end{array}$ & $\begin{array}{l}\text { Almost o. } \\
\text { Sediment. } \\
\text { Incomplete. }\end{array}$ \\
\hline
\end{tabular}

TABLE XII

M.M. (Cerebral Syphilis)

Syphilis Extract.

0.2

0.I

0.05

o.or
Serum May 28, r9o7. Before Inunction Treatment.

o

o

0

small sediment
Serum July 5 , x907. After Inunction Treatment.

o

o

o

small sediment

The biological reaction is different from the behavior of the lymphocytes in its apparent lack of ability to be influenced by mercury. In one case of cerebral syphilis, and also in one case of paresis, I saw a distinct sinking in the cellular contents (in one case of cerebral syphilis from 424 cells in I cu.mm. to 128) without, at the same time, any diminution in biologically reacting substances taking place. 


\section{COMPARATIVE SEROLOGICAL AND CYTO- LOGICAL INVESTIGATIONS}

The enumeration of the lymphocytes was done in the counting chamber according to the Fuchs-Rosenthal method. The judgment of the results was founded on the great experience which had been acquired by Dr. O. Rehm in our clinic. Following him we have designated as a negative finding $0-5$ cells in $I$ cu.mm. as slight and not a positive pathological increase (Borderland), $6-9$ cells, as a positive finding a content of ten cells and upwards.

\section{Nonsyphilitic}

This group is made up of 56 cases in which syphilis was accurately ruled out, and where the picture of the mental disorder gave no occasion for differential diagnostic questions with reference to the presence of a syphilitic or postsyphilitic disturbance.

In general, this group showed throughout biologically negatively reacting spinal fluids, and no pathological increase in the cells. In 48 cases the cell findings were entirely negative- -5 cells in I cu.mm.) ; in four (4) cases the normal findings were increased but not above the limit which is to be regarded as pathological (Io cells in I cu.mm.) ; in the remaining four cases, however, there was found a pathological cell increase while both the spinal fluid and blood serum were completely negative biologically. These were one case each of hemorrhagic pachymeningitis, of epilepsy, of delirium following spinal anæsthesia with cocaine and an uncertain case in which the diagnosis lay between epilepsy and bromism. To this may be added one case of tuberculous meningitis with marked lymphocytosis, and a negative biological reaction.

II. Syphilis Without Involvement of the Nervous System

In 27 cases the cytological and biological investigations were made simultaneously. In 24 cases the biological investigation included both the spinal fluid and the blood serum of the same 
patient, in one case the examination of the serim was not done, in two that of the spinal fluid.

The following tables, XIII-XVI, contain the contrasting biological and cytological findings in the single cases. The tables are arranged according to the stage of the disease.

\section{TABLE XIII}

\section{Secondary Manifest Stages}

$+=$ positive. $0=$ negative. $-=$ not investigated.

\begin{tabular}{|c|c|c|c|c|c|}
\hline \multirow{2}{*}{ Case. } & \multicolumn{2}{|c|}{ Serological. } & \multirow{2}{*}{$\begin{array}{c}\text { Cytological. } \\
\text { Positive. }\end{array}$} & \multicolumn{2}{|c|}{ Number of Cells in Spinal Fluid. } \\
\hline & Spinal Fluid. & Blood Serum. & & Borderland. & Negative. \\
\hline No. I & o & + & + & - & - \\
\hline No. 2 & 0 & + & 77 & - & - \\
\hline No. 3 & - & + & 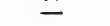 & - & 2 \\
\hline No. 4 & o & + & - & 6 & - \\
\hline No. 5 & o & + & - & 6 & - \\
\hline No. 6 & o & + & - & - & 3 \\
\hline No. 7 & o & + & - & 8 & - \\
\hline No. 8 & o & + & - & - & 3 \\
\hline No. 9 & o & + & 14 & - & - \\
\hline No. ro & o & + & - & 8 & - \\
\hline I0 & 9 neg. I- & ro pos. & 3 pos. & 4 bordld. & 3 neg. \\
\hline
\end{tabular}

TABLE XIV

Secondary Latent Stage

\begin{tabular}{r|c|c|c|c|c}
\hline \multirow{2}{*}{ Cases. } & \multicolumn{2}{|c|}{ Serological. } & \multicolumn{3}{|c}{ Cytological. } \\
\cline { 2 - 6 } & Spinal Flnid. & Serum. & Positive. & Borderland. & Negative. \\
\cline { 2 - 5 } No. I & 0 & + & - & 7 & - \\
No. 2 & 0 & + & - & - & - \\
No. 3 & 0 & + & 16 & - & - \\
No. 4 & 0 & + & - & - & - \\
\hline 4 & 4 neg. & 4 pos. & I pos. & 2 bordld. & I neg. \\
\hline
\end{tabular}

TABLE XV

Manifest Tertiary Stage

I Case: Spinal fluid negative; serum positive; no cellular increase. 
TABLE XVI

Latent Tertiary Stage

\begin{tabular}{|c|c|c|c|c|c|}
\hline \multirow{2}{*}{ Cases. } & \multicolumn{2}{|c|}{ Serological. } & \multirow{2}{*}{$\frac{\text { Cytological. }}{\text { Positive. }}$} & \multicolumn{2}{|c|}{ Number of Cells in Spinal Fluid. } \\
\hline & Spinal Fluid. & Serum. & & Borderland. & Negative. \\
\hline No. I & 0 & - & - & 6 & - \\
\hline No. 2 & 0 & 0 & - & - & 2 \\
\hline No. 3 & 0 & + & - & - & 3 \\
\hline No. 4 & 0 & + & - & - & 5 \\
\hline No. 5 & - & + & 22 & - & - \\
\hline No. 6 & 0 & + & - & - & 4 \\
\hline No. 7 & 0 & o & - & - & 3 \\
\hline No. 8 & o & + & - & - & 5 \\
\hline No. 9 & 0 & + & 33 & - & - \\
\hline No. ro & o & + & - & - & 3 \\
\hline No. II & 0 & + & - & - & 5 \\
\hline No. 12 & 0 & + & 一 & 一 & 5 \\
\hline 12 & I I neg. I- & $\begin{array}{l}9 \text { pos. } \\
2 \text { neg. } \\
\text { I - }\end{array}$ & 2 pos. & I bordrld. & 9 neg. \\
\hline
\end{tabular}

A marked increase in the number of cells, $14-77$, in I cu.mm. was found in 6 cases, 3 of which belonged to the manifest secondary, one to the latent secondary and two to the latent tertiary stages. In seven cases there were findings $6-9$ cells in one cu.mm. which exceeded the customary findings in the healthy but not with certainty to be regarded as pathological. The other I4 patients showed no cellular increases. Thus there were in the cases investigated a high grade or slighter lymphocytosis 13 times, i. e., in 48 per cent.

When we observe the results of the biological tests of these cases, we see that the spinal fluid uniformly reacts negative. Also the spinal fluid showing definite lymphocytosis does not show the slightest tendency to complement fixation. The serum, however, behaves quite differently, which, with the exception of two patients in the lateral tertiary stages, always reacted positive. The two cases in which the serum was negative showed no cellular increase in the spinal fluid. In general no relation between the strength of the serological result and the cellular content of the spinal fluid could be recognized.

From this contrast there follows with definiteness:

I. That the phenomenon of lymphocytosis does not go parallel with the biological reaction of the spinal fluid, so that the mechan- 
ism which causes the lymphocytosis is not identical with that which causes the appearance of the biologically reacting substances in the spinal fluid. Lymphocytosis can occur without the simultaneous appearance of the Wassermann reaction in the spinal fluid. Whether the opposite be true, that lymphocytosis can fail with a positive Wassermann reaction of the spinal fluid cannot be determined from the cases of this group, and will be discussed later.

2. That the appearance of a Wassermann reaction in the blood serum need not be accompanied by an increase of the lymphocytes in the spinal fluid.

3. That cellular increase may still be found in latent tertiary stages with any syphilitic manifestations in the central nervous system.

\section{General Paresis}

With few exceptions there was a complete agreement of the cytological and biological findings. In 138 cases the spinal fluid reacted biologically positive, and there was at the same time an increased lymphocytosis.

The cases which showed any variation had, without exception, positive findings on the part of the serum, therefore in this place only, the biological, in contrast to the cytological character of the spinal fluid will be discussed.

A divergence in two directions is possible, and as a matter of fact was observed, and occasionally the spinal fluid can react negatively with positive cytology, and on the contrary can show biologically positive and cytologically negative characters.

Thus there are the six cases with negative and the two cases with doubtful biological reactions of the spinal fluid. In all of these patients the cell content was distinctly increased. At all events it is to be remarked that in these the diagnosis of paresis is not for the most part unassailable: the possibility that not paresis but cerebral syphilis was present is for the majority of the cases not to be excluded. Since, however, we have, for the time being, diagnosed the cases as paresis, we shall also, for the time being, assume that cases of paresis exist with biologically negative and cytologically positive findings in the spinal fluid. In this relation a clinically not definitely explained case of so-called stationary paresis may be mentioned whose spinal fluid was bio- 
logically negative, and whose serum strongly positive, yet had negative cytological findings, 3 cells in I cu.mm.

I have counted eight cases of paretics with cytologically negative and biologically positive spinal fluids. In all of these cases, however, the cellular findings were not absolutely negative, a slight increase of the cells was regularly found, but it was too slightunder ro cells to the cu.mm.- - to be reckoned as pathological. One of the cases went as a cerebral syphilis, and only at the autopsy was it shown to be an ordinary advanced case of paresis ( 7 cells). Another case was one of taboparesis ( 6 cells). Five cases were beginning paretics, and in the eighth and last case the diagnosis of paresis was made, without my being convinced, however, that it may perhaps have been cerebral syphilis.

With the exceptions of the cases of taboparesis, and the last mentioned doubtful case, the spinal fluid reacted not weakly, but intensely positive, and the serum gave a negative, or only unimportant grade of reaction.

Whether the absence of a marked lymphocytosis has its cause in the early stage which these patients presented I shall leave undecided. I have seen enough cases of beginning paresis with very decided cellular increase. The ascertaining of the fact in cases of beginning paresis that the spinal fluid can give a distinct Wassermann reaction, without, or previous to, showing a cellular increase is always of importance.

\section{TABES}

Comparative cytological and biological investigations could be performed in ro cases. In nine cases both serum and spinal fluid were examined. In the tenth only the serum was investigated. Marked cellular increase was found in 6 cases, slight, not to be regarded as pathological in 2 , and likewise in 2 no cellular increase.

Of the Io sera tested for the Wassermann reaction, nine gave positive results, one was questionable. Of the nine spinal fluids seven reacted positive, in one the result was regarded as doubtful, and in another it was negative.

In one case, whose spinal fluid was negative, and whose serum reacted questionably, there was a positive cytological finding. 
Further I found a negative cytological count with a questionable biological result in the spinal fluid, and a positive result in the blood serum. One case with negative cytological results showed a definite Wassermann reaction in the spinal fluid, and likewise the two patients, in whom only a slight cellular increase was shown, reacted biologically positive in both media. The remaining cases showed similar findings cytologically and biologically. Finally a case of tabes may be mentioned whose spinal fluid and serum reacted positively and which showed an almost negative cytological finding ( 6 cells in $\mathrm{r}$ cu.mm.).

The contrast teaches that the combined use of both methods of investigation can prove itself to be very useful in tabes, in that a questionable or negative result in the one, and a contrary result in the other investigation can further the diagnosis.

\section{Cerebral Syphilis}

Including one case of cerebral syphilis on an hereditary syphilitic basis, 2I cases were taken for simultaneous cytological and biological investigation of the spinal fluid and the serum.

Only one case was cytologically negative, three cases were on the borderline $(5-9$ cells in I cu.mm.), whereas the remaining cases, $i . e$., 17 , showed a distinct cellular increase, the highest count showed 424 cells in I cu.mm.

In one case the spinal fluid reacted strongly biologically, in three weakly positive, in the remaining 17 cases negative. The sera reacted positive throughout, with one exception.

From the comparative observation of the results it appears that the majority of the cases showed a definite character, namely cytologically positive, biologically, with reference to the spinal fluid, negative, with reference to the blood serum, positive. There were 12 of these cases.

The three cases, which showed borderline cytological findings and to which may be added a single case which was absolutely negative cytologically, showed biologically no variation for the above findings; the spinal fluid gave a negative, the serum a positive result.

Those cases whose biological behavior varies from the usual findings deserve, in view of their cytological character, special 
attention. The four patients with biologically positive spinal findings showed a cellular increase throughout, to be sure of quite different grades. The patient with biologically strong reaction had 17 cells; the other three had respectively Io, I0 3 and 345 cells in I cu.mm. One patient was negative with reference to the spinal fluid and the blood. She showed however an increase in cells (5o cells in I cu.mm.).

The complete independence of the cytological and biological behavior shows the most distinctly in this group. Especially is it clear that under no conditions is it necessary, when in a syphilitic the lymphocytes are increased in the spinal fluid, that the biologically reactive substance should be present at the same time. The number of lymphocytes may reach any height without any alteration of the biological reaction of the spinal fluid. Spinal fluids have been found with a cell content of 150,200 or even over 400 cells to the cu.mm., with a negative Wassermann reaction. The 4 biological positive reacting cases show no striking value cytologically. Here, furthermore, the independence of the two phenomena makes clear, that in positive biological reaction of the spinal fluid, the intensity of the same permits no recognition of the height of the cell contents. One patient in whom the Wassermann reaction was very strong, on the part of the spinal fluid had only I7 cells; another patient who only showed the slightest biological reaction had 245 cells in I cu.mm. One of the biologically positive cases showed a minimal cell increase, only ro cells in I cu.mm.

Finally one case gives evidence that in cerebrospinal syphilis the Wassermann reaction may fail in the spinal fluid as well as in the serum, and notwithstanding this there may be a lymphocytosis. 


\section{LITERATURE}

Alzheimer. Allg. Z. f. Psych., 64, Vereinsblatt. Zent. f. N. u. P., 1904 Allg. Z. f. Psych., 52. Hist. Studien zur Differentialdiagnose, d. pro. Paralyse, Jena, 1904.

Bab, H. Münch. med. Woch., 1907, No. 46. Deut. med. Woch., 1906, No. 49. Münch. med. Woch., 1907, No. 7.

Bauer, J. Berl. klin. Woch., 1908, No. 17. Deut. med. Woch., 1908, No. 16. Wien. klin. Woch., 1908, No. 36.

Binswanger. Die Epilepsie, 1899.

Boas, H., und Hauge, G. Berl. klin. Woch., 1908, No. 34.

Bonhoeffer. Die akute Geisteskrankheiten der Gewohnheitstrinker, Igor. Bordet et Gengou. Annales de l'Institut Pasteur, 15, I90I, p. 289.

Braun, H. Berl. klin. Woch., 1907, No. 48.

Bresler. Erbsyphilis u. Nervensystem, Schmidt's Jahrb., 1904, Heft 4.

Bruck u. Stern. Deut. med. Woch., 1908, Nos. Io, II, I2.

Cassirer. Tabes und Psychose, Berlin, 1903.

Citron, J. Deut. med. Woch., 1907, No. 29. Berl. klin. Woch., 1908, No. 48. Cramer. Die Nervosität, 1906 .

Edel, M. Berl. klin. Woch., 1908, No. 12. Diskussionsbemerkung.

Ehrlich u. Morgenroth. Berl. klin. Woch., 1900, 190r.

Eitner. Wien. klin. Woch., 1906, No. 5r.

von Eissler. Wien. klin. Woch., 1908, No. 13.

Elias, Neubauer, Porges u. Salomon. Wien. klin. Woch., 1908, No. 23.

Wien. klin. Woch., 1908, Nos. 18, 21 .

Fischer, W., u. Meier, G. Deut. med. Woch., 1907, No. 52.

Fleischmann. Berl. klin. Woch., 1908, No. ro.

Förster, R. Zent. f. N. u. P., 1908, No. 9. Vereinsbericht,

Fornet. Münch. med. Woch., 1906, No. 38.

Fornet u. Schereschewsky. Münch. med. Woch., 1907, No. 3o. Berl. klin. Woch., 1908, No. 18.

Fornet, Schereschewsky, Eisenzimmer u. Rosenfeld. Deut. med. Woch., 1907, No. 41.

Fournier. La Syphilis hereditaire, Paris, I886. Les Affections parasyphilitiques, Paris, 1894.

Frenkel-Heiden. Neur. Z., 1908, No. 8. Vereinsbericht.

Friedberger, E. Wien. klin. Woch., 1907, No. 29.

Freud. Zur Kenntnis d. zereb. Diplegien des Kindersalter, Leipzig u. Wien, 1893 .

Fritz-Kren. Wien. med. Woch., 1908, No. 12.

Gaupp. All. Zeit. f. Psych., 64, Vereinsbericht.

Gengou. Annales de l'Institut Past., 16, 1902.

Gross u. Volk. Wien. klin. Woch., 1908, No. I8. 
Hartoch u. Jakimoff. Wein. klin. Woch., 1908, No. $4 \mathrm{I}$.

Heller u. Tomarkin. Deut. med. Woch., 1907, No. 20.

Heubner. Syphilis im Kindesalter. Tübingen, I896. Zeit. f. d. Erfosch. d. jug. Schwach., I, p. 97.

Hochsinger. Studien über die hereditäre Syphilis. Leipzig u. Wien, I898. Hoehne, F. Berl. klin. Woch., I908, No. 38.

Homén. Arch. f. Psych. u. N., 24, 1902.

Jobling. J1. Exp. Med., 8, No. 6.

Jochmann u. Töpfer. Münch. med. Woch., I908, No. 32.

Klaussner, E. Wien. med. Woch., I908, Nos. I1, 26.

König, W. Neur. Zt., 1900, No. 7. Allg. Z. f. Psych., 26, 1907.

Kraepelin. Lehrbuch, 7 Auf. Arch. f. Psych., 28.

Krause u. Volk. Wien. med. Woch., 1907, No. I7.

Kroner, R. Berl. klin. Woch., 1908, No. 4 .

Landsteiner, Müller u. Pötzl. Wien. klin. Woch., I907, Nos. 46, 50.

Lesser, F. Berl. klin. Woch., I908, No. 39. Derm. Zeit., II, No. 9.

Leuchs. Berl. klin. Woch., I907, No. 2, 3.

Levaditi et Marie. Soc. de Biol., I908, p. 872.

Levaditi et Jamanouchi. Soc. de Biol., I907, p. 740, 1908.

Levaditi, Ravaut, et Jamanouchi. Soc. de Biol., I908, p. 814.

Lüdke. Beitr. z. Klinik d. Tub., 7, I907, No. I.

Marie et Levaditi. Ann. de 1'Institut. Past., 2I, No. 2.

Marie, Levaditi, et Jamanouchi. Soc. de Biol., I907, p. I69.

Maslakowitz u. Liebermann. Z. f. Bakt., 47, No. 3.

Meier, G. Berl. klin. Woch., I908, No. 5I. Med. Klinik, I908, No. 36.

Michaelis, L. Berl. klin. Woch., 1907, No. 46; 1908, No. 35.

Michaelis u. Lesser. Berl. klin. Woch., I908, No. 6.

Morgenroth u. Rabinowitsch. Deut. med. Woch., 1907, No. 18.

Morgenroth u. Stertz. Virch. Arch., 98, 1907.

Much. Med. Klinik, r9o8, Nos. 28, 29.

Much u. Eichelberg. Med. Klinik, I908, No. I8. Münch. med. Woch., 1908, No. 22.

Mühlens. Zent. f. Bakt., 43, No. 7.

Müller, R. Wien. med. Klinik, I908, No. 9.

Müller u. Oppenheim. Wien. klin. Woch., 1906, No. 23.

Neisser, A. Die experimentelle Syphilisforschung. Berlin, I906.

Neisser, M. u. Sachs. Berl. klin. Woch., 1905, No. I4.

Neisser, A., Bruck u. Schucht. Deut. med. Woch., 1906, No. I8.

Nobl u. Arzt. Wien. klin. Woch., 1908, No. 9.

Nonne. Syphilis u. Nervensystem, I u. 2 Auflage.

Peritz. Berl. klin. Woch., 1908, No. 2.

Pieper. Zur Aetiologie d. Idiotie. Berlin, I893.

Plaut, F. Monats. f. Psy. u. Neur., 22, 1907, No. 2. Münch. med. Woch., 1907, No. 30.

Plaut, F. Zent. f. N. u. Psych., I908, No. 8.

Plaut, Heuck u. Rossi. Münch. med. Woch., 1908, No. 2.

Plaut u. Heuck. Berl. klin. Woch., I908, No. 24. 
Porges u. Meier. Berl. klin. Woch., 1908, No. I5.

Rehm, O. Münch. med. Woch., 1908, No. 3I.

Raviart, Breton u. Petit. Soc. de Biol., 1908, No. 8, p. 335.

Rumpf. Die Syph. Erkrankungen des Nervensystems. Wiesbaden, I887.

Sachs u. Altmann. Berl. klin. Woch., I908, Nos. 10, I4.

Seligmann u. Klopstock. Berl. klin. Woch., 1908, No. 38.

Shuttleworth. Brit. Jour. Children's Diseases, I904.

Spiegler. 25 Kongress f. inn. Med. in Wien. Ref. in Berl. klin. Woch., 1908, No. 17.

Schleissner. Wien. klin. Woch., 1908, No. 40.

Schütze. Zt. f. klin. Med., 65, Nos. 5, 6. Berl. klin. Woch., 1907, No. 5.

Stern. Berl. klin. Woch., I908, No. 32.

Stertz. Allg. Z. f. Psy., 65, 1908, No. 4.

Wachsmuth. Arch. f. Psych., 1902.

Wassermann, A. 25 Kongress f. inn. Med. in Wien. Ref. in Berl. klin. Woch., 1908, No. 18. Berl. klin. Woch., 1907, Nos. I, 50, 51. Wien. klin. Woch., 1908, No. 21.

Wassermann u. Bruck. Deut. med. Woch., 1906, No. I2.

Wassermann, Neisser u. Bruck. Deut. med. Woch., 1906, No. I9.

Wassermann, Neisser, Bruck u. Schicht. Zeit. f. Hyg. u. Im., 55, I906, No. 3 .

Wassermann u. Plaut. Deut. med. Woch., 1906, No. 44.

Wechselmann u. Meier. Deut. med. Woch., 1908, No. 3r.

Weil u. Braun. Wien. klin. Woch., 1908, No. 5. Berl. klin. Woch., I907, No. 49. Wien. klin. Woch., I908, Nos. $18,26$.

Weil u. Nakayama. Münch. med. Woch., 1906, No. 2I.

Weil u. Strauss. Wien. klin. Woch., 1908, No. 20.

Westphal, A. Med. Klinik, 1905, No. 27; 1907, Nos. 4 u. 5. Allg. Zt. f. Psych., 65, No. I908. Vereinsbericht.

Weygandt. Sitz. d. Phys.-med. Gesell. z. Würzburg, I907.

Zappert. Handbuch d. Kinderhheilkunde v. Pfaundler-Schlossmann, Leipzig, 1906.

Ziehen. Die Geisteskrankheiten des Kindesalters. Berlin, I902. 


\section{INDEX.}

ACOHOLIC extracts, II

A Alcoholic paranoia, 72

Alcoholic pseudopares, 69

Alcoholic psychoses and paresis, 69

Appearance of reaction, 59

Aqueous extracts, 20

Arteriosclerosis, 38

Arteriosclerosis and cerebral syphilis, I21

Atypical findings, 53

B ACKWARD children, I39

Blood in paresis, 47

Bordet and Gengou, I

CELL count in paresis, 180

Cerebral syphilis, 88

and arteriosclerosis, I2I

and cytology, 182

and dementia præcox, II3

and epilepsy, I I9

and hallucinosis, III

and organic psychoses, I Io

and paranoia, III

cases, 9I

diagnosis, 61

Circular paresis, I 18

Clinical Investigations, 42

Specificity, in Paresis, 34

Colloid reactions, I6

Comparative findings, 52

Cytology in nonsyphylitics, 177

and serology, I77

in syphilis, 177

Cure, reaction of, 43

DEMENTIA præcox and cerebral syphilis, II 3

progressive, ${ }^{158}$

traumatic, 65

Development of sero diagnosis, I
F HRLICH, I

Epilepsy and cerebral syphilis, II9

Errors, 27, 28

Explanations of Wassermann reaction, 18

FAMILY serology, I70

Feeblemindedness and hereditary syphilis, I32, I55 and infantile cerebral palsy, 150 without motor signs, 155

Frambesia tropica, 35

GENERAL Paresis, 45

G Globulin substitutions, I5

Gummata, 92

$H_{\text {ALLUCINOSIS and cerebral }}^{\text {Alis, III }}$ Haemolysis from alcoholic and aqueous extracts, 22 retardation, 23

Hereditary syphilis and feeble mindedness, 132

Hereditary syphilitic child, I39

Hutchinson triad, I43

[DIOCY, 138

Imbecility, 138, I60

Infantile cerebral palsy, I34, I37, I5O, 154

JUVENILE paresis, I46

K ORSAKOW'S psychosis, 7I, 72

I ATENT syphilis, 42

Lecithin, 12

Leucemia, 38

Luetic antibody, 7

Lipoid analogies, 12

reactions, 24 
Literature, 184

Little's Disease, I34, I50, 154

Lymphocytosis, 177, 179

M ANIC-depressive and paresis, 76

$M$ Manic excitement in syphilis, $8 \mathrm{I}$

Mercurial treatment and reaction, 172

Meta-syphilitic affections, diagnosis, 60

Miscellaneous diseases, 39

Monkey experiments, 5

Multiple sclerosis, 38

NATURE of paresis, 85

$N$ of serodiagnosis, I

Neurasthenia and syphilis, I4O

Neurological cases, 39

Non-progressive paresis, 100

PARANOID psychoses in syphil-

Pitics, III

Paresis and alcoholic psychoses, 69 and cell count, 180

and cerebral syphilis 89, IIo

as circular psychosis, 118

and cytology, 180

differential diagnosis, 6

doubtful cases, 50-55

early diagnosis, 60

exceptions in, $54,55,56,57,58$

juvenile, 146

and manic-depressive psychosis, 76

nature of, 85

and post-traumatic psychoses 63

stationary, 100, 105

time of appearance of reaction, 59

Paretic attacks and reaction, 174

Post-traumatic psychosis, 63

Precipitation tests, 14

Pregnancy curve in syphilis, 142

Psoriasis, reaction in, 35
Psychopathic children, I65 inferiority, 14I

Psychoses, 39

of tabes, 125

$\mathrm{R}_{\text {EACTION, appearance of, } 59}$

effect of treatment in, 172 negative in spinal fluid, $5^{\mathbf{I}}$ and syphilitic manifestations, 86

in syphilitic children, 167 type in cerebral syphilis, 9I

SCARLET fever, 37

Serology and cytology, 177

Spastic diplegia, I36, 150

Specific treatment, 43

Spinal fluid in cerebral syphilis, 94 in non nervous cases, 44 in paretics, 48, 49, 5I

Syphilis without nervous symptoms, 42

Syphilitic endarteritis, 93

infection, history of, 48

meningitis, 92

softening, 95

TABES and cell count, I8I

and tabetic psychoses, I25

Tabetic psychoses, 125

Table of diseases, 39

Technique of reaction, 27

Tertiary latent, 42

manifest, 42

Time of appearance, 59

Traumatic dementia, 65

Treatment, effect on reaction by, 43

and reaction, 172

Trypanosomiasis, 36

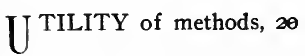

WASSERMANN and Plaut, 5 reaction and treatment, 172 






\section{${ }_{3}^{|||||||||||||||||||||||||||| \mid ~}$}

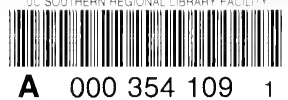




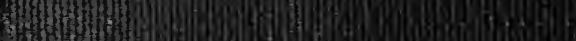
sisto 